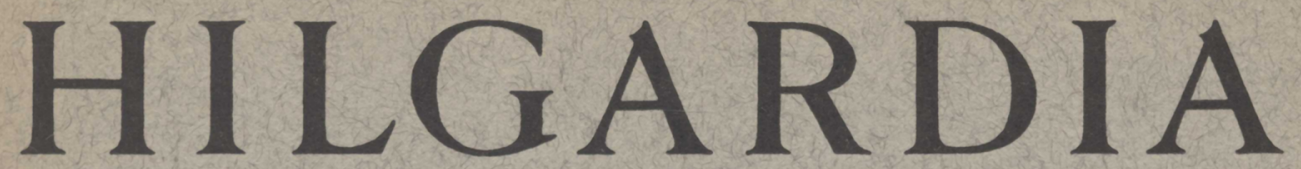

A Journal of Agricultural Science Published by the California Agricultural Experiment Station

\title{
EVALUATION OF CERTAIN ACARICIDES AND INSECTICIDES FOR EFFECTIVENESS, RESIDUES, AND INFLUENCE ON CROP FLAVOR
}

\author{
Edited by \\ E. GORTON LINSLEY
}

UNIVERSITY OF CALIFORNIA - BERKELEY, CALIFORNIA 
The present series of reports includes pesticidal, flavor, and chemical or bioassay residue studies of certain acaricides applied to pears, apples, and peaches and of insecticides applied to soils in which several root crops were grown. The chemical names and formulas of the acaricides may be found in table 1, page 47; those of the insecticides in table 1, page 87. The technical results reported in this series of studies do not constitute pest-control recommendations. Public Law No. 518, the so-called Miller Amendment to the Food, Drug, and Cosmetic Act of 1938, applies to these compounds when used on these fruit and vegetable crops. Specific recommendations for pest-control use are issued by the Agricultural Extension Service.

Pesticidal properties were studied in the field by H. F. Madsen and A. D. Borden of the Department of Entomology and Parasitology at Berkeley, and by F. M. Summers, W. H. Lange, Jr., and E. C. Carlson of the Department of Entomology and Parasitology at Davis. Flavor evaluations were made by E. Hinreiner and M. Simone of the Department of Food Technology at Davis. Residue analyses were provided by W. M. Hoskins, W. R. Erwin, and R. P. Miskus of the Department of Entomology and Parasitology at Berkeley. It will be noted that residue analyses were made on certain truck crops, after foliage or soil application of insecticides, that are not discussed in the other studies.

These investigations show that several acaricides, when used in accordance with described procedures, will give satisfactory control of the tetranychid mites affecting apples, pears, peaches, and almonds in California. Most of these materials have performed well without giving rise to serious residues or disagreeable alterations of flavor in the canned fruits.

Several soil insecticides applied at different rates as general broadcast treatments demonstrated initial and residual effects on wireworms damaging sweet potatoes, white potatoes, and carrots. A laboratory bioassay technique utilizing Limonius canus (LeConte) indicated considerable variation in the speed of action of the insecticides used, and in their residual nature in soils of different textural classes. Field-performance trials of certain insecticides at specified rates gave excellent protection against wireworms for white potatoes and sweet potatoes. 


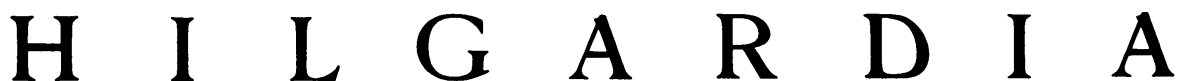

A Journal of Agricultural Science Published by

the California Agricultural Experiment Station

VOL. 26

AUGUST, 1956

No. 1

\section{EVALUATION OF CERTAIN ACARICIDES AND INSECTICIDES FOR EFFECTIVENESS, RESIDUES, AND INFLUENCE ON CROP FLAVOR}

\section{E. GORTON LINSLEY}

ONLY A FEW years ago the question of the physiological effects of pesticide applications upon the quality and flavor of foodstuffs was largely academic, although limited flavor tests were being made in a few research laboratories and agricultural experiment stations, including that of the University of California. In 1952 flavor evaluation was given special attention in New York, New Jersey, Florida, Wisconsin, Ohio, Maryland, Washington, Oregon, California, and was expanded elsewhere in 1953, 1954, and 1955.

In several of these states, off-flavors have appeared in some fresh or processed foods and in some cases food processors have written prohibition of certain materials into contracts offered to growers.

Federal and state regulatory agencies also are concerned with the problem of off-flavors, and there has been an increasing demand for flavor data in relation to applications for registration. The California State Bureau of Chemistry (1952) issued a warning against the use of benzene hexachloride or lindane (its pure gamma isomer) on vegetable crops or on soil where edible root crops will be grown within a 2-year period.

The canning industry, particularly the National Canners Association, has taken the lead in encouraging coöperative research on flavor effects. In June, 1951, industry representatives met in San Francisco and formed a Technical Steering Committee on Pesticides, which proposed that the California Agricultural Experiment Station undertake to determine the effect of applied pesticides on the flavor and quality of fruits and vegetables and upon the subsequently canned product. The California Station agreed to undertake a limited exploratory program in 1951 . As a result, in northern California ${ }^{3}$ pears were processed from plots which had been treated with five different acaricides, tomatoes from plots treated with five insecticides, and carrots grown in soils treated with six insecticides. Residue analyses, either chemical or biological, were made of the unwashed raw product, after washing, and after processing. Flavor evaluation was made by the Department of Food

\footnotetext{
${ }^{1}$ Received for publication April 29, 1955.

${ }^{2} \mathrm{Mr}$. Linsley is Professor of Entomology and Entomologist in the Experiment Station, Berkeley.

${ }^{8}$ A similar program was initiated in southern California (Citrus Experiment Station) for citrus products.
} 
Technology at Davis. The results of the 1951 studies were sufficiently provocative to encourage further work in 1952, 1953, and 1954.

In the meantime, some things have been learned about the problems of entomological technique involved. These procedures are placing an additional burden on the experimental program, but it appears to be essential if the exacting requirements of the food technologists are to be met. This is particularly true of the great care which must be given to the provision of suitable control samples. Among the matters of general interest that have developed from flavor work, the following may be mentioned as having some bearing on the planning of the research program:

1. In foliage applications the interval of time between treatment and harvest and the number of treatments involved influence the likelihood of detection of variation in flavors. Thus the more persistent pesticides should be investigated, as should crops which require frequent treatment for successful pest control.

2. Since persistence is a quality much desired in soil pesticides, these should be given special attention in flavor studies, not only in relation to root crops but also with regard to other crops which may be grown in rotation.

3. Since absorption and translocation should increase the likelihood of flavor effects, any materials having these properties should be studied. Fortunately, some information is being assembled along this line but in many cases we still lack data on the subject.

4. Flavor variations have been detected in processed foodstuffs which contained no detectable chemical residue identifiable as the original pesticide by chemical or biological means. This suggests that the pesticide may have undergone some change which resulted in a chemical product producing a flavor variation-or, in some cases, that the pesticide may modify the physiological processes of the plant in such a way as to affect its maturity, sugar production, or some other factor which is reflected in flavor. In any event it does not necessarily follow that absence of detectable residues means that absence of flavor effects can be taken for granted.

5. Variations in flavor have sometimes been detected in processed foods after given periods of storage when no difference was evident immediately after processing.

6. The method of preparation of the foodstuff for eating may influence the degree of off-flavor detected.

7. It is impractical to test routinely for flavor effects while screening compounds for pesticidal properties. Ideally this screening for flavor effects, if it is to be introduced, should be brought into the experimental program during the second year of field testing of a compound upon anyone particular crop against a particular pest or group of pests. In any event, a compound's effect on flavor-if any-should not be considered until enough information is available upon its pesticidal qualities to indicate the probable commercial value of the compound, and upon such factors as timing and rates of application as to indicate probable commercial methods of use.

The present series of reports includes pesticidal, flavor, and chemical or bioassay residue studies of certain acaricides applied to pears, apples, and 
peaches and of insecticides applied to soils in which several vegetable root crops were grown. The chemical names and formulas of the acaricides may be found in table 1, page 47 ; those of the insecticides in table 1, page 87 . The technical results reported in this series of studies do not constitute pestcontrol recommendations. Public Law No. 518, the so-called Miller Amendment to the Food, Drug, and Cosmetic Act of 1938, applies to these compounds when used on these fruit and vegetable crops. Specific recommendations for pest-control use are issued by the Agricultural Extension Service.

Pesticidal properties were studied in the field by H. F. Madsen and A. D. Borden of the Department of Entomology and Parasitology at Berkeley, and by F. M. Summers, W. H. Lange, Jr., and E. C. Carlson of the Department of Entomology and Parasitology at Davis. Flavor evaluations were made by E. Hinreiner and M. Simone of the Department of Food Technology at Davis. Residue analyses were provided by W. M. Hoskins, W. R. Erwin, and R. P. Miskus of the Department of Entomology and Parasitology at Berkeley. Included are residue analyses made on certain truck crops, after foliage or soil application of insecticides, that are not discussed in the other studies.

These investigations show that several acaricides, when used in accordance with described procedures, will give satisfactory control of the tetranychid mites affecting apples, pears, peaches, and almonds in California. Most of these materials have performed well without giving rise to serious residues or disagreeable alterations of flavor in the canned fruits. For details of successful control programs, reference should be made to the articles by Madsen and Borden (1956) on apple and pear pests and by Summers (1956) on those affecting peaches and almonds.

The correlations between efficiency of pest control, level of residue, and effect on flavor, have been summarized by the principal investigators in the following paragraphs. Unless noted, the results for different seasons are in agreement. Since the 1952 pears were not of high quality and some of the chemicals and their formulations were only in the first year of commercial production, more reliance doubtless should be given to the 1953 and 1954 tests.

\section{ACARICIDES}

Aramite. This material gave consistently good to excellent results on the two-spotted mite affecting apples, pears, and peaches; against Pacific mite on almonds; and variable but generally adequate results against European red mite on apples and pears.

Residues were less than 0.1 p.p.m. in fresh pears and in canned pears, peaches, and applesauce; yet there were effects on flavor of pears after $2 \frac{1}{2}$ to 11 months' storage and of peaches after $1 \frac{1 / 2}{2}$ and $71 / 2$ months. Hence some degradation product not giving the Aramite test may be responsible. Lack of effect in applesauce containing 0.7 p.p.m. may be the result of a different mode of degradation.

Chlorobenzilate, Genite-876, and Dimite. Chlorobenzilate and Genite-876 showed sufficient promise in these trials to warrant more extensive study. 
Dimite gave favorable results in the tests on two-spotted, Pacific, and European red mites.

Low residues in canned pears and peaches agree well with favorable flavor ratings. In case of applesauce from chlorobenzilate application, the development of a marked change in flavor after six months' storage probably is due to a slowly formed degradation product since only 0.3 p.p.m. residue was found. This also would appear to be the situation with Genite-876 on peaches and Dimite on pears. Unfortunately, analyses were not made on either fresh or newly canned pears, peaches, or apples.

Genite-923. This material has proved to be exceptionally effective when used on pears against the European red mite. On this host it also satisfactorily controls the two-spotted mite. Genite-923 also gave excellent control of brown almond mite when applied to peaches and almonds in pre- or postbloom sprays. The results obtained in trials of this material on peaches and almonds for the two-spotted and Pacific mite were not favorable.

A residue of less than 0.1 p.p.m. on fresh pears agrees with lack of flavor alteration in canned pears of 1953 crop but contrasts with marked off-flavor found in 1952 canned pears. A slightly greater residue (0.2 p.p.m.) in canned applesauce accounts in part for marked flavor change in canned applesauce after storage. Heavy residue on fresh peaches, and its absence in strongly off-flavor canned peaches of 1952 and 1953 seasons indicate that a degradation product not responding to the Genite test was responsible. This situation probably played a part in the flavor change in canned applesauce also. Prebloom applications, however, did not result in any important flavor changes in canned peaches or in canned pears.

Ovotran. Except for unexplained failures in particular areas, Ovotran provided excellent control of the two-spotted and the European red mite on apples and pears. The control of brown almond mite with pinkbud and petal-fall sprays applied to peaches and almonds was good. When used in preventive sprays, very satisfactory control of the two-spotted and the Pacific mite was obtained on these hosts.

Low residues in fresh pears and very low residues in canned pears agree with favorable flavor ratings in 1953 but differ from strong off-flavor developed during storage of pears canned in 1952. Low residues in canned peaches and applesauce are consistent with generally favorable flavor ratings on these canned fruits. Almonds were not affected adversely by Ovotran applications.

Sulphenone. In the trials during the period 1950 to 1952, spider-mite control with this material was variable. However, in 1953 and 1954, results with Sulphenone against the European red mite and the two-spotted mite on apples and pears were satisfactory. This was true also with respect to the two-spotted mite on peaches for the 1953 trial.

Flavor tests with treated pears in 1952 indicated an undesirable effect on flavor, but this was not true for any of the three canned fruits of 1953 . Residues were not determined because a satisfactory method was lacking.

Malathion, Diazinon, and Systox. Initial control of spider mite with malathion was moderate to good for the range of species involved, with residual effect diminishing noticeably during the second or third week after 
application. Diazinon, although not appearing to have the long residual effect of the sulphonate or sulphite acaricides, did give acceptable results in these exploratory trials. In preliminary trials with heavy dosages of Systox, the control of spider mite on the four hosts was judged to be excellent.

Very low residues in all canned fruits are consistent with favorable flavor ratings with the exception of malathion on pears of the eleven months' storage (1952). The off-flavor was not found with malathion-treated pears in 1953. The flavor result on apples $2 \frac{1}{2}$ months after canning in 1953 appears anomalous since only 0.1 p.p.m. malathion was on the fresh apples at harvest.

OMPA. In the single field trial reported for pears, OMPA provided excellent control of European red mite. One test on almonds in midseason for control of Pacific mite was not encouraging.

Pears carrying a fairly heavy residue of OMPA when fresh were not tasted in 1953 after canning, but those treated similarly in 1954 had no off-flavor.

\section{CHLORINATED HYDROCARBON INSECTICIDES}

Several years' study of soil treatment with persistent insecticides has shown that a number of chlorinated hydrocarbons at the stated rates will effectively control the Pacific Coast wireworm, Limonius canus, and related species, without measurable phytotoxicity to carrots, sweet potatoes, or white potatoes. The chemicals differ in rapidity of action, lindane exemplifying those acting rapidly and DDT those that have a slow effect. DDT, for example, did not adequately protect white potatoes from wireworm damage when applied about a month prior to planting (Lange and Carlson, 1956). With the exception of $\mathrm{BHC}$ and lindane, the chemicals give equally good control of wireworms at first in light and heavy soils, but in certain soils containing much colloidal clay, the effectiveness soon diminishes. For this reason, greatly increased dosages may be required in some localities.

Although BHC and lindane are very effective in the control of many species of wireworms, they should not be used in the soil within two years of planting root vegetables due to the undesirable effects imparted to the crop. However, under certain conditions they may be safely used as seed or strip treatments where reduced dosages are involved (Lange, Carlson, and Leach, 1949).

The unpleasant flavor changes noted by the taste panel with canned carrots and sweet potatoes from benzene hexachloride plots are in agreement with the comparatively high organic chloride analyses and the positive result by bioassay of fresh carrots. Since no toxicity to insects in bioassay was found with the canned samples, it is clear that the chief flavor changes resulted from nontoxic isomers or degradation products. That deleterious flavor changes may not be related to presence of toxic compounds is shown also in the case of lindane. By bioassay, only negative results were obtained with all three canned vegetables which received a poor taste grading, especially some months after canning. This situation also held with fresh white 
potatoes from the lindane plot. The results with carrots indicate a marked loss of the toxic substance during the canning process.

These investigations indicate that wireworms can be effectively controlled under most conditions by soil applications of the following chemicals: aldrin, 2 to 5 pounds per acre; heptachlor, 2 to 5 pounds; dieldrin, 2 to 5 pounds; chlordane, 5 to 10 pounds; endrin, 2 to 5 pounds; or DDT, 10 to 40 pounds. Dosages will vary with soil characteristics, species and abundance of soil insects, and many other variables. Residual treatments of this nature may give control for one or several years. Isodrin shows good wireworm control at rates of 2 to 5 pounds per acre in soil, but caution should be exercised in its use until the full significance of the off-flavors is determined.

There is complete correlation between the negative bioassays and lack of flavor alteration for vegetables from chlordane, heptachlor, aldrin, dieldrin, and endrin plots. In the case of isodrin, the slight positive residue results with canned carrots and sweet potatoes in 1953 may be related to the offflavor finding three months after canning. Fresh sweet potatoes of 1954 had undesirable flavor changes, but no residual isodrin was found.

\section{LITERATURE CITED}

California Department of Agriculture

1952. Use of benzene hexachloride. Bur. of Chem. Announcement EP-68. 1 p. Mimeo.

Lange, W. H., Jr., E. C. Carlson, and L. D. Leach

1949. Seed treatments for wireworm control with particular reference to the use of lindane. Jour. Econ. Ent. 42:942-55.

LANGe, W. H., and E. C. Carlson

1956. Residual soil insecticides for the control of wireworms affecting vegetable crops. Hilgardia 26:60-75.

Madsen, H. F., and A. D. Borden

1956. Field tests of acaricides for control of mites on pears and apples. Hilgardia 26:7-18.

Summers, F. M.

1956. Field tests of acaricides for control of spider mites on almonds and peaches. Hilgardia 26:19-34. 


\title{
FIELD TESTS OF ACARICIDES FOR CONTROL OF MITES ON PEARS AND APPLES
}

\author{
HAROLD F. MADSEN and ARTHUR D. BORDEN ${ }^{2}$
}

SPIDER MITES are one of the major pest problems of the pear and apple grower. Mite attack can cause leaf damage, with eventual defoliation, which in turn will bring about a reduction in the crop and a poor set of fruit for the following season.

Two major mite species are found on pear and apple in California, the European red mite, Metatetranychus ulmi (Koch), and the two-spotted mite, Tetranychus bimaculatus Harvey. The Pacific mite, Tetranychus pacificus McGregor, and the clover mite, Bryobia praetiosa Koch, also occur on apples and pears, but are not of major importance in California, although they are listed by Pritchard and Baker (1952) as pests of apple and pear in the United States.

The European red mite overwinters in the egg stage on the twigs and branches of the tree, and hatches shortly after petal-fall time. Populations build up slowly until warm weather comes in June; then the mites increase rapidly. They spread out over the entire tree, feeding mostly on the upper leaf surface. Their attack causes a bronzing of the foliage, and high populations will cause defoliation.

The two-spotted mite overwinters as an adult in the trash at the base of the trees or on the covercrop in the orchard. During June and July the mites move up the tree, characteristically attacking the center of the tree first and, as populations build up, spreading over the entire tree. Twospotted mites feed on the lower leaf surfaces, and tend to colonize in spots, producing some webbing. On pear leaves their feeding causes a blackened area extending to the margin of the leaf. The mites evidently inject some toxin into the leaf, for even low populations can cause considerable damage.

Previous to the advent of DDT, mites were controlled during the foliage season with oil or DN-111 sprays, with varying results. When the new organic compounds were developed, many new acaricides became available and it was necessary to evaluate these compounds for mite control, phytotoxicity, and residue. From 1946 to the present time, numerous acaricides have been tested under field conditions, with some seven or eight compounds finding commercial usage.

In 1951, the question was raised of the possible flavor effects on canned fruit resulting from the use of these acaricides.

During the 1952 season an experimental plot was set up to evaluate several compounds for mite control and to ascertain their flavor effects on the canned fruit. The acaricides chosen for the test were: Aramite, Ovotran, Sulphenone, Genite-923, and malathion. Most of these compounds had been tested in previous seasons and some were suggested for grower use.

Aramite was first tested in 1949 and while this acaricide gave excellent

\footnotetext{
${ }^{1}$ Received for publication April 29, 1955.

2 Mr. Madsen is Lecturer in Entomology and Assistant Entomologist in the Experiment Station, Berkeley; Mr. Borden is Entomologist, Emeritus, in the Experiment Station, Berkeley.
} 
control of the two-spotted mite on pears, it was less effective against the European red mite. The compound had a long residual effect, gave a quick knockdown of active stages, and was ovicidal on the summer eggs of the mites.

Ovotran also received initial tests in 1949 and was shown to be an excellent material against all species of mites attacking apples and pears, although some adverse phytotoxic effects occurred with high dosages of the compound. The material had a long residual effect, and showed excellent ovicidal properties, but was rather slow in killing the active stages.

Sulphenone was initially tried during 1950 and, though results were erratic, showed considerable promise against both two-spotted and European red mite. It gave a good kill of active stages and was partially ovicidal, but the residual effect of this material seemed to be shorter than that of other compounds.

Genite-923 was tested during 1948 and gave good control of all mite species attacking pears. Phytotoxicity to some apple varieties, however, prevented the use of the material on this crop. Genite-923 showed a good knockdown of active stages, a long residual effect, and was shown to be ovicidal on the summer eggs of the mites.

Malathion was first available for test in 1951, and this organic phosphate compound showed promise for both mite and aphid control. The low human toxicity of the compound was one of its important desirable features and it offered possibilities as a substitute for the highly toxic parathion. In limited tests, malathion was effective against European red and two-spotted mite, providing a quick knockdown and a fairly long residual effect. It did not show any ovicidal properties.

In addition to results obtained in California, these acaricides had been evaluated by Lienk and Chapman (1953) in New York and by Newcomer and Dean (1952) in Washington, as well as by Barnes (1951) in southern California.

\section{TESTS}

Bartlett pears, which are the principal canning variety in California, were selected for the tests. A uniform block of Bartlett pears was obtained in the Di Giorgio orchard at Marysville. The trees were large, of the same age and size, and the soil type throughout the block was as uniform as could be expected.

A blower sprayer was used to apply the materials because it was deemed necessary to simulate normal orchard operations. Since this type of equipment was used, the plots were of necessity rather large, in order to minimize the danger of drift and contamination. Acre plots $(9 \times 10$ trees $)$ were used for each material and plots were unreplicated. An acre check plot was included which would not receive any acaricides during the duration of the experiment.

The center 16 trees in each plot were used for the seasonal mite counts and for collection of the fruit for residue and flavor analysis. This procedure left a buffer of 3 tree rows between the center 16 trees and the adjoining plot. 
It was decided to apply the materials when the mite populations had built up to the point where orchardists would normally treat, and to repeat applications as necessary, based on mite counts taken at 2 -week intervals throughout the season. Dosages of the acaricides were based on previous experimental data and grower practice. The gallonage applied was kept constant in each plot. In this particular orchard 900 gallons of dilute spray per acre were employed.

Prior to the acaricide applications, the orchard had received three copper fungicide dustings for fire-blight control during bloom, and three sprays of DDT for codling-moth control.

TABLE 1

1952 SEASONAL MITE COUNTS SHOWING EFFECTS OF ACARICIDES ON TWO-SPOTTED MITE INFESTING BARTLETT PEARS. DI GIORGIO ORCHARD, MARYSVILLE, CALIFORNIA

Fruit harvested July $22^{\mathrm{a}}$

\begin{tabular}{|c|c|c|c|c|c|c|c|c|}
\hline \multirow{2}{*}{ Acaricide } & \multicolumn{2}{|c|}{$\begin{array}{c}\text { Amounts applied } \\
\text { per acre }\end{array}$} & \multicolumn{6}{|c|}{ Per cent infested leaves } \\
\hline & June 10 & July 23 & $\begin{array}{c}\text { Pre-spray } \\
\text { June } 9\end{array}$ & June 16 & July 2 & July 16 & July 29 & August 13 \\
\hline Aramite. . & $11.8 \mathrm{lbs}$. & 0.0 & 18.5 & 0.0 & 0.5 & 0.5 & 7.5 & 34.0 \\
\hline Genite-923. & 2 gals. & 2.4 gals. & 12.0 & 10.0 & 25.5 & 46.5 & 10.5 & 40.0 \\
\hline Ovotran... & 5.1 lbs. & 0.0 & 10.5 & 13.5 & 6.0 & 5.0 & 9.0 & 41.0 \\
\hline Malathion... & 1 gal. & 0.0 & 13.0 & 0.5 & 1.0 & 8.5 & 17.5 & 64.5 \\
\hline Sulphenone..... & $12.5 \mathrm{lbs}$. & $\left(\begin{array}{c}0.0 \\
\text { Sul- }\end{array}\right)$ & 23.0 & 12.5 & 9.0 & 14.0 & 49.0 & 87.5 \\
\hline Check. & 0.0 & $\left\{\begin{array}{c}\text { phenone } \\
28.0 \text { lbs. }\end{array}\right\}$ & 12.5 & 13.0 & 30.0 & 52.5 & 15.5 & 31.0 \\
\hline
\end{tabular}

a Residue and flavor analyses made.

The acaricides were applied on June 10, when the mite populations had increased to treatment level. The following dosages were employed for the acaricides: 15 per cent wettable Aramite, 11.8 pounds per acre; 50 per cent emulsible Genite-923, 2 gallons per acre; 50 per cent emulsible malathion, 1 gallon per acre; 50 per cent wettable Ovotran, 5 pounds per acre; and 40 per cent wettable Sulphenone, 18 pounds per acre.

Mite counts were taken at 2-week intervals following the application and all plots were checked for phytotoxicity. Two-spotted mite was the only species present in this plot the entire season. At each mite count, 200 leaves were collected at random from the inside and outside of the trees and rated for presence or absence of mites. This method of counting mites is commonly referred to as the plus (presence of mites) and minus (absence of mites) system. The results are expressed as percentage of infested leaves. Since the two-spotted mite first attacks the center and lower portions of the tree, then gradually spreads over the tree, colonizing on the lower leaf surface, this method is satisfactory for comparison of treated plots.

The check plot did not receive any acaricide application until after harvest but was sprayed three times with water during the season in an attempt to hold down the mite populations. 
Table 1 summarizes the materials used, dates of application, and the seasonal mite counts.

The pears were harvested on July 22 , and were picked according to commercial standards in size, pressure test, and sugar-acid ratio. As soon as possible after picking, the pears were delivered to the Department of Food Technology for ripening, processing, and flavor analysis (Hinreiner and Simone, 1956). At the same time, samples from each of the plots were collected for residue analysis (Miskus, Erwin, and Hoskins, 1956).

The effect of each acaricide on the two-spotted mite was as follows: Aramite and Ovotran held the mites in check for about 9 weeks. Malathion and Sulphenone were effective for 6 weeks, then populations built up rapidly. Genite-923 was effective for about 4 weeks, but required respraying immediately after harvest. Two applications in the plot did not prevent leaf damage to the trees.

The check plot developed high mite populations by harvest time, but only a moderate amount of leaf damage was present.

Phytotoxicity effects were these: Genite-923 caused yellow spots on the fruit, but these spots faded out by harvest and were not of damaging nature. Malathion-sprayed fruit showed a green ring around the calyx end, but this symptom faded out by harvest. Aramite produced russet spots on the skin of the fruit; although these spots were very shallow, they would be a factor in fresh shipped pears. Ovotran caused no phytotoxic effects with the exception of a few burn spots on the sucker growth in the center of the trees. No fruit or foliage injury was detected in the Sulphenone-sprayed plot.

\section{TESTS}

To check the 1952 results, it was decided to re-run the experiment on both pears and apples during 1953. The same materials used in the 1952 tests were included-Aramite, Ovotran, Genite-923, Sulphenone, and malathion.

Four experimental acaricides were also used: Systox, a systemic insecticide which has shown much promise in control of mites and aphids; Diazinon, an organic phosphate which had not been previously tested; Chlorobenzilate, an acaricide that had given good mite control in limited tests the previous season; and Genite-876, which had previously been tested on a limited scale only.

Dimite, an acaricide in current use, was also tested. This acaricide had first been tested during the 1948 season and had given excellent results against all species of mites on apples and pears. Dimite possesses a quick knockdown, has a long residual effect, and acts as an ovicide on the summer eggs of mites. However, this compound has not been generally used by growers because of its high cost and limited availability.

All of these acaricides were also tested on peaches (Summers, 1956), as well as on the pears and apples.

It was decided to apply the materials on both apples and pears, using two applications at predetermined intervals, the last application to be approximately 30 days prior to harvest. This procedure was followed in order to simulate normal orchard operations, where two acaricide applications are usually needed to achieve satisfactory control. 
Tests on Pears. The same orchard used in the 1952 tests was selected for the 1953 experimental plot on Bartlett pears. As in 1952, acre plots for each material were established, but with three check plots, each an acre in extent, randomized through the treated plots. Blower sprayer equipment was again used to apply the acaricides, using 900 gallons of dilute spray per acre for each application. The center 16 trees in each plot provided leaf samples for the mite counts and fruit samples for flavor and residue analysis. Previous to the mite sprays, the entire block had received several copper fungicide dustings for blight control and three DDT sprays for codling-moth control.

TABLE 2

1953 SEASONAL MITE COUNTS SHOWING EFFECTS OF ACARICIDES ON TWO-SPOTTED MITE INFESTING BARTLETT PEARS. DI GIORGIO ORCHARD, MARYSVILLE, CALIFORNIA

200 leaves examined per plot. Fruit harvested July 21 a and August 6

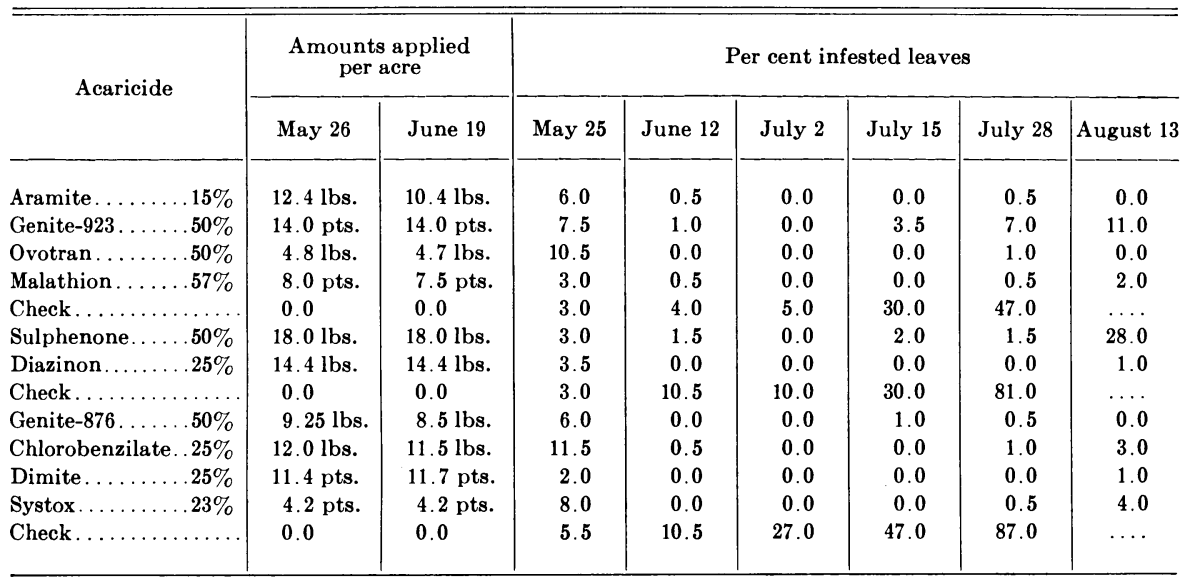

a Fruit taken for residue analysis July 21 only; fruit taken both dates for flavor analysis.

Applications were made on May 26 and on June 19. Although mite counts were made throughout the season, they were not used as a means of timing the applications.

To minimize the possibility of contamination the materials were applied under the best weather conditions possible. After each application, the leftover spray liquid was dumped and the tank washed out with clear water. Water was also sprayed through the nozzles in order to clean out the pump and pipe lines.

Mite counts were taken before the first application and continued at 2 week intervals throughout the season. The plus and minus system previously explained was used to evaluate the mite populations. Although the twospotted mite was again the principal mite species involved, one of the treated plots developed a high European red mite population.

Since three check plots were included in the experimental design, it was not practical for the grower to spray the checks with water as was done in 1952. As a result, the check plots developed high mite populations with considerable leafburn and some defoliation prior to harvest. 
Table 2 summarizes the dates of application, materials used, dosages, and the seasonal mite counts.

The pears for the flavor evaluation were harvested in two pickings, July 21 and August 6, and delivered to the Department of Food Technology for processing and flavor analysis (Hinreiner and Simone, 1956). Because of the volume of fruit required, it was not possible to secure all of the fruit in a single picking. As in 1952, the pears were picked according to commercial standards in size, pressure, and sugar:acid ratio. The fruit for residue analyses was obtained at the first picking of July 21 (Miskus, Erwin, and Hoskins, 1956).

All of the acaricides gave, in two applications, excellent control of the two-spotted mite for the season. While mites were not especially severe during 1953 it can be seen from the check plots that high mite populations would have developed if no acaricides were applied.

It was not possible to differentiate between compounds on this plot, but from previous experience with these compounds, differential results might have been obtained if only a single application had been made. This stresses the difficulties encountered in attempting to evaluate materials by a single season's results. Mite buildup varies from season to season according to a number of ecological factors. There have been seasons when even two acaricide applications have failed to give adequate control.

A severe European red mite population developed on the Ovotran-sprayed plot. European red mites were not present on any of the other plots, not even the checks. There is no clear explanation of these results, especially as Ovotran has given good control of European red mite in other pear-growing areas of the state. The Ovotran plot showed considerable leaf damage, but no defoliation at harvest.

All of the plots were checked for phytotoxicity throughout the season. Genite-876 caused black spots on the back side of the pear fruit, but no leaf damage. Aramite produced the same russet spots on the fruit that were reported during 1952. Chlorobenzilate-sprayed trees showed a very slight mottling of the foliage which did not prove to be serious. None of the other acaricides produced any phytotoxic effects on the fruit or foliage.

As a point of additional interest, Diazinon gave excellent control of aphids which were present in the orchard, and also controlled a tentiform leafminer, Lithocolletis sp. Malathion and Systox also gave good aphid control, but did not reduce the leaf-miner populations in so marked a degree as did Diazinon.

Tests on Apples. All the acaricides used on pears, except Diazinon, were used on the apple plot.

The apple variety selected for the tests was Yellow Newtown, since it is one of the principal varieties used for canning as applesauce in California. Moreover, this variety can be kept for a considerable time in cold storage without breakdown.

The plot was established in a uniform block of Yellow Newtown apples at Watsonville. The trees were 15 to 17 years old, of uniform size, and were located on sandy soil.

As with the pears, two applications of the acaracides were given in order 
to simulate normal orchard practice. Since the amount of fruit needed for the flavor analyses was relatively small, it was decided to apply the materials by hand, and the University spray truck was used. It consists of a Bean 20 high-pressure pump, delivering 20 gallons per minute, and orchardtype spray guns were used. Dosages of the acaricides were based on amounts per 100 gallons, as determined by previous experimental work and grower practice.

Since hand-spraying minimized the drift problem, 12 tree plots were set up $(3 \times 4$ trees $)$ for each material and were unreplicated. The two center trees in each plot were used for the mite counts and fruit samples. Two check plots were included, one at each end of the treated plots, and consisted of 12 trees each.

Previous to the acaricide applications, the entire block had received a cluster-bud spray of lime-sulfur and wettable sulfur for scab and mildew control. DDT plus parathion was used at petal fall for codling moth and rosy apple aphid control, and DDD in June for orange-tortrix control. Other than these, the check plots received no further treatments.

The acaricides were applied on July 1 and on August 6, under weather conditions which were as favorable as possible. Spraying operations started at 10 a.m. because early-morning fog left the trees wet until that time. After each acaricide was applied, the spray tank was emptied and washed out with clear water, and water was run through the hoses and spray guns. Applied gallonage at each application date averaged 400 gallons per acre.

Mite counts were made prior to the first application, and continued at 2 week intervals throughout the season. Two mite species were involved in the plot, the European red mite and the two-spotted mite. Counts were made by selecting 50 leaves at random from each of the two center trees in each plot, making 100 leaves per treatment.

With the two-spotted mite, the plus and minus system previously described was used, and the data expressed as percentage infested leaves. This system of counting, however, is not feasible in the case of the European red mite, due to the tendency of the mites to scatter throughout the tree. Therefore, the active mite stages were counted, and the data are expressed as the average number of mites per leaf.

Tables 3 and 4 summarize the material used, dosages, and the seasonal mite counts.

The fruit was harvested on September 29, when the apples had reached proper maturity by grower standards. As soon as possible after picking, the fruit was placed in cold storage until processing by the Food Technology Department (Hinreiner and Simone, 1956).

Considerable specificity was apparent in control of the two mite species among the various acaricides. Both Aramite and Genite-876 gave excellent control of the two-spotted mite, but neither was very effective with European red mite. Genite-923 and Systox were just the opposite, giving excellent control of the European red mite, but only weak control of two-spotted mite.

Ovotran and Dimite were the most consistent materials in control of both mite species. Chlorobenzilate and Sulphenone, although giving commercial control, did not measure up to some of the other compounds. Malathion did 
TABLE 3

1953 SEASONAL MITE COUNTS SHOWING EFFECTS OF ACARICIDES ON TWO-SPOTTED MITE INFESTING YELLOW NEWTOWN APPLES. STOLICH ORCHARD, WATSONVILLE, CALIFORNIA 100 leaves examined per plot. Fruit harvested September $29^{\mathrm{a}}$

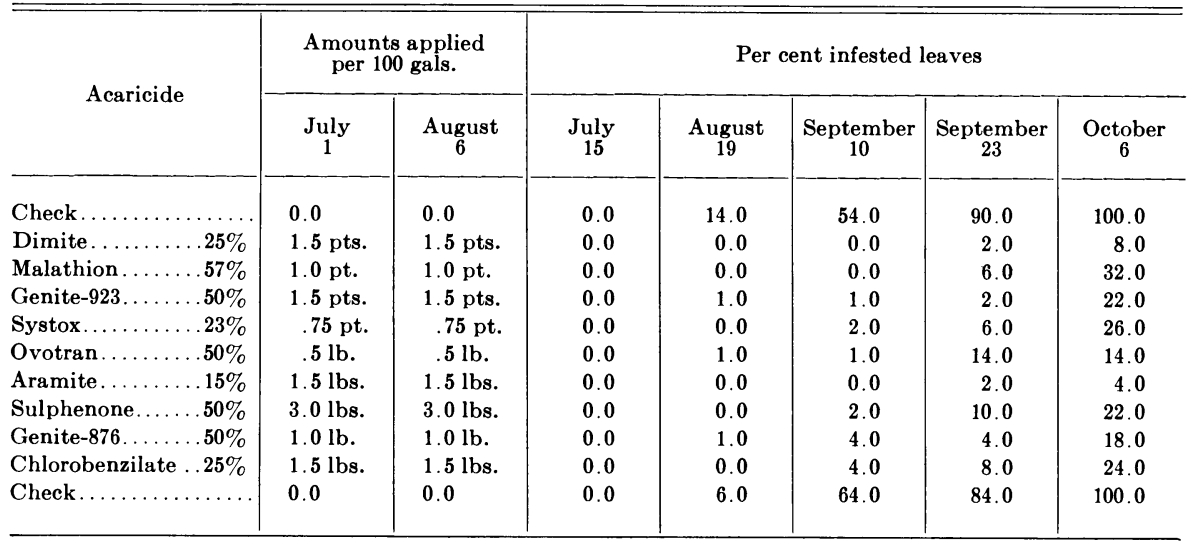

a Flavor analysis of fruit made.

TABLE 4

1953 SEASONAL MITE COUNTS SHOWING EFFECTS OF ACARICIDES ON EUROPEAN RED MITE INFESTING YELLOW NEWTOWN APPLES. STOLICH ORCHARD, WATSONVILLE, CALIFORNIA 100 leaves examined per plot. Fruit harvested September $29^{\mathrm{a}}$

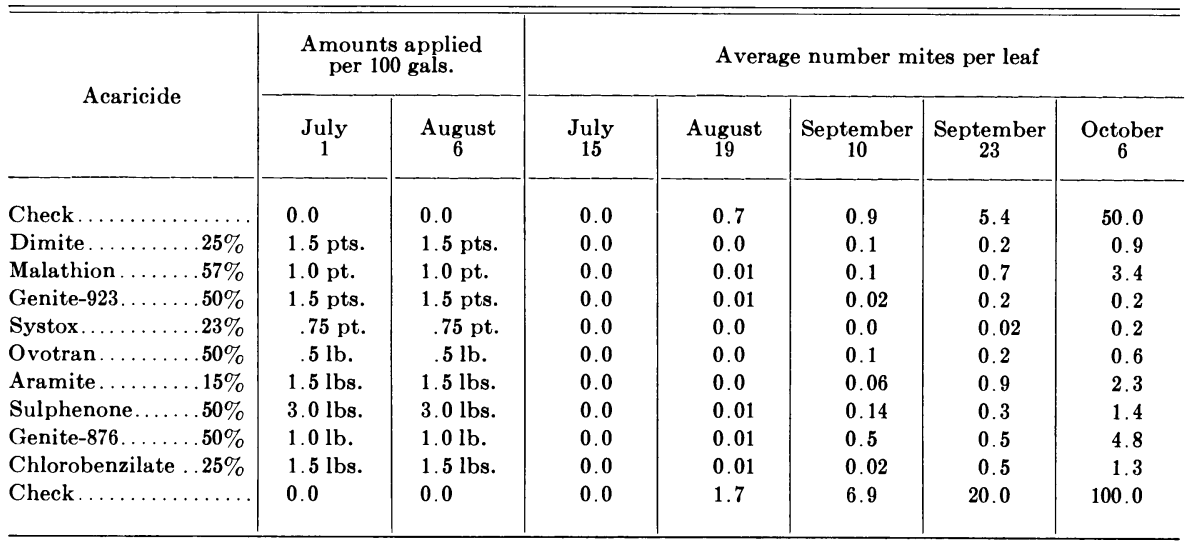

a Flavor analysis of fruit made.

not possess sufficient residual effect to prevent a late-season buildup. As can be seen in the tables, mite populations did not build up in the check plots until after the acaricides had been applied on the treated plots. Therefore, the experiment turned out to be a test of the residual effectiveness of the acaricides. The check trees developed very high mite populations, and considerable leaf injury was apparent by October. 
It should be pointed out that even though differences were apparent between the various acaricides, all gave what could be considered commercial control on this variety of apple.

An acaricide with a long residual effect is needed on apples as the growing season is long and treatment is difficult after August when props are set in the orchard. The European red mite presents an additional problem in control as, under pressure of moderate to high populations, the species will often lay overwintering eggs in the calyx end of apples. In the canning process, these eggs are difficult to remove, and cause a high insect-parts count in the finished product. Very often the calyx end of apples will have numerous eggs, even though-because of late buildup of the mites-little foliage damage occurs to the trees.

In addition to mites, woolly apple aphids were present in the orchard, and the degree of infestation was noted after the acaricide applications. Malathion-treated trees were free of woolly aphid colonies for the entire season. In the Systox plot, aphid colonies were present on the trunks and main limbs but no infestations were noted in the aerial portions of the trees. None of the other acaricides showed any degree of control of the woolly apple aphid.

Apple varieties differ considerably in their susceptibility to mite attack. Yellow Newtown and Gravenstein apples can maintain high populations with little leaf damage, but varieties such as Red Delicious, Golden Delicious, and Jonathan show leaf damage and defoliation with much lower mite populations.

The plots were checked throughout the season for phytotoxicity. Genite923 produced black spotting on the surface of the fruit and Genite-876 caused brown sunken spots on the sides of the fruit. This injury was severe enough in the case of both compounds to prevent their use on Yellow Newtown apples.

None of the other acaricides showed any adverse effects on fruit or foliage.

\section{TESTS}

Tests on Pears. During the 1954 season, mite-control plots were established in Lake County, California, to test a number of acaricides for European red mite control. The plots were located in a Bartlett pear orchard of mature trees grown under conditions of a ladino clover permanent covercrop. Each plot consisted of four trees in a square, replicated three times, and randomized throughout the plot area.

It was decided to set up the plots as a mite-control experiment rather than to apply the compounds at two specified intervals as in 1953. Small, hand-sprayed plots were used.

Using conventional ground equipment, compounds were applied when mite populations reached a point where treatment was deemed necessary. Trees were re-treated when populations built up to five or more mites per leaf. Amounts applied averaged 400 gallons per acre.

Materials used were Ovotran, Sulphenone wettable, Sulphenone emulsible, Diazinon, Systox, OMPA, and Mitox. 


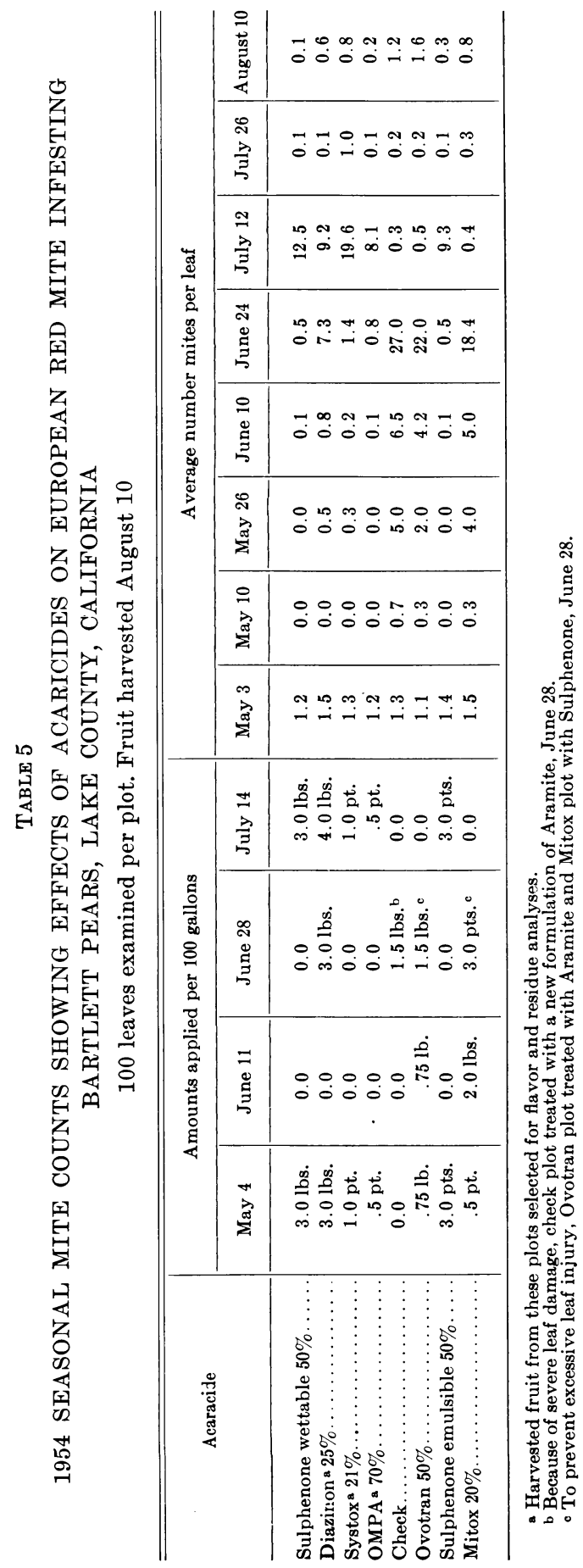


The materials were applied on May 4, when the mite counts showed an average of 1.5 European red mites per leaf and numerous eggs.

Mite counts were taken at 2-week intervals throughout the season. At each count, 100 leaves were collected at random from each plot and the active stages of mites counted. Data are expressed as average number of mites per leaf. European red mite was the only species of mite involved in these plots; although two-spotted mite was present on the covercrop, infestations did not develop in the trees. Table 5 summarizes the materials used, dosages, and the seasonal mite counts.

Sulphenone wettable and emulsible, Systox, and OMPA gave excellent control. The first application in May held the mites in check until July, when the mites built up to levels requiring treatment. A second application reduced the populations and provided control through the harvest season. Diazinon did not hold as long, requiring a second application in June. This spray did not give adequate control and a third application was necessary in July. Following the July treatment, mites were held in check the remainder of the season.

Ovotran and Mitox did not provide control and mite counts paralleled those in the check plot. A second application in early June failed to reduce populations; to prevent excessive leaf injury, the Ovotran plot was treated with Aramite, and the Mitox plot with Sulphenone.

It was originally intended to include an unsprayed plot, but by the latter part of June, leaf damage was so severe on the check plot that it was deemed necessary to treat in order to prevent complete defoliation. Consequently a new formulation of Aramite was applied which reduced the mite populations and held the mites in check the remainder of the season.

The plots were checked for phytotoxicity during the season with the following observations: OMPA caused a marginal leafburn, especially noticeable on sucker growth in the centers of the trees. Sulphenone wettable, after the first application in May, caused a yellowing of the foliage, but no injury was noted after the second application in July. The emulsible formulation did not show as much leaf yellowing as the wettable powder. The new formulation of Aramite was quite phytotoxic, and both leaf and fruit injury was apparent. The standard Aramite formulation did not show any leaf injury, but some russet spots were present on the fruit. None of the other materials showed any fruit or foliage injury.

The fruit for the flavor evaluation (Hinreiner and Simone, 1956) and residue analysis (Miskus, Erwin, and Hoskins, 1956) were harvested on August 10, when the fruit had reached maturity according to grower standards. Fruit treated with OMPA, Systox, and Diazinon were selected for the flavor evaluations and residue analysis, and fruit from the original unsprayed plot, treated with Aramite in June, was used for a check. Sulphenone was not included as three seasons' work had been completed on this material. Since they did not control the mites, Mitox and Ovotran were not included in the fruit selected for residue and flavor analysis.

Flavor Tests of Prebloom Genite-923 Treatments. For the past two seasons, experimental plots have been conducted on prebloom treatments for control of European red mite eggs on pears. The results of these tests 
have been published by Madsen (1955) and Madsen and Borden (1955); therefore they will not be discussed in this paper.

Fruits from the 1954 plots, treated with a prebloom application of Genite923 were harvested on August 11 and delivered to the Department of Food Technology for flavor analysis (Hinreiner and Simone, 1956). Fruit from an untreated check plot was also included.

Flavor Tests of Malathion Treatments. Since the 1953 flavor analysis of malathion-treated apples raised the question of a possible flavor change, this acaricide was again applied for flavor analysis in 1954. There was no attempt to evaluate malathion for mite control this season. In order to secure an adequate check plot for the flavor analysis an orchard was selected in which only an early-season application had been made. The orchard was located in the Sebastopol district and the variety was Red Rome. Two pounds of 25 per cent wettable malathion per 100 gallons was applied to a 4-tree plot on September 17 at the rate of 17 gallons per tree, and fruit was harvested from treated and check trees on October 12 and delivered to the Department of Food Technology for flavor analysis (Hinreiner and Simone, 1956). Samples were also collected at random for residue analysis (Miskus, Erwin, and Hoskins, 1956).

\section{LITERATURE CITED}

BARNES, M. M.

1951. Studies with acaricides for control of mites in apple and pear orchards in southern California. Jour. Econ. Ent. 44:672-84.

HiNREINER, E., and M. Simone

1956. Effects of acaricides on flavor of almonds and canned fruits. Hilgardia 26:35-45.

LiENK, S. E., and P. J. ChAPMAN

1953. Evaluation of acaricides on orchard mites in 1952. Jour. Econ. Ent. 46:1085-86.

MAdSEN, H. F.

1955. Early sprays for European red mite. California Agr. 9:4-15.

Madsen, H. F., and A. D. Borden

1955. Prebloom treatments to control European red mite eggs on pears in California. Jour. Econ. Ent. $48: 103-5$.

Miskus, R. P., W. R. Erwin, and W. M. Hoskins

1956. Harvest residues of acaricides used on deciduous fruits. Hilgardia 26:46-59.

Newcomer, E. J., and F. P. Dean

1952. Orchard mites resistant to parathion in Washington. Jour. Econ. Ent. 45:1077-78.

Pritchard, A. E., and E. W. BAKer

1952. A guide to the spider mites of deciduous fruit trees. Hilgardia 21:253-87.

SuMMers, F. M.

1956. Field tests of acaricides for control of spider mites on almonds and peaches. Hilgardia 26:19-34. 


\section{FIELD TESTS OF ACARICIDES FOR CONTROL OF SPIDER MITES ON ALMONDS AND PEACHES}

\section{F. M. SUMMERS ${ }^{2}$}

The PURPose of this report is to present observations on the acaricidal value of 22 spray chemicals applied in peach or almond orchards of central California. Some of the materials tested were holdovers from tests performed earlier than those described in this paper. Others were tested for the first time by the writer in the trials to be described. It was possible to test some of the materials repeatedly in plot work as well as in coöperative trials with interested growers, whereas others have received little more than preliminary tryouts on a small scale. The wholly unpromising ones were not difficult to eliminate from further consideration. However, most of those introduced for commercial testing within the past three years have shown sufficient promise to warrant more extensive testing on peaches and almonds than was possible to cover in this segment of field work.

Three species of spider mites were involved: the brown almond mite (Bryobia praetiosa K.), the two-spotted mite (Tetranychus bimaculatus Harvey) and the Pacific mite (T. pacificus McG.). The first species seriously infests both peaches and almonds. Its peak attack occurs during late spring. The species of Tetranychus appear later, usually not before July 1. The summer mite of peaches is the two-spotted mite. The summer mite of almonds is most apt to be the Pacific mite. The time sequence and host preference thus make it possible to study the effects of sprays on one species without the complication of mixed populations. But the selection of sample leaves for counts of Tetranychus mites often requires that persisting symptoms of damage attributable to the brown almond mite be disregarded.

Entomologists use a variety of sampling procedures and rating systems for securing measurement data on the performance of sprays applied for the control of spider mites. Since the data obtained in various ways do not always measure similar phenomena under similar conditions, it is desirable to outline the sampling procedures employed during the course of this study.

The behavior of the brown almond mite varies considerably according to host. On peach trees, the crawling stages disperse over large areas of the hangerwood and main scaffolds. During favorable parts of the day the mites observed on leaves represent only the feeding fraction of the whole population; larger numbers remain on the woody parts. The sprays applied to peaches were appraised by counting only those mites which were taken on the leaves-on 100 selected leaves picked and examined one at a time. Only the older, basal leaves were selected where the level of damage indicated maximum populations of mites. The leaves were picked during sunny periods of the day when air temperatures remained between $70^{\circ}$ and $85^{\circ} \mathrm{F}$. One limitation of this mites-per-leaf method-as used for brown almond mites-is that their excursions from wood to leaves or vice versa are affected by comparatively small changes in temperature and, possibly, sunlight.

${ }^{1}$ Received for publication April 29, 1955.

${ }^{2} \mathrm{Mr}$. Summers is Associate Professor of Entomology and Associate Entomologist in the Experiment Station, Davis. 
A different procedure was devised for brown almond mites infesting almond trees (Summers and Baker, 1952). Almond trees tend to support heavier populations of this species than do peach trees, and the crawling stages congregate on the small, stubby spurs and distal brushwood. Therefore, the following method was developed for estimating the numbers of mites recovered from reasonably uniform twigs cut at random from host trees. The mites were dislodged from both leaves and wood by beating the twigs over sheets of paper. Mites thus collected on the paper sheets were fixed in position by crushing. Template counts of these were then converted into units-mites per shoot per template-suitable for comparing populations in relative terms. Although the sprays were applied at various times, the samples were not drawn from the trees until the period of crisis or peak attack.

Two-spotted mites on peaches and Pacific mites on almonds were sampled on a mites-per-leaf basis, with basal leaves selected from local areas of maximum infestation. Peach leaves were individually picked, 25 leaves per sample, and only the active mites on these were counted immediately. The almond leaves were also selected from areas of maximum infestation. Spurs or simple shoots were pulled from the trees and, at the counting bench, a single leaf was selected from each of 25 shoots. A succession of counts was made in order to establish time trends. Small numbers of mites (0 to 25 mites) were counted accurately; larger numbers were estimated. The periodic samplings were continued until the onset of natural decline occúrred in untreated trees. The numbers of mites recorded for individual samples are regarded as indicative only insofar as they are consistent with the trend of the counts for successive samplings. A subjective element is involved in the selection of sample leaves as well as in the judgment of what constitutes adequate control.

In the interior valleys of California troublesome infestations of Tetranychus mites appear most frequently on almonds and peaches during July or August. However, within this period the start of a definitive attack and its duration are quite variable. Infestations developing after August 1 are perhaps less seriously regarded from the standpoint of impaired plant vitality (Cutright, 1951) than from that of complaints of harvest crews about personal discomforts or, in the case of almonds, of excessive leaf trash on harvesting sheets. It frequently happens that experimental plots are abandoned because initially threatening attacks are checked by changing weather conditions or increases in numbers of controlling organisms. For this reason the information to be presented in an accompanying report by Hinreiner and Simone (1956) on the flavor characteristics of spray-treated almonds and peaches and the data showing the effects of the sprays on the mite infestations were not always obtained from the same series of plots.

\section{TESTS ON BROWN ALMOND MITES}

Brown almond mites produce fairly stable populations in stone-fruit orchards. Annual fluctuations are not likely to vary through extremes of trace to very damaging levels of infestation. An orchard badly damaged during one season may be expected to carry over enough winter eggs to produce a 
comparable infestation during the next season. This characteristic is an added incentive for growers to use preventive sprays for this pest.

In exploratory trials on almonds the acaricides Ovotran and Genite-923 showed special promise for use in preventive sprays. These two materials not only gave superior results against mites but also showed good possibilities for incorporation in the copper fungicide sprays frequently applied to almonds just before bloom. Extensive tests of these materials were made from 1950 through 1952. The data for this series of tests have been published elsewhere (Summers, 1952). It was found that popcorn or petal-fall sprays containing 1.5 to 2.0 pounds of Ovotran $50-\mathrm{W}$ (50 per cent wettable) or Genite-923 50-E (50 per cent emulsion) per 100 gallons consistently yielded controls of 95 per cent or better when appraised in May or June, at the approximate time of the peak attack. Commercial usages of these sulphonate acaricides in popcorn or petal-fall sprays have given very gratifying results to date.

Information concerning the possibility of flavor changes in spray-treated nuts was obtained in conjunction with tests applied later in the season for the control of Pacific mites (Hinreiner and Simone, 1956).

The pink-bud and petal-fall sprays developed for almonds were tested on peaches during 1952 (Elberta, Paloro, Fortuna, Johnson, and Lovell varieties). For the most part, the infestations on peaches were not as heavy as those occurring on almonds and the results were more difficult to evaluate. Measurement data from the best of the plots are shown in tables 1 and 2 .

Sprays containing 2 pints of Genite-923 per 100 gallons produced excellent results in both pre- and postbloom applications. The pink-bud sprays in which a dosage of 1 pint was tested were somewhat less effective but still within the range of acceptable control 67 days after treatment.

Ovotran sprays applied in the pink-bud period did not appear to give such striking results as when applied to almonds in the popcorn period. In this experiment the results were estimated to be fair control, with little apparent difference between dosage levels. On the other hand, petal-fall applications of Ovotran at 1.5 pounds per 100 gallons- 5.3 gallons of spray per tree as compared with 7.3 gallons per tree for the pink-bud spray-gave outstanding results. Inadequate controls were obtained with the various sulfur materials tested in this series on plots. The sprays listed in tables 1 and 2 were duplicated in two other localities. No contradictory results were observed. There was no evidence of spray injury to the peach trees within the range of materials, dosages, and varieties tested. Ripe peaches from the Ovotran and Genite plots shown in tables 1 and 2 were harvested for residue analyses (Miskus, Erwin, and Hoskins, 1956) and flavor tests (Hinreiner and Simone, 1956). Additional treatments with Ovotran and Genite-923 were applied at a later date (July 25) for tests of this type.

\section{PACIFIC MITES ON ALMONDS}

Heavy Infestation. 1950 test. A fairly critical test of eleven materials, listed in table 3, was obtained in an almond orchard severely infested with Pacific mites before the sprays were applied, on July 17, 1950. On this date 
nearly all of the leaves were infested in some degree and considerable portions of the foliage showed near-maximum numbers of mites. Sample counts made 10 days after treatment (July 27) showed maximum numbers of mites on moderately damaged leaves. The severely damaged leaves were beginning to drop and a surplus population of mites was accumulating on cultivated ground beneath the trees. The final samples were drawn 22 days after spray-

TABLE 1

CONTROL OF BROWN ALMOND MITES ON PEACHES DURING PINK-BUD PERIOD; MODESTO, CALIFORNIA 1952

Sprayed February 29, approximately 7.3 gallons per tree; Paloro variety. Mites counted May 6, before peak of attack

\begin{tabular}{|c|c|c|c|c|}
\hline Plot & Acaricide & $\begin{array}{l}\text { Amount per } \\
100 \text { gals. }\end{array}$ & $\begin{array}{c}\text { Total mite count } \\
\text { on } 100 \text { leaves }\end{array}$ & $\begin{array}{l}\text { Per cent } \\
\text { reduction }\end{array}$ \\
\hline
\end{tabular}

a Sprays on plots A-E inclusive contained $1 \mathrm{lb}$. DDT 50-W and Bordeaux 5-5-50.

b Samples of fruit taken for flavor tests.

TABLE 2

CONTROL OF BROWN ALMOND MITES ON PEACHES DURING PETALFALL PERIOD; MODESTO, CALIFORNIA 1952

Sprayed April 4, approximately 5.3 gallons per tree; Paloro variety. Mites counted May 6

\begin{tabular}{|c|c|c|c|c|}
\hline Plot & Acaricide & $\begin{array}{l}\text { Amount per } \\
100 \text { gals. }\end{array}$ & $\begin{array}{c}\text { Total mite count } \\
\text { on } 100 \text { leaves }\end{array}$ & $\begin{array}{l}\text { Per cent } \\
\text { reduction }\end{array}$ \\
\hline $\mathbf{A}$ & Ovotran $50-\mathrm{Wa}$. & \multirow{6}{*}{ 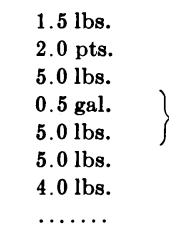 } & 75 & 97 \\
\hline $\mathbf{B}$ & Genite-923 50-E ... & & 110 & 95 \\
\hline $\mathrm{C}$ & Kolofog $\ldots \ldots \ldots \ldots \ldots \ldots \ldots \ldots$ & & 1,329 & 43 \\
\hline $\mathbf{E}$ & 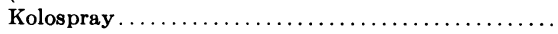 & & 1,433 & 39 \\
\hline $\mathbf{F}$ & Magnetic " 70 " sulfur paste $\ldots \ldots \ldots \ldots \ldots \ldots \ldots$ & & 1,572 & 33 \\
\hline & 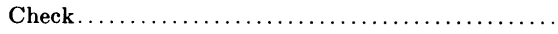 & & 2,347 & $\cdots$ \\
\hline
\end{tabular}

- Samples of fruit taken for flavor tests.

ing. At this time the level of leaf injury was too advanced in some of the plots to provide a selection of sample leaves of the types desired.

In this experiment only two of the test materials, Aramite 15-W and EPN 27-W, were sufficiently effective to give immediate relief against an advanced infestation of this sort. However, the final results with these two materials differed appreciably.

The two plots sprayed with Aramite varied according to the concentration used. The spray containing 2 pounds of this acaricide per 100 gallons immediately reduced and continuously held the infestation at such low level 


\begin{tabular}{|c|c|c|c|}
\hline \multirow[b]{2}{*}{$\underset{2}{\circ}$} & \multicolumn{2}{|c|}{ 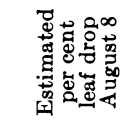 } & 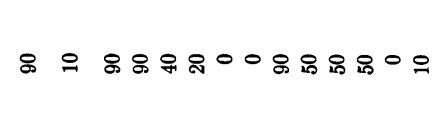 \\
\hline & \multirow{3}{*}{ 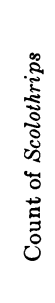 } & 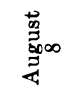 & 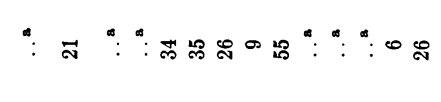 \\
\hline \multirow{5}{*}{ 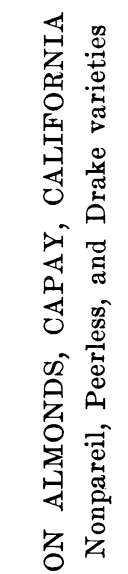 } & & בุ๋ & 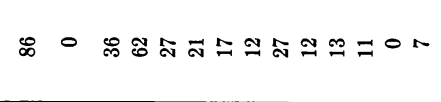 \\
\hline & & ไี่ & $\infty N 0 m N-\infty n 00000$ \\
\hline & \multirow{3}{*}{ 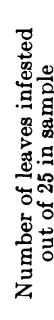 } & 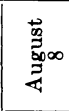 & $\because:$ : : : : \\
\hline & & ไ⿳่大ล & న \\
\hline & & छึส & เ ని สิ \\
\hline \multirow{6}{*}{ 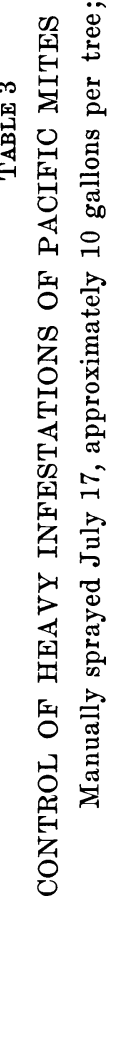 } & \multirow{3}{*}{ 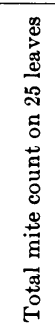 } & 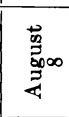 & “ \\
\hline & & בై & 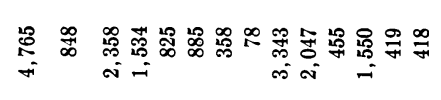 \\
\hline & & ఫైి & 员胥 \\
\hline & \multicolumn{2}{|c|}{ 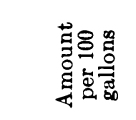 } & 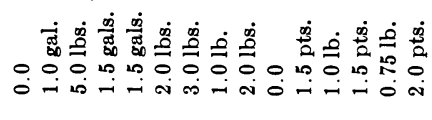 \\
\hline & \multicolumn{2}{|r|}{ : } & $\begin{array}{c}\vdots \\
\vdots \\
\vdots\end{array}$ \\
\hline & & $\stackrel{\overrightarrow{0}}{\sim}$ & $4-\infty \infty \pi \infty n \infty \infty \pi=9$ \\
\hline
\end{tabular}


that further damage to the foliage thereafter was not apparent. The foliage on the trees in this plot remained in satisfactory condition for the remainder of the growing season. The spray containing 1 pound of Aramite per 100 gallons prevented defoliation but allowed a noticeable increase in numbers of mites on the leaves prior to the period of natural decline.

The application of EPN produced the most complete initial cleanup of the foliage (table 3, plot 11). But each 10-day sampling thereafter showed a decline in its residual effect and the beginning of a renewed attack - in part from mites surviving on the trees and in part by reinfestation from the ground. Trees sprayed with this acaricide held their leaves throughout the period of sampling but on the final sampling date the trees were again in distress. The condition of the trees in this plot deteriorated rapidly thereafter.

TABLE 4

RESIDUAL CONTROL OF LIGHT INFESTATIONS OF PACIFIC SPIDER MITES ON ALMONDS, CAPAY, CALIFORNIA 1951

Manually sprayed June 20, approximately 8.3 gallons per tree; Nonpareil, NePlus, Peerless, and Drake varieties

\begin{tabular}{|c|c|c|c|c|c|c|c|c|}
\hline \multirow{2}{*}{ Plot } & \multirow{2}{*}{ Acaricide } & \multirow{2}{*}{$\begin{array}{c}\text { Amount } \\
\text { per } 100 \\
\text { gallons }\end{array}$} & \multicolumn{6}{|c|}{ Total mite count on 25 leaves } \\
\hline & & & June 29 & July 6 & July 16 & July 23 & July 30 & August 13 \\
\hline A & None, Check I. & 0.0 & 33 & 58 & 342 & 339 & 405 & 289 \\
\hline 1 & Aramite $15-W$. & $1.0 \mathrm{lb}$. & 0 & 0 & 23 & 88 & 245 & 281 \\
\hline 2 & Aramite $15-W$. & $2.0 \mathrm{lbs}$. & 0 & 2 & 33 & 31 & 38 & 52 \\
\hline 3 & Ovotran $50-W$ & $1.0 \mathrm{lb}$. & 4 & 3 & 5 & 90 & 276 & 188 \\
\hline 4 & Ovotran $50-\mathrm{Wa}^{\mathrm{a}}$ & $2.0 \mathrm{lbs}$. & 4 & 0 & 0 & 7 & 0 & 135 \\
\hline 5 & Sulphenone $40-W$ & $2.6 \mathrm{lbs}$. & 35 & 19 & 125 & 268 & 652 & 146 \\
\hline 6 & Genite-923 50-E. . & $2.0 \mathrm{pts}$. & 1 & 3 & 69 & 122 & 203 & 103 \\
\hline B & Check II........ & 0.0 & 251 & 256 & 442 & 489 & 114 & 19 \\
\hline 7 & $\left\{\begin{array}{l}\text { Lime sulfur and } \\
\text { wettable sulfur. }\end{array}\right.$ & $\left.\begin{array}{l}1.0 \mathrm{gal} . \\
5.0 \mathrm{lbs} .\end{array}\right\}$ & 71 & 67 & 227 & 211 & 799 & 1,676 \\
\hline
\end{tabular}

a Nonpareil almonds taken on normal harvest date, September 7, for flavor evaluation.

The most prevalent predator in the orchard, Scolothrips sexmaculatus (Perg.), was nearly excluded from the EPN-treated plot during the course of the observation period (see table 3 ).

Light Infestation. 1951 test. A longer test of the effective residual action of several newer acaricides is shown in table 4 . In this instance the test sprays were applied early in the season-when the mites were generally distributed in small colonies over the outer foliage. An anticipated attack failed to materialize immediately because of weather change. Relatively cool nights and daytime temperatures below $85^{\circ} \mathrm{F}$ during the first half of July retarded mite development and prolonged the period of population buildup. Accordingly, the experiment developed into one of preventive sprays being applied to an unusually sluggishly reproducing population of mites. The maximum population density occurred about 4 weeks after spraying.

The sprays containing Aramite or Ovotran gave satisfactory control for an extended period of time. The dosages of 1 pound per 100 gallons of either 
Aramite $15-\mathrm{W}$ or Ovotran 50-W appeared to inhibit buildup for some 33 days after application. An appreciable number of mites developed in these plots 39 days after application. The 2-pound dosage of these two acaricides remained effective throughout the period of potential mite buildup.

The sprays containing Genite-923, Suphenone, or lime-sulfur did not yield adequate control under the conditions of the test. The delayed buildup in the lime-sulfur plot was possibly not related to the nature of the spray; for this plot was unfavorably located in respect to irrigation and roadside dust.

Samples of nuts treated with Genite-923 and Ovotran were harvested for flavor analyses. Nonpareil nuts were harvested for this purpose from plots 4,6, and check A in the Capay orchard reported upon in table 4. Similarly treated nuts of the Texas (Mission) variety were taken from a duplicate experiment in another locality, where the acaricides were used in the spring against brown almond mite rather than in midsummer for Pacific mite as in the Capay orchard. Thus the information on flavor analyses obtained from the midseason treatments (Hinreiner and Simone, 1956) covers two contingencies of possible usage.

Moderate Infestation. 1953 test. Table 5 shows the results when a group of acaricides were applied in an orchard moderately damaged and with spotty distribution of mites at the time of spraying. The upward trend of the infestation proved to be of short duration and an acute attack did not develop. The infestation attained a low maximum density about two weeks after sprays were applied and the subsequent decline was gradual. Initial counts made five days after date of application were higher than anticipated. Despite heavy volumes of spray-11 gallons per tree-significant numbers of leaves showed incomplete spray coverage on upper surfaces. Apparently this was caused by an unusual condition of rolled leaves, many having margins curled towards the upper midline. In this connection it should be noted that Pacific mites colonize principally the upper surfaces of almond leaves.

Favorable controls, initially and finally, were obtained with Systox, Ovotran with dinitro supplement, Chlorobenzilate, Dimite, and Genite-876 at the concentrations indicated (table 5).

Initial control with Aramite, Sulphenone, and malathion was relatively poor. However, the effect of these sprays differed in the later samplings. Aramite eventually gave good control. Sulphenone and malathion did not. There was an eventual uptrend of the infestation in the plot treated with malathion, and the trees in this plot partly defoliated in late August.

\section{TWO-SPOTTED MITES ON PEACHES}

The methods used in the work on two-spotted mites affecting peaches were similar to those used for Pacific mites on almonds. The field experiments with almonds and peaches often ran concurrently. When similar groups of materials were used, the information obtained for one host often tended to confirm that obtained for the other. Tabular data are given for four series of tests with acaricides applied to peaches. Supplemental information was 


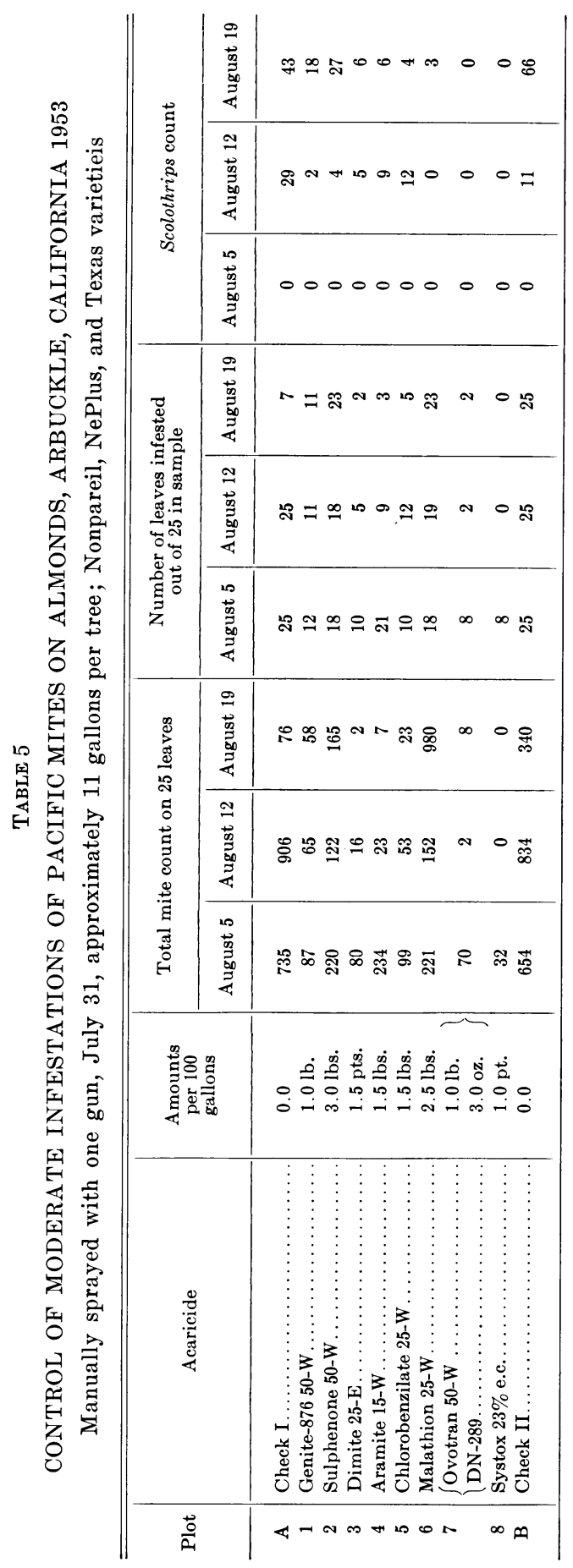


obtained from additional experimental plots and grower trials for which data were not recorded.

Postharvest Sprays. 1950. The data of table 6 were obtained during 1950 for postharvest sprays applied to Shasta clings. Dryness, dust, and high temperatures favored rapid buildup of mites in this orchard for about 15 days beyond the date (August 16) on which the plots were sprayed. No sprays were applied to the orchard as a whole. Partial defoliation occurred during the course of the experiment. Noticeable surpluses of mites accumulated on the bare orchard floor but reinfestation from the ground was not pronounced. The summer oil and TEPP sprays were repeated 6 days after the first application. All others were single applications.

The level of control obtained with Aramite was outstanding-clearly superior to the other acaricides included in the group. Satisfactory results were obtained with Dimite and with two applications of TEPP, one of which contained wettable sulfur. A double application of TEPP alone gave excellent short-term relief but no lasting control. In this instance it appeared that the addition of 5 pounds of wettable sulfur per 100 gallons to the first TEPP spray extended the period of effective control at least through the tenth day after the second application. Initial reduction of mites with parathion was outstanding. Later, however, the infestation recurred in greater severity than was observed during the crisis of the attack on untreated trees at an earlier date.

An opposite trend occurred in the plot sprayed with Ovotran. The effect of the Ovotran was imperceptible in the initial sampling but subsequent samples revealed a gradually diminishing population, which resulted in almost mite-free foliage 30 days after treatment. Unfortunately the infestation was not reduced quickly enough to provide adequate relief against the rapidly accumulating injury by the mites.

Poor control was obtained with Neotran, with Compound 923 (later named Genite-923) formulated as a wettable powder, and with medium oil emulsion applied in two sprays 6 days apart.

Light Infestation. 1952 test. During 1952 the two-spotted mite infestations were generally light and irregularly distributed throughout the peachproducing areas of the interior valleys. Only a few orchards were severely affected during August and September. A short series of trials was run in one of these in an effort to secure measurement data on two dosages of Aramite (table 7 ). Wettable sulfur was added to one of these sprays. Additional experimental materials, Compound NP-602 and Genite-876, were tested in companion plots. The results obtained were of limited significance because the spider-mite populations on unsprayed trees began to decline soon after the plots were established.

Initial control with Aramite differed appreciably according to dosage. Three days after treatment, very few mites remained on trees sprayed with 2 pounds of this material per 100 gallons whereas trees sprayed with 1 pound showed residual populations of nearly 10 mites per leaf. The result obtained with Aramite plus wettable sulfur appeared to be at least as good as that obtained from the corresponding treatment with Aramite alone and possibly better. 
Even under these poor conditions for testing spray materials, the effect of the heavy dosage of Compound NP-602-approximately 21 pounds of actual toxicant per acre-was unsatisfactory.

The trials with Genite- 876 were inconclusive. It is believed that the dosages selected for initial tryouts were probably too low. Posttreatment examinations on the third day showed considerable numbers of mites remaining on the foliage but most of these were partly incapacitated or erratic in movement.

TABLE 6

CONTROL OF POSTHARVEST INFESTATIONS OF TWO-SPOTTED MITES ON PEACHES, EMPIRE, CALIFORNIA 1950

Manually sprayed, August 16, approximately 7.5 gallons per tree; Shasta variety

\begin{tabular}{|c|c|c|c|c|c|c|}
\hline \multirow{2}{*}{ Plot } & \multirow{2}{*}{ Acaricide } & \multirow{2}{*}{$\begin{array}{l}\text { Amounts } \\
\text { per } 100 \\
\text { gallons }\end{array}$} & \multicolumn{4}{|c|}{ Total mite count on 25 leaves } \\
\hline & & & August 18 & August 24 & September 1 & September 14 \\
\hline A & Check I............ & & 1,310 & 2,995 & 3,618 & 251 \\
\hline 1 & Medium oil emulsion ${ }^{a}$. & 1.5 gals. & 475 & 645 & 943 & 583 \\
\hline 2 & TEPP $20 \%$ solution.... & $0.5 \mathrm{pt}$. & 39 & 1 & 177 & 831 \\
\hline 3 & $\left\{\begin{array}{l}\text { TEPP } 20 \% \text { solution } \ldots \ldots \ldots \\
\text { wettable sulf } u \text { ur............ }\end{array}\right.$ & $\left.\begin{array}{l}0.5 \mathrm{pt} . \\
5.0 \mathrm{lbs} .\end{array}\right\}$ & 97 & 5 & 116 & 128 \\
\hline 4 & Neotran $40-W$. & $1.0 \mathrm{lb}$ & 991 & 2,116 & 2,103 & 2,431 \\
\hline 5 & Neotran $40-\mathrm{W}$. & $2.0 \mathrm{lbs}$. & 544 & 922 & 594 & 1,013 \\
\hline 6 & Aramite $15-W$ & $1.0 \mathrm{lb}$ & 49 & 47 & 7 & 6 \\
\hline 7 & Dimite $25-\mathrm{E} \ldots \ldots$ & $1.0 \mathrm{pt}$. & 142 & 58 & 206 & 268 \\
\hline 8 & Ovotran $50-W \ldots \ldots$ & $2.0 \mathrm{lbs}$. & 1,715 & 914 & 637 & 35 \\
\hline 9 & Compound 923 25-W........ & $3.0 \mathrm{lbs}$. & 16 & 2,373 & 2,550 & 285 \\
\hline 10 & Parathion $25-W \ldots \ldots \ldots \ldots$ & $1.0 \mathrm{lb}$ & 3 & 29 & 1,021 & 6,941 \\
\hline B & Check II . ............... & $\ldots \ldots$ & 1,693 & 3,226 & 5,025 & 1,133 \\
\hline
\end{tabular}

a Plots 1-3 inclusive received a second spray, August 22; sulfur omitted from second application in plot 3.

Light Infestation. 1953 test. A coördinated effort was made in 1953 to test a similar group of acaricides on apples and pears (Madsen and Borden, 1956 ), as well as on peaches, to provide comparably treated fruits for flavor testing. The sprays indicated in table 8 were applied only once to peaches of the Stuart variety as soon as the level of infestation seemed to be appropriate. for corrective spraying. The remainder of this orchard was sprayed with Aramite by its owner.

The mites infesting the two check plots failed to increase beyond the level first observed and there was very little mite activity in the treated plots. Nevertheless, weekly samples were taken until the thirty-third day, beyond which there was little hope for a reversal of the downward trend of the mite population. The infestation was at trace level when peaches were picked on September 7 for flavor testing. Untreated peaches for the flavor tests were harvested in the two check plots-28 boxes from each plot-and mixed into one composite sample. The results of the flavor tests are reported by Hinreiner and Simone (1956) and residue analyses of the canned peaches by Miskus, Erwin, and Hoskins (1956).

Heavy Infestation. 1953 test. A second series of plots was established later in the season in a near-by peach orchard which was more heavily infested 
(table 9). These sprays were applied to trees already seriously affected but not quite beginning to defoliate. The course of this experiment was conditioned by three factors: heavy deposits of road dust on the foliage, dense ground cover of knee-high watergrass, and location of plots on the margin of an otherwise unsprayed orchard. Two to three weeks after the plots were established, the trees in both the unsprayed checks and in the orchard as a whole began to defoliate. Large numbers of mites collected on the grass and invaded the treated areas. Towards the end of the sampling period, the

TABLE 7

\section{CONTROL OF LIGHT, LATE INFESTATIONS OF TWO-SPOTTED MITES} ON PEACHES, HUGHSON, CALIFORNIA 1952

Sprayed August $26^{a}$, approximately 6 gallons per tree; near crisis or start of population decline; Peak variety

\begin{tabular}{|c|c|c|c|c|}
\hline \multirow{2}{*}{ Plot } & \multirow{2}{*}{ Acaricide } & \multirow{2}{*}{$\begin{array}{c}\text { Amounts } \\
\text { per } 100 \\
\text { gallons }\end{array}$} & \multicolumn{2}{|c|}{ Total mite count on 25 leaves } \\
\hline & & & August 29 & September 5 \\
\hline 1 & NP-602 50-W. & $8.0 \mathrm{lbs}$. & 856 & 168 \\
\hline 2 & Genite-876 50-W . . . . . . . . . . . . . . . . . . & 0.5 lbs. & $384^{b}$ & 6 \\
\hline 3 & 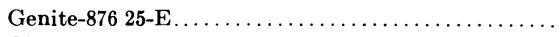 & $1.0 \mathrm{pt}$. & 522 & 53 \\
\hline A & Check $^{c} \ldots \ldots \ldots \ldots \ldots \ldots \ldots \ldots \ldots \ldots \ldots \ldots$ & $\ldots .$. & 4,555 & 743 \\
\hline 4 & Aramite $15-W \ldots \ldots \ldots \ldots \ldots \ldots \ldots \ldots \ldots \ldots$ & $1.0 \mathrm{lb}$. & 229 & 1 \\
\hline 5 & 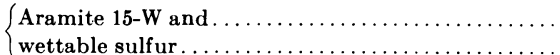 & $\begin{array}{l}1.0 \mathrm{lb} . \\
5.0 \mathrm{lbs} .\end{array}$ & 140 & 1 \\
\hline 6 & 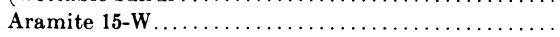 & 2 lbs. & 13 & 1 \\
\hline
\end{tabular}

a Condition of trials generally poor; late infestation, well into period of increasing biological control.

b Majority of those counted as alive were abnormal-partly incapacitated or erratic in movement.

c 20 per cent defoliated initially.

mites on the watergrass moved onto the treated trees, thus providing a severe test of the waning residues.

All of the acaricides applied in this series gave satisfactory initial control. Although slightly greater numbers of mites were observed in the malathion and Chlorobenzilate plots at the end of the first week, the counts of the second week were not significantly higher than those obtained for the other sprays.

Marked variations between treatments appeared at the end of three weeks. Trees sprayed with Systox, Sulphenone, and Aramite continued to show very good control. A slightly greater buildup occurred on the trees sprayed with Genite-876, Chlorobenzilate, and Diazinon. Those sprayed with malathion and the 1-pound dosage of Ovotran plus dinitro supplement were estimated to be approaching the end of effective control. All of the treatments showed appreciable mite buildup or reinfestation during the fourth week. The least infested leaves were picked from trees sprayed with Systox. The most heavily infested leaves were taken from the plots treated with Diazinon, Ovotran plus DN-289, and malathion.

Residues of Systox and Aramite showed continued lethal effect 29 days after application. Good numbers of dying mites were seen on sample leaves. Presumably these were mites which had moved up from the infested ground 


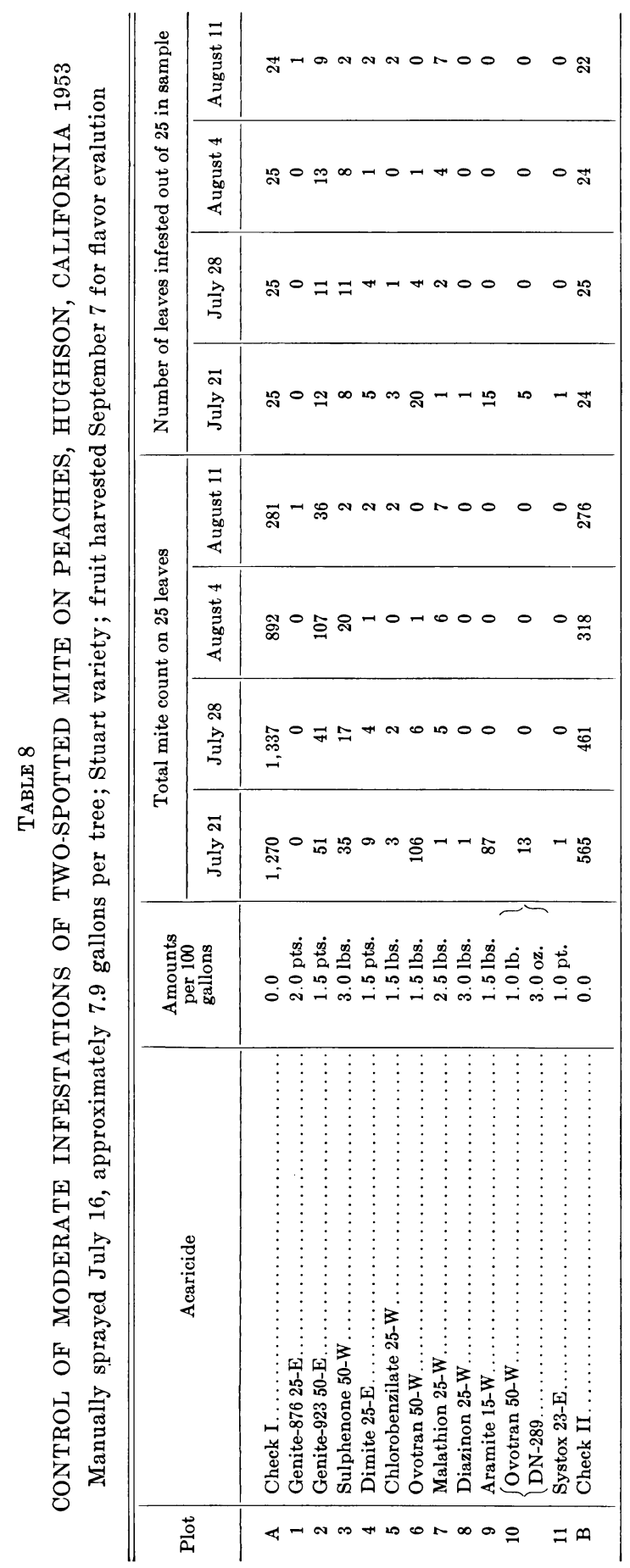


cover. The entire layout was too badly infested and in such poor condition that later samplings were not attempted.

The amount of Systox applied in this trial-approximately 39.6 ounces of active agent per acre-probably exceeds the rate presumed feasible for commercial uses. The peaches harvested for taste tests from the plots sprayed in July (table 8) were similarly overdosed.

\section{DISCUSSION OF RESULTS}

Among the acaricides tested, only two so far identified-Ovotran and Genite-923-have produced outstanding results in pink-bud or petal-fall sprays applied to infestations of brown almond mites. The best controls were obtained when these materials were applied in drenching sprays prior to the hatching of the overwintered eggs, either shortly before bloom or soon thereafter. These acaricides are primarily ovicides which act slowly or indirectly to reduce populations comprising late nymphs and adults. This tendency limits their usefulness for quick relief against the damaging infestations encountered in midseason.

Tests of Aramite have shown consistently good to excellent results on both two-spotted and Pacific mites. The levels of control obtained with dosages of 1 and of 2 pounds per 100 gallons were distinguishable in several of the field trials. When applied to established, high-level infestations, better initial kill was obtained with the larger amount (tables 3,7 ).

At the 1-pound rate, satisfactory controls were observed for 22 days (table 3 ) to 30 days (table 6 ) under conditions of moderate to severe infestations; or to at least 33 days when sluggishly reproducing, low-grade infestations were involved (table 4 ). In the interior valleys of California where these experiments were conducted, infestations of two-spotted or Pacific mites on these hosts do not usually become serious until July or August. The duration of chemical control with single sprays appears to overlap with the period of increasing biological control in late summer. None of these trials provided a favorable opportunity to observe a sharp increase in numbers of mites beyond the fifth week after application.

Sprays containing Ovotran, Sulphenone, and Genite-923 gave different results when applied to populations of the Tetranychus species. Whether the dissimilarities were due to intrinsic differences in the responses of the species of mites to each of the toxicants or to differences in the attributes of the foliage of the two hosts was not discovered.

Ovotran gave effective control of two-spotted mites on peaches and $\mathrm{Pa}$ cific mites on almonds, but immediacy of control was contingent upon level of infestation at the time of treatment. Applications to fairly heavy infestations did not disinfest foliage in sufficient time to be considered as effective control (tables 3,6 ).

In preventive sprays applied for Pacific mites (table 4), however, there was no appreciable buildup of mites on the treated foliage for at least 33 days. In this series of test plots, a difference in results from the 1-pound and 2-pound dosages of Ovotran 50-W became apparent after the third week. The slow, indirect action of Ovotran in reducing numbers of adult mites was 


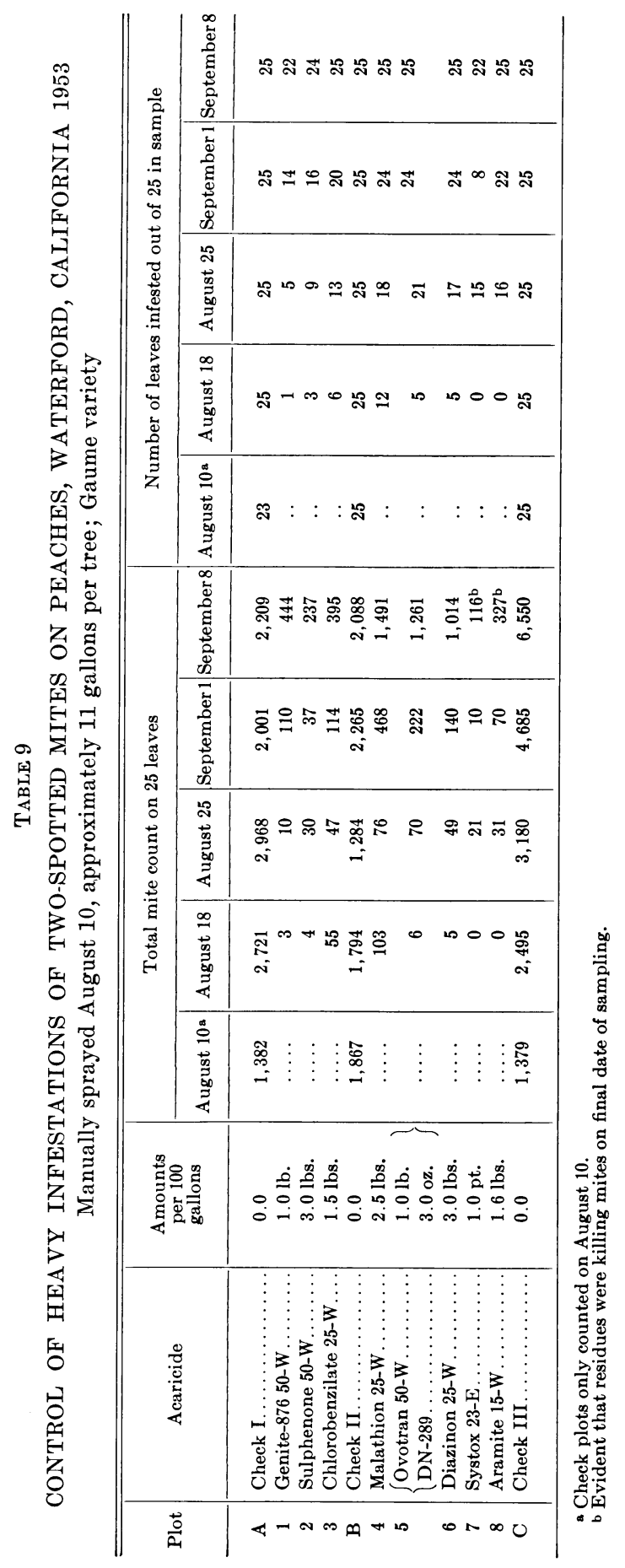


remedied by the addition of a small quantity of the triethanolamine salt of dinitro-o-secondary butylphenol ; that is, 3 ounces per 100 gallons of DN-289, a commercial formulation containing 8 ounces of parent phenol per quart (tables 5, 8, 9).

Wettable formulations of 40 to 50 per cent Sulphenone, in the range of 2.6 to 3 pounds per 100 gallons, have not given satisfactory results to date for Pacific mites on almonds. A recent, fairly critical test of this acaricide applied for two-spotted mites on peaches yielded results which ranked the treatment among the best three of the group (see plots 2, 7, and 9, table 9).

Neither two-spotted mites on peaches nor Pacific mites on almonds were effectively controlled with Genite-923. Whereas this material is known to have a pronounced ovicidal action when applied to infestations of brown almond mites, a comparable effect was not noted in connection with trials on the two species of Tetranychus.

Of the commercially available ethyl phosphate acaricides, TEPP has been generally acceptable to peach and almond growers for preharvest spraying. Two successive treatments 7 to 10 days apart, and with varying modes of application, gave results ranging from palliative or temporary control of persistent infestations (for example, plot 2, table 6) to adequate suppression of late-season infestations of the passive type.

The limited tests with parathion and EPN produced striking initial kill and residual control for periods of moderate length. Commercial sprays containing parathion and EPN applied primarily for mite control have been observed from time to time in the interior valley areas. In the grower trials as well as in small test plots, the single-application treatments given in July or August have shown that mite attacks may recur when residual control lapses. This possibility is illustrated for parathion in table 6 (plot 10). In this instance the first two posttreatment counts showed almost mite-free foliage, but thereafter the condition deteriorated. Severe reinfestation occurred in the interval between the third and fourth inspection dates. Similar but less pronounced relapses occurred in plots of almonds sprayed with EPN (table 3) and malathion (table 5). The acaricidal effectiveness of malathion $25-\mathrm{W}$, in the range of 2.5 pounds per 100 gallons, was somewhat lower than that shown for parathion and EPN at lower rates of application.

Results obtained in preliminary trials of Systox, Genite-876, Chlorobenzilate, and Diazinon were sufficiently encouraging to justify further testing.

\section{ACKNOWLEDGMENT}

The writer wishes to acknowledge his gratitude for the splendid assistance given by Mr. Albert G. Volz and Mr. Norman W. Ross, Farm Advisors, Stanislaus County, who coöperated in the tests performed at Modesto, Empire, Hughson, and Waterford. 


\section{LITERATURE CITED}

CUtright, C. R.

1951. Late season control of European red mite. Jour. Econ. Ent. 44:363-67. HinReiner, E., and M. Simone

1956. Effects of acaricides on flavor of almonds and canned fruits. Hilgardia 26:35-45. Madsen, H. F., and A. D. Borden

1956. Field tests of acaricides for control of mites on pears and apples. Hilgardia 26:7-18

Miskus, R. P., W. R. ERwin, and W. M. Hoskins

1956. Harvest residues of acaricides used on deciduous fruits. Hilgardia 26:46-59.

Sum Mers, F. M.

1952. New materials in early sprays for control of brown almond mites. Jour. Econ. Ent. 45:974-81.

Sum mers, F. M., and G. A. Baker

1952. A procedure for determining relative densities of brown almond mite populations on almond trees. Hilgardia 21:369-82. 


\title{
EFFECTS OF ACARICIDES ON FLAVOR OF ALMONDS AND CANNED FRUITS
}

\author{
ELLY HINREINER and MARION SIMONE ${ }^{2}$
}

\section{INTRODUCTION}

There have been many reports of the development of undesirable flavors in potatoes, carrots, peanuts, and other food plants grown in soil treated with pesticides such as benzene hexachloride (Greenwood and Tice, 1949; Stitt and Evanson, 1949 ; Jameson and Tanner, 1951; Kirkpatrick, et al., 1951; Gilpin and Geissenhainer, 1953; Gilpin, et al., 1953). These have led to questions regarding the effect on flavor of all of the new organic chemicals employed to control insects, mites, and similar pests on food crops.

Investigations of flavor, however, have not kept pace with the development of new chemicals, and relatively little information has appeared as yet concerning the effects of chemicals other than benzene hexachloride and its isomers.

Of the materials used as acaricides, Genite-923 was reported (Reynolds, Anderson, and Swift, 1952) to produce an off-flavor in beans when sprayed on the plants. Ovotran created no flavor change when used on corn (Raffensberger and Rutschky, 1953). Malathion was found to have no detrimental effect on flavor when applied as a spray to such fruits and vegetables as cherries, apples, pears, peaches, strawberries, potatoes, beans, and peas (Hard and Ross, 1954).

This report presents the results of flavor studies on the effect of Genite923 and Ovotran sprays on almonds, and of Genite-923, Ovotran, malathion, Aramite, Sulphenone, Chlorobenzilate, Diazinon, Dimite, Genite-876, and Systox on canned peaches, pears, and applesauce. The samples used for the flavor evaluations were from the same plots on which the entomological studies (Summers, 1956; Madsen and Borden, 1956), and the residue analyses (Miskus, Erwin, and Hoskins, 1956) were made.

In the 1951 season, comparisons were made on two varieties of almondsTexas (Mission) and Nonpareil-between nuts from trees sprayed with Genite-923 and with Ovotran, and nuts from their corresponding controls. The possible effect on flavor of canned clingstone peaches from pink-bud, petal-fall, and preharvest applications of Genite-923 and Ovotran was investigated the following year. Also, a series of pear samples from plots sprayed with Genite-923, Ovotran, Aramite, malathion, and Sulphenone during this season was canned and evaluated after 2, 6, and 11 months of storage.

In 1953 the project was expanded to include studies of the effect of these 10 acaracides on the flavor of the three fruits-pears, peaches, and apples. Diazinon on apples was the only omission. Although some of these 29 acaricide-fruit combinations have no importance from the standpoint of com-

\footnotetext{
${ }^{1}$ Received for publication April 29, 1955.

${ }^{2}$ Miss Hinreiner was Assistant Professor of Food Technology and Assistant Food Technologist in the Experiment Station, Davis; resigned June 30, 1956; Miss Simone is Senior Laboratory Technician, Department of Food Technology, Davis.
} 
mercial practice, it was felt that by testing each acaricide on several fruits, a better evaluation of its tendency to create flavor problems might be achieved.

In the hope of clearing up some specific questions arising from the 1952 and 1953 data a few acaricide tests were run on deciduous fruits in 1954. These included a repeat of the prebloom Genite-923 spray on peaches, of the malathion spray on apples, and of the Diazinon, Genite-923, and Systox sprays on pears. OMPA was also applied to pears in 1954 .

A precise description of the spray treatments given to each of the experimental plots is given in the papers on the entomological effectiveness of the acaricides (Madsen and Borden, 1956 ; Summers, 1956).

\section{METHODS USED IN ORGANOLEPTIC TESTS}

Storing and Canning of Samples. All samples, including the check or control, in a given series of treatments were harvested at the same time, always within a period of 1 or 2 days at most. All of the pears and peaches were canned in the pilot plant of the Department of Food Technology, University of California, Davis. Also, all of the lots in a series were packed at about the same time, on the same day where possible, or within a 2- or 3 -day period at most. The fruit actually packed was carefully selected to be of comparable maturity within the series and within each sample batch; specimens with defects were eliminated. Peaches were canned as peeled halves in $40^{\circ}$ Brix sucrose sirup, pears as peeled halves or quarters in $25^{\circ}$ Brix sucrose sirup. However, the actual weight of the fill was adjusted to $19 \pm 0.1$ ounces for the peaches, and to $18 \pm 0.1$ ounces for the pears by addition or removal of small slices of the fruit. Exactly $11 \pm 0.1$ ounces of sirup was added per No. $21 / 2$ ean in each instance. Such precise control of processing variables is not, of course, standard commercial procedure. For determination of flavor differences caused by acaricide application, however, it was necessary to eliminate as nearly as possible all variables other than the acaricide application itself.

The apples treated in 1953 were stored in a cold room for about 11/2 months after harvesting. They were then peeled and made into applesauce with the addition of a minimum amount of sugar, and packed in No. 2Z baby-food cans. The apples were stored and processed at the Gerber Products Company, Oakland, California.

In 1954 the apples (single treatment and control) were peeled and diced, siruped and processed in No. $2 \frac{1}{2}$ cans at the pilot plant in Davis.

Selection of Judges. Panels of about fifteen members were selected on the basis of ability to detect the particular acaricide in low concentrations. In selecting the almond panels it was necessary to test their ability to distinguish emulsions of the 50-E Genite-923 preparation in water, containing $1.0,0.5$, and 0.1 p.p.m. of actual Genite, from aqueous solutions containing corresponding quantities of an emulsifier and diluent similar to those employed in the Genite formulation. In the selection of the other panels, concentrations close to the threshold values for each of the various pesticides were added to ground samples of drained, canned fruit and compared with 
ground, canned fruit to which no pesticide had been added. The samples were compared in each instance by groups of about thirty potential judges in a "triangular" design (Helm and Trolle, 1946). Around six to eight triangular sets (no more than two at any one session) were given to each prospective judge, and the fifteen with the highest number of correct answers were selected as the final panel.

In a triangular test three samples are presented to the judge in coded containers. Two of these are identical, and they are randomly arranged, so that if the control sample is A and the treated sample is B, a given set of samples has an equal probability (1/6) of being any one of the six possible arrangements: $\mathrm{AAB}, \mathrm{ABA}, \mathrm{BAA}, \mathrm{BBA}, \mathrm{BAB}$, or $\mathrm{ABB}$. The judge is required to separate the duplicate samples from the odd sample, by guessing if necessary, and in these experiments he was also asked to identify the pesticide-treated sample (s) as the odd or the duplicate specimens.

Since guesses would yield the correct separation one third of the time, and the correct identification one sixth $(1 / 2 \times 1 / 3)$ of the time, the data must be analyzed statistically. A table prepared by Roessler, Warren, and Guymon (1948) was used to determine whether the number of judges correctly separating the duplicate samples indicated a statistically significant difference between the control and treated samples. The statistical significance of the identification of the samples was determined by a chi-square analysis.

Design of Tasting Experiments. For organoleptic evaluation of the fruits and nuts actually treated in the field with acaricides, the same triangular design was employed, with the selected panel members required both to separate the identical samples and to identify which sample or samples had received pesticide treatment. It was decided shortly after commencing the experiments, however, that some information on the severity of the flavor differences would be desirable. Accordingly, judges were asked to check a 6-point scale (ranging from "no off-flavor" = 0 to "highly off-flavored" $=5$ ) to indicate whether the flavor difference they observed, if any, was too slight to be of any practical importance, or moderately distasteful, or quite objectionable. The off-flavor scores of judges unable to separate the identical samples correctly were ignored. The scores given by judges who both separated and identified the treated samples correctly were added together and credited to the treated sample. Where correct separations were made, but the controls were erroneously identified as the samples which had received pesticide treatment, the scores were credited to the control sample.

No attempt was made to analyze the scoring data statistically; indeed, it was only after some experience with the system that even qualitative interpretations could be placed on the off-flavor scores. Since the number of judgments for a given triangular comparison varied somewhat in our experiments, obviously the precise numerical totals were impractical but the range in which they fell could be used as a guide. It became evident that where these total scores were fairly low, and especially if the totals for the treated sample and the control were nearly equal, it could be assumed that any differences in flavor observed by the tasters were of no practical importance, and indeed might be attributed to small, unavoidable differences such as sweetness or texture, that had nothing to do with the acaricide treat- 
ment. With the usual 30 to 40 total judgments, a difference of around 10 points between the total off-flavor scores for the treated sample and the total for the control suggests possible, though probably not serious, flavor difficulties. A difference as great as 25 usually indicates a sample that is distinctly disagreeable to many or all of the panel members.

Preparation of Tasting Samples. For presentation to the panel, the almonds were shelled and all of the meats of the treated and check lots to be used in a single session were ground in a food chopper from about 30 minutes to 1 hour before the judging period. This was done to obtain a more homo-

TABLE 1

RESULTS OF TRIANGULAR TESTS FOR EFFECTS OF 1952 ACARICIDE ON FLAVOR OF PEACHES

Peaches harvested August 4 and canned on August 6

\begin{tabular}{|c|c|c|c|c|c|c|c|}
\hline \multirow[b]{2}{*}{ Acaricide } & \multirow[b]{2}{*}{ Spray date } & \multirow[b]{2}{*}{ Storage period } & \multicolumn{3}{|c|}{ Triangular taste tests } & \multicolumn{2}{|c|}{ Off-flavor score } \\
\hline & & & $\begin{array}{c}\text { Total } \\
\text { number } \\
\text { of } \\
\text { judg- } \\
\text { ments }\end{array}$ & $\begin{array}{c}\text { Number } \\
\text { of correct } \\
\text { separa- } \\
\text { tions }\end{array}$ & $\begin{array}{l}\text { Number } \\
\text { correct } \\
\text { identifi- } \\
\text { cations of } \\
\text { treated } \\
\text { sample(s) }\end{array}$ & $\begin{array}{l}\text { Treat- } \\
\text { ment }\end{array}$ & Control \\
\hline \multirow{7}{*}{ Genite-923 50-E } & (February 29 & $\{21 / 2$ mos.. & 38 & 15 & $13 \dagger$ & . & .. \\
\hline & & $7 \operatorname{mos} . .$. & 30 & 15 & $13 \ddagger$ & 28 & 2 \\
\hline & April 4 & $2 \operatorname{mos} . .$. & 44 & $26 \ddagger$ & $23 \ddagger$ & .. & .. \\
\hline & & $7 \mathrm{mos} . .$. & 34 & $20 \dagger$ & $14 \ddagger$ & 40 & 10 \\
\hline & July 25 & $2 \operatorname{mos} \ldots \ldots$ & 37 & $22 \ddagger$ & $21 \ddagger$ & .. & .. \\
\hline & & $\{7$ mos...... & 30 & 15 & $13 \ddagger$ & 53 & 7 \\
\hline & April 4 & $\{21 / 2 \operatorname{mos} \ldots \ldots \ldots \ldots \ldots$ & 35 & 13 & 6 & .. & .. \\
\hline \multirow{5}{*}{ Ovotran $50-\mathrm{W}$} & & $71 / 2 \operatorname{mos} \ldots \ldots \ldots \ldots \ldots$ & 32 & 14 & 8 & 17 & 9 \\
\hline & July 25 & $21 / 2 \operatorname{mos} \ldots \ldots \ldots \ldots \ldots$ & 33 & $17^{*}$ & $12 \dagger$ & .. & .. \\
\hline & & $\{71 / 2 \operatorname{mos} \ldots$ & 38 & $19^{*}$ & $14 \dagger$ & 34 & 9 \\
\hline & April 4 & $21 / 2 \operatorname{mos} \ldots \ldots$ & 24 & $15 \dagger$ & $8^{*}$ & .. & . \\
\hline & July 25 & $71 / 2 \operatorname{mos} \ldots \ldots$ & 31 & 12 & 6 & 7 & 15 \\
\hline
\end{tabular}

a For quantities and formulations of acaricides, see Summers (1956) tables 1 and 2.

* Indicates a statistically significant difference between the treated samples and the control at the 95 per cent probability level.

† Indicates a statistically significant difference between the treated samples and the control at the 99 per cent probability level.

$\ddagger$ Indicates a statistically significant difference between the treated samples and the control at the 99.9 per cent probability level.

geneous sample and prevent the distinctive flavor or appearance of an occasional individual nut from unduly influencing the judgment. For the same reason, as well as to minimize possible texture differences, the canned peaches and pears were drained and ground through a food chopper. For each sample used in a tasting session, the contents of three or four cans were combined and mixed together to give a more uniform sample. It was impractical to utilize all of the sirup that was drained off, but a definite proportion was returned to the ground samples. All of the samples were served in coded, $50 \mathrm{ml}$ beakers accompanied by a spoon and score sheet.

The tasting was done between 9 and 11 a.m. and 2 and 4 p.m. Individual tasters were isolated in air-conditioned booths. Each treated sample was compared with the corresponding check sample in three or four sessions (de- 
pending on attendance) so that 30 to 40 or more triangular sets were judged for each treatment.

Each of the canned fruit samples was tasted 1 or 2 months after processing, when the fruit and sirup had had sufficient time to attain equilibrium, then again after one or two longer storage intervals. Primarily, this procedure was a check on the possibility of an increase or decrease in pesticide off-flavor with storage. It also contributed to a more thorough and reliable knowledge of the flavor effect of each treatment by allowing a greater total number of tastings to be performed on each sample.

TABLE 2

\section{RESULTS OF TRIANGULAR TESTS FOR EFFECTS OF 1952 ACARICIDES ON FLAVOR OF PEARS}

Pears sprayed on June 10, harvested July 22, and canned August 8 to 11

\begin{tabular}{|c|c|c|c|c|c|c|}
\hline \multirow[b]{2}{*}{ Acaricide $^{\text {a }}$} & \multirow[b]{2}{*}{ Storage period } & \multicolumn{3}{|c|}{ Triangular taste tests } & \multicolumn{2}{|c|}{ Off-flavor score } \\
\hline & & $\begin{array}{c}\text { Total } \\
\text { number of } \\
\text { judgments }\end{array}$ & $\begin{array}{l}\begin{array}{l}\text { Number of } \\
\text { correct } \\
\text { separations }\end{array} \\
\text {. }\end{array}$ & $\begin{array}{l}\text { Number } \\
\text { correct } \\
\text { identifica- } \\
\text { tions of } \\
\text { treated } \\
\text { sample(s) }\end{array}$ & Treatment & Control \\
\hline & 3 mos.. & 43 & $30 \ddagger$ & $22 \ddagger$ & . & $\ldots$ \\
\hline \multirow{3}{*}{ Aramite } & 6 mos.. & 31 & $20 \ddagger$ & $16 \ddagger$ & 39 & 6 \\
\hline & $11 \frac{1}{2} \operatorname{mos} .$. & 30 & $17 \dagger$ & $14 \ddagger$ & 27 & 4 \\
\hline & $2 \mathrm{mos} . . .$. & 47 & $29 \ddagger$ & $26 \ddagger$ & . & . \\
\hline \multirow{3}{*}{ Genite-923 50-E } & $\{6 \mathrm{mos}$. & 38 & $21 \dagger$ & $17 \ddagger$ & 38 & 9 \\
\hline & $11 \operatorname{mos} . . . \ldots$ & 35 & $23 \ddagger$ & $21 \ddagger$ & 22 & 0 \\
\hline & $21 / 2 \operatorname{mos} \ldots \ldots \ldots \ldots \ldots \ldots \ldots$ & 38 & $20^{*}$ & 11 & . & . \\
\hline \multirow[t]{3}{*}{ Malathion 50-E } & $\{6 \operatorname{mos} \ldots \ldots \ldots \ldots \ldots \ldots \ldots \ldots$ & 32 & 12 & 9 & 19 & 3 \\
\hline & $(11 \operatorname{mos} \ldots \ldots \ldots \ldots \ldots \ldots \ldots$ & 42 & $26 \ddagger$ & $20 \ddagger$ & 18 & 8 \\
\hline & $3 \operatorname{mos} \ldots \ldots \ldots \ldots \ldots \ldots \ldots$ & 28 & $16^{*}$ & $11 \dagger$ & . & .. \\
\hline \multirow[t]{3}{*}{ Ovotran 50-W } & $\{\mathrm{mos} . . . .$. & 34 & $20 \dagger$ & $16 \ddagger$ & 38 & 5 \\
\hline & $111 / 2 \operatorname{mos} . . .$. & 35 & $23 \ddagger$ & $16 \ddagger$ & 18 & 2 \\
\hline & $3 \operatorname{mos} \ldots \ldots \ldots$ & 40 & $28 \ddagger$ & $24 \ddagger$ & . & . \\
\hline Sulphenone & $\{61 / 2 \operatorname{mos} . \ldots \ldots \ldots \ldots \ldots \ldots$ & 34 & $28 \ddagger$ & $24 \ddagger$ & 35 & 11 \\
\hline $50-W$ & $11 \operatorname{mos} \ldots$ & 34 & $20 \dagger$ & $17 \ddagger$ & 29 & 3 \\
\hline
\end{tabular}

a For quantities and formulations of acaricides see Madsen and Borden (1956) tables 1 and 2.

* $\ddagger$ See table 1 , footnotes.

\section{DISCUSSION OF RESULTS}

Results of triangular tests are given in tables 1 to 5 . It would be unreasonable to interpret the results of the organoleptic tests too specifically in terms of permissible acaricides, dosage rates, and crops. Such variables as season and climatic conditions, harvest maturity, sirup concentration, processing time and temperature, and acuity of the individual tasters may be as important as the conditions specified in these studies. It is not too surprising, therefore, to find some apparently anomalous results in the data. In view of the many flavor evaluations in which a particular acaricide was involved, however, the information obtained can be interpreted in general terms of whether or not that acaricide has a tendency to create flavor differences in processed fruits. 
TABLE 3

RESULTS OF TRIANGULAR TESTS FOR EFFECTS OF 1953 ACARICIDE TREATMENT ON FLAVOR OF CANNED PEARS, PEACHES, AND APPLESAUCE

\begin{tabular}{|c|c|c|c|c|c|c|}
\hline \multirow[b]{2}{*}{ Acaricide ${ }^{2}$} & \multirow[b]{2}{*}{ Storage period } & \multicolumn{3}{|c|}{ Triangular taste tests } & \multicolumn{2}{|c|}{ Off-flavor score } \\
\hline & & $\begin{array}{l}\text { Number of } \\
\text { judgments }\end{array}$ & $\begin{array}{c}\text { Number of } \\
\text { correct } \\
\text { separations }\end{array}$ & $\begin{array}{c}\text { Number } \\
\text { correct } \\
\text { identifica- } \\
\text { tions of } \\
\text { treated } \\
\text { sample(s) }\end{array}$ & Treatment & Control \\
\hline
\end{tabular}

PEARS

Sprayed May 26 and June 19, harvested July 21, canned August 7 and 8

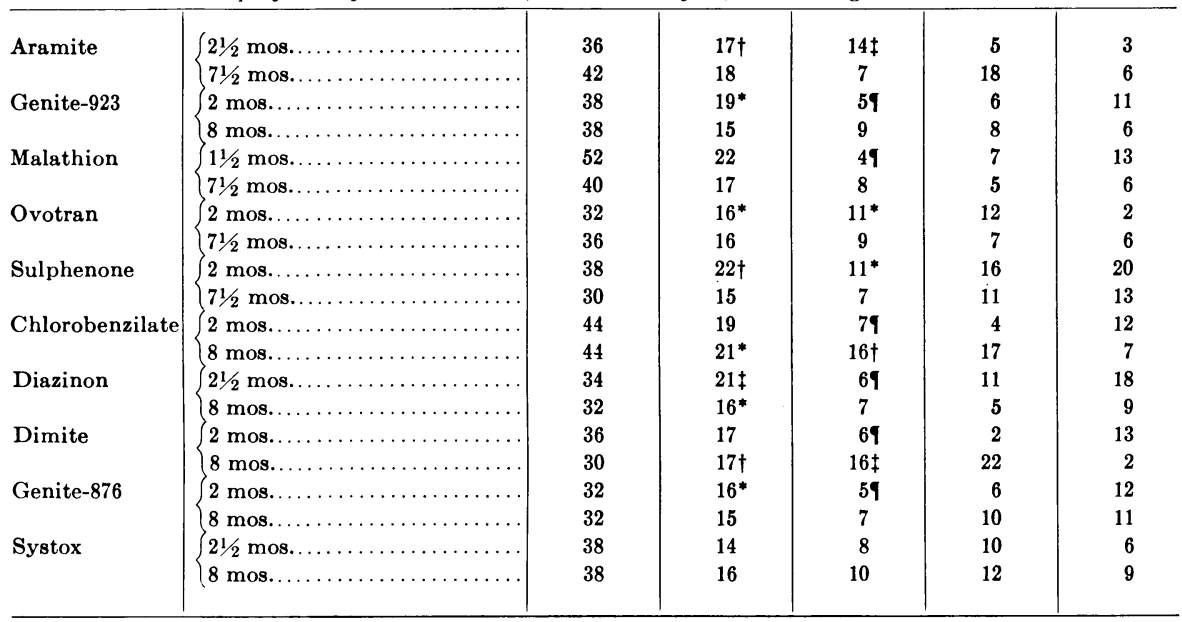

PEACHES

Sprayed July 16. harvested September 7, canned September 9

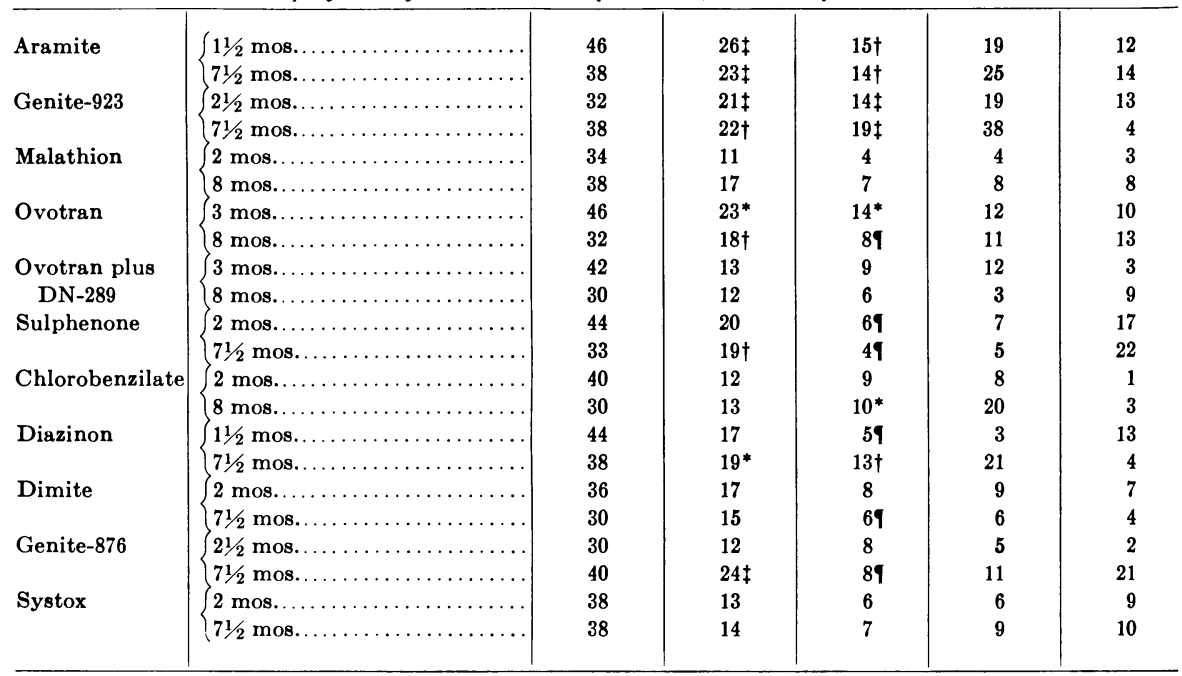


TABLE 3-Continued

\begin{tabular}{|c|c|c|c|c|c|c|}
\hline \multirow[b]{2}{*}{ Acaricide* } & \multirow[b]{2}{*}{ Storage period } & \multicolumn{3}{|c|}{ Triangular taste tests } & \multicolumn{2}{|c|}{ Off-flavor score } \\
\hline & & $\begin{array}{l}\text { Number of } \\
\text { judgments }\end{array}$ & $\begin{array}{l}\text { Number of } \\
\text { correct } \\
\text { separations }\end{array}$ & $\begin{array}{c}\text { Number } \\
\text { correct } \\
\text { identifica- } \\
\text { tions of } \\
\text { treated } \\
\text { sample(s) }\end{array}$ & Treatment & Control \\
\hline
\end{tabular}

APPLESAUCE

Apples sprayed July 1 and August 6, harvested September 29, in cold storage until processed November 11

\begin{tabular}{|c|c|c|c|c|c|c|}
\hline \multirow{2}{*}{ Aramite } & $\int 3 \mathrm{mos} .$. & 34 & 13 & 7 & 10 & 13 \\
\hline & $61 / 2 \operatorname{mos} . . . .$. & 44 & 17 & 9 & 13 & 3 \\
\hline \multirow[t]{2}{*}{ Genite-923 } & $21 / 2 \operatorname{mos} \ldots \ldots \ldots \ldots \ldots \ldots \ldots \ldots$ & 32 & $16^{*}$ & $13 \dagger$ & 31 & 0 \\
\hline & $61 / 2 \operatorname{mos} . \ldots$. & 34 & $21 \ddagger$ & $20 \ddagger$ & 49 & 2 \\
\hline \multirow[t]{2}{*}{ Malathion } & $\{21 / 2 \operatorname{mos} \ldots \ldots \ldots \ldots \ldots \ldots \ldots \ldots \ldots \ldots$ & 32 & $16^{*}$ & $14 \ddagger$ & 25 & 0 \\
\hline & $6 \operatorname{mos} . \ldots \ldots \ldots \ldots \ldots \ldots \ldots$ & 38 & 17 & 9 & 12 & 8 \\
\hline \multirow[t]{2}{*}{ Ovotran } & $\{3 \operatorname{mos} . \ldots \ldots \ldots \ldots \ldots \ldots \ldots$ & 42 & 18 & 9 & 17 & 16 \\
\hline & $61 / 2 \operatorname{mos} \ldots$. & 30 & 8 & 6 & 10 & 4 \\
\hline \multirow[t]{2}{*}{ Sulphenone } & $\int 3 \operatorname{mos} . \ldots \ldots$ & 38 & 16 & $11^{*}$ & 14 & 10 \\
\hline & $61 / 2 \operatorname{mos} . . . .$. & 44 & 13 & 9 & 15 & 9 \\
\hline \multirow[t]{2}{*}{ Chlorobenzilate } & $\int 3 \operatorname{mos} \ldots \ldots \ldots \ldots \ldots \ldots$ & 34 & 13 & 6 & 4 & 7 \\
\hline & $6 \mathrm{mos} . . . .$. & 42 & $25 \ddagger$ & $12^{*}$ & 21 & 11 \\
\hline \multirow[t]{2}{*}{ Dimite } & $\{21 / 2 \operatorname{mos} \ldots \ldots \ldots \ldots \ldots$ & 30 & 14 & $10^{*}$ & 17 & 6 \\
\hline & $6 \mathrm{mos} . \ldots \ldots \ldots \ldots$ & 44 & $21^{*}$ & $13^{*}$ & 23 & 9 \\
\hline \multirow[t]{2}{*}{ Genite-876 } & $\int 3 \operatorname{mos} \ldots \ldots \ldots \ldots \ldots \ldots \ldots \ldots$ & 34 & 14 & 5 & 3 & 8 \\
\hline & $\{6 \operatorname{mos} \ldots \ldots \ldots \ldots \ldots \ldots \ldots \ldots$ & 40 & $23 \dagger$ & $14 \dagger$ & 10 & 11 \\
\hline \multirow[t]{2}{*}{ Systox } & 3 mos..................... & 34 & 15 & 39 & 2 & 26 \\
\hline & $61 / 2 \operatorname{mos} . \ldots \ldots \ldots \ldots \ldots \ldots \ldots$ & 30 & $19 \ddagger$ & $12 \dagger$ & 24 & 9 \\
\hline
\end{tabular}

- For quantities and formulations of acaricides and spray dates, see Madsen and Borden (1956), table 2 for pears, and table 3 for apples; see Summers (1956), table 8 for peaches.

* $†$ See table 1, footnotes.

Indicates that the control was incorrectly identified as the treated sample a statistically significant (95 per cent probability level or better) number of times.

Genite-923 on Peaches. A general survey of the data reported here indicates that of the acaricides investigated, Genite-923 seems the most likely to cause flavor difficulties. The Genite panels were nearly always able to identify the treated sample at a fairly high level of statistical significance, and the total off-flavor points accrued by the Genite-treated samples often became quite high. There appears to be some tendency - though the trend is not definite-for the undesirable flavor of the Genite-treated samples to intensify during storage.

The 1952 investigations on peaches, in which the time of application was varied from prebloom to shortly before harvest, suggest the possibility of using Genite-923 for very early sprays (table 1), at which time it actually has its maximum entomological usefulness as an ovicide against brown almond mites (Summers, 1956). Even for the earliest spray application (pink-bud stage), however, the data indicate that although less than a statistically significant-95 per cent probability level-number of judges were able to distinguish the treated sample from the untreated, of those who were able to make the separation 13 out of 15 associated an undesirable flavor with the treated sample; judging from the off-flavor score, they found it to be fairly unpleasant. 
A repetition of the prebloom spray on peaches in 1954 gave more promising results. The panel did not appear to find any unfavorable flavor difference in the Genite-treated samples after $4 \frac{1}{2}$ months in the can (table 5 ).

Ovotran on Canned Fruit. Similarly, Ovotran appeared in 1952 to cause more flavor difficulties than most of the other acaricides (tables 1 and 2), but the 1953 data are quite favorable (table 3 ). This reflects a rather general tendency observed in these experiments for the treated pear samples (pears were the only fruit on which extensive acaricide comparisons were made in both seasons ) to compare much less favorably with the controls in 1952 than in 1953. Indeed, in 1953 the controls were sometimes judged to be less desirable than the acaricide-treated fruit. It was also noted that the natural pear flavor of the 1952 control samples was definitely superior to that of the 1953 pears.

A possible interpretation of these seemingly anomalous results is that with a heavier mite infestation in the check plots in 1953 and the resultant injury and defoliation of the untreated trees (Madsen and Borden, 1956) the leafto-fruit ratio in the control orchards was not adequate to produce as fullflavored pears as in the treated trees, where the mite population was controlled. Since pesticide treatment has sometimes been associated with a deadening of taste receptors, or with a reduction in intensity of natural fruit or vegetable flavor, or with undesirable flavors, it is easy to understand why the panel might identify the less flavorsome sample as the treated one, particularly in the absence of a definite insecticide flavor per se.

The results of the petal-fall application of Ovotran to peaches in 1952 (table 1) are far more encouraging than for the similar early Genite application in that year, and suggest that such treatment would probably bc safe as far as flavor effects go. In this case, however, there are data for only one such early application.

Genite-923 and Ovotran on Almonds. Ovotran and Genite-923 were also applied to almonds, and the nuts were tasted without any prior heat treatment. Both varieties of almonds to which these two materials were applied seemed to be unaffected flavorwise by the treatment (table 4). Even where the proportion of judges correctly separating the identical samples was statistically significant, half or more of those who could make this distinction incorrectly identified the control sample as having received the chemical treatment. The almond meats are, of course, naturally protected from direct contact with the spray materials by their thick, fleshy hulls and the shells. Also, since they receive no heat treatment, there is less possibility for any residual acaricide to be converted during processing to a possibly more highly off-flavored substance, as has been postulated for some pesticides (Mahoney, 1952).

Aramite and Sulphenone on Canned Fruit. Aramite and Sulphenone gave unfavorable organoleptic results on the pears in 1952 (table 2), but in 1953 (table 3 ) there appeared to be no important differences involving undesirable flavors between the treated and untreated pears and apples. Taste data on the Aramite-treated peaches did indicate the possibility of a flavor problem in the 1953 series, but considering the relatively low proportion of correct separations in which the correct identification also was made-not 
much greater than 50 per cent-it appears that, while there was certainly a significant difference between the two samples, the treated peaches were only slightly less acceptable in flavor than the controls. With sulphenone on the 1953 crop of peaches the difference was actually in favor of the acaricide. This result again may be due to better flavor production in fruit trees where insect infestation is kept under control.

Malathion. Malathion appears to cause few, if any, flavor difficulties. In addition to the work reported here, we have made extensive tests on fresh grapes, melons, and dried figs treated with this pesticide. Except for the applesauce in 1953 (table 3) and possibly the 1952 pears (table 2) after long

TABLE 4

\section{RESULTS OF TRIANGULAR TESTS FOR EFFECTS OF 1951 ACARICIDE TREATMENT ON FLAVOR OF ALMONDS}

Almonds harvested September, 1951. Taste tests run in 1952, after approximately 10 months' storage

\begin{tabular}{|c|c|c|c|c|}
\hline \multirow[b]{2}{*}{ Variety } & \multirow[b]{2}{*}{ Acaricidea } & \multicolumn{3}{|c|}{ Triangular taste tests } \\
\hline & & $\begin{array}{l}\text { Total number } \\
\text { of judgments }\end{array}$ & $\begin{array}{l}\text { Number of cor- } \\
\text { rect separations }\end{array}$ & $\begin{array}{c}\text { Number of } \\
\text { correct identifi- } \\
\text { cations of } \\
\text { treated samples }\end{array}$ \\
\hline $\begin{array}{l}\text { Texas } \\
\text { (Mission) } \\
\text { Nonpareil }\end{array}$ & $\left\{\begin{array}{l}\text { Genite- } 92350-\mathrm{E} \ldots \ldots \\
\text { Ovotran } 50-\mathrm{W} \ldots \ldots \\
\text { Genite- } 923 \text { 50-E ..... } \\
\text { Ovotran } 50-\mathrm{W} \ldots \ldots \ldots\end{array}\right.$ & $\begin{array}{l}42 \\
40 \\
46 \\
43\end{array}$ & $\begin{array}{l}14 \\
19 \\
26 \ddagger \\
24 \dagger\end{array}$ & $\begin{array}{c}9 \\
9 \\
13^{*} \\
99\end{array}$ \\
\hline
\end{tabular}

a For quantities and formulations of acaricides used on Nonpareil almonds and spray date, see Summers (1956), table 4; applications on Texas were the same.

$* \dagger \ddagger$ See table 1 , footnotes.

I See table 3, footnotes.

storage, no indications of flavor differences due to use of malathion have been observed in these tests. Even in the case of the pears the total offflavor score is not especially high; moreover, there is not much disparity between the scores for the treated sample and the control. Probably this is due largely to the exceptional (for a pesticide) volatility of the chemical.

The applesauce result would perhaps be credited to chance, especially in view of the lack of any significant observable difference between this treatment and the corresponding control in a later tasting, except that the offflavor was so pronounced at the time of the first tasting and was commented on by so many people, including many tasters who were not on the official panel. A repetition of this particular experiment in the 1954 season showed no flavor differences whatsoever in the treated sample one month after canning (table 5), and a negligible difference after 5 months. This suggests that some extraneous variable may have been responsible for the 1953 result.

Other Acaricides. Most of the remaining five acaricides were tested in a single season only, and as evidenced by the disparate results on pears in the 1952 and 1953 seasons, it is unwise to come to any definite conclusions on the basis of just one season's work. None of the five consistently caused flavor problems, although there were a few sporadic cases that were ques- 
tionable. Dimite, for example, appeared to produce no change when tasted soon after canning, but the pears and applesauce treated with Dimite seemed to develop some off-flavor upon longer storage (table 3 ). The same is true of Chlorobenzilate and perhaps also of Diazinon. In the latter case, only pears and peaches were evaluated, and while the treated samples apparently were

TABLE 5

RESULTS OF TRIANGULAR TESTS FOR EFFECTS OF 1954 ACARICIDES ON FLAVOR OF PEARS, PEACHES, AND APPLES

\begin{tabular}{|c|c|c|c|c|c|c|}
\hline \multirow[b]{2}{*}{ Acaricidea } & \multirow[b]{2}{*}{ Storage period } & \multicolumn{3}{|c|}{ Triangular taste tests } & \multicolumn{2}{|c|}{ Off-flavor score } \\
\hline & & $\begin{array}{c}\text { Total } \\
\text { number of } \\
\text { judgments }\end{array}$ & $\begin{array}{l}\text { Number of } \\
\text { correct } \\
\text { separations }\end{array}$ & $\begin{array}{c}\text { Number } \\
\text { correct } \\
\text { identifica- } \\
\text { tions of } \\
\text { treated } \\
\text { sample(s) }\end{array}$ & Treatment & Control \\
\hline
\end{tabular}

PEARS

Canned September 2 and 7

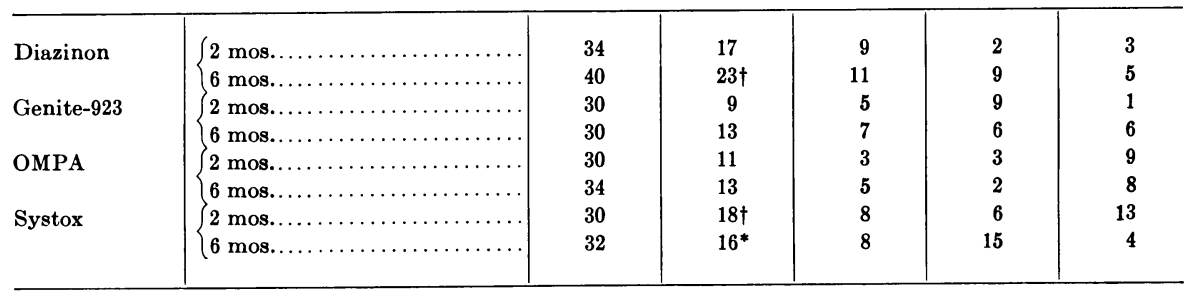

PEACHES

Canned August 20

\begin{tabular}{|c|c|c|c|c|c|c|}
\hline Genite-923 & $\left\{\begin{array}{l}41 / 2 \operatorname{mos} . \ldots \ldots \ldots \ldots \ldots \ldots \ldots \ldots \ldots \ldots \ldots \ldots \ldots \ldots \\
6 \operatorname{mos} . \ldots \ldots \ldots \ldots \ldots \ldots\end{array}\right.$ & $\begin{array}{l}32 \\
32\end{array}$ & $\begin{array}{l}12 \\
12\end{array}$ & $\begin{array}{l}6 \\
5\end{array}$ & $\begin{array}{l}3 \\
3\end{array}$ & $\begin{array}{l}4 \\
8\end{array}$ \\
\hline
\end{tabular}

APPLES

Processed as diced apples October 14

\begin{tabular}{|c|c|c|c|c|c|c|}
\hline Malathion & $\left\{\begin{array}{l}1 \operatorname{mo} . \ldots \ldots \ldots \ldots \ldots \ldots \ldots \ldots \ldots \ldots \ldots \ldots \ldots \ldots \\
5 \operatorname{mos} . \ldots \ldots \ldots \ldots \ldots \ldots \ldots\end{array}\right.$ & $\begin{array}{l}40 \\
34\end{array}$ & $\begin{array}{l}14 \\
14\end{array}$ & $\begin{array}{c}8 \\
10^{*}\end{array}$ & $\begin{array}{r}6 \\
10\end{array}$ & $\begin{array}{l}\mathbf{5} \\
\mathbf{3}\end{array}$ \\
\hline
\end{tabular}

a For quantities, formulations, and spray dates on pears and apples, see Madsen and Borden (1956); on peaches, see Summers (1956).

initially better tasting than the controls, they became about equal or slightly worse after eight months.

Systox treatment showed no undesirable effect except possibly for the applesauce after $61 / 2$ months' storage (table 3 ). Genite- 876 also had no undesirable effect on flavor, since even where the data indicate significant differences, the proportion of correct identifications and the off-flavor scores suggest that the treated fruit is equal or possibly even superior in flavor to the untreated (table 3 ).

It would be unwise to come to any conclusion regarding the flavor effect of OMPA on the basis of the single favorable test made in 1954 (table 5). 


\section{ACKNOWLEDGMENT}

The writers wish to express their sincere appreciation to Mr. Sherman Leonard, Associate Specialist in the Department of Food Technology, and to members of his staff, and to Mr. Bruno Grossi and the Gerber Products Company, for their processing of the various samples used in these tests.

\section{LITERATURE CITED}

Gilpin, G. L., E. H. DAwson, E. L. Geissenhainer, and H. Reynolds

1953. Flavor of peanuts and peanut products as affected by certain insecticides used in growing peanut crops. Food Technol. 7:132-35.

GilPin, G. L., and E. L. GeIsSEnHAINER

1953. Flavor of sweet potatoes as affected by certain agricultural chemicals used as insecticides. Food Technol. $7: 137-38$.

Greenwood, J. L., and J. M. Tice

1949. Palatability tests on potatoes grown in soil treated with the insecticides benzene hexachloride, chlordane, and chlorinated camphene. Jour. Agr. Res. 78:477-82.

HARD, M. M., and E. Ross

1954. Effect of malathion on flavor of certain fruits and vegetables. Jour. Agr. Food Chem. 2:20-22.

Helm, E., and B. Trolle

1946. Selection of a taste panel. Wallerstein Lab. Commun. 9:181.

JAMESON, H. R., and C. C. TANNER

1951. Taint in potatoes grown on land treated with crude benzene hexachloride against wireworms. Jour. Sci. Food Agr. 2:171-75.

KIRKPATRICK, M. E., et al.

1951. Flavor and odor of cooked potatoes as affected by the use of lindane and benzene hexachloride as insecticides. Amer. Potato Jour. 28 :792-98.

Madsen, H. F., and A. D. Borden

1956. Field tests of acaricides for control of mites on pears and apples. Hilgardia $26: 7-18$.

MahoNeY, C. H.

1952. Speech before the Agricultural and Food Chemistry Division of the American Chemical Society, Milwaukee, Wisconsin. Chem. and Engin. News 30:1509.

Miskus, R. P., W. R. Erwin, and W. M. Hoskins

1956. Harvest residues of acaricides used on deciduous fruits. Hilgardia 26:46-59.

RAFFensberger, E. M., and C. W. Rutschky

1953. A comparison of ovicides against corn-ear worm eggs. Jour. Econ. Ent. 46: 100-2.

Reynotins, H. T., T. D. A nDfrson, and .J. F. Swift

1952. Acaricide dusts on vegetable and field crops in southern California, 1949-50. Jour. Econ. Ent. $45: 359-65$.

Roessler, E. B., J. WARREN, and J. F. GUYMON

1948. Significance in triangular taste tests. Food Res. 13:503-5.

STiTT, L. L., and J. Evanson

1949. Phytotoxicity and off-quality of vegetables grown in soil treated with insecticides. Jour. Econ. Ent. 42:614-17.

SumMERs, F. M.

1956. Field tests of acaricides for control of spider mites on almonds and peaches. Hilgardia 26:19-34. 


\title{
HARVEST RESIDUES OF ACARICIDES USED ON DECIDUOUS FRUITS ${ }^{1}$
}

\author{
R. P. MISKUS, W. R. ERWIN, and W. M. HOSKINS ${ }^{2}$
}

The INTRODUCTION of numerous new chemicals for control of plant-infesting mites has led to much interest in the residual amounts at harvest resulting from various control programs. Such data are also pertinent to studies on changes in flavor associated with use of acaricides. This report is a summary of analyses made in the insect toxicology laboratory of the Department of Entomology and Parasitology at Berkeley on fresh and processed fruits from plots treated during the 1951 to 1954 seasons (Madsen and Borden, 1956; Summers, 1956). Many of the data relate directly to the samples which were examined in the Department of Food Technology at Davis for flavor alteration (Hinreiner and Simone, 1956), but some samples run in connection with other field work furnish additional pertinent information. Similar data on parathion residues on fresh fruits were given in an earlier publication (Hoskins, 1949). As yet, relatively few data have been published on the residues of newer acaricides resulting from commercial usage.

\section{NAMES AND FORMULAS OF THE ACARICIDES ANALYZED}

As a convenience, the names and formulas of all acaricides analyzed are collected in table 1, together with a reference to the corresponding analytical method enumerated in the section on methods.

The chemicals fall into four general groups:

1. An aliphatic aromatic sulfite (compound 1)

2. Chlorophenyl relatives of DDT (compounds 2, 3, 4)

3 . Chlorophenyl sulfonates (compounds 5, 6)

4. Organic phosphates of rather widely differing structures (compounds $7,8,9,10$ )

\section{METHODS OF EXTRACTION, PURIFICATION, AND ANALYSIS}

Extraction. Residual organic toxicants may be removed from the exterior surface of fruits by washing with almost any organic solvent, but extraction of internal residual chemicals necessitates that the fruit be minutely subdivided first. This process liberates considerable water in which sugars, starches, gums, and other substances are dissolved. Strong shaking with a water-insoluble solvent such as benzene or chloroform sometimes results in formation of a tight emulsion of the solvent in the mass of fruit pulp so that little, if any, can be recovered. Also, the solvent makes very poor con-

\footnotetext{
${ }^{1}$ Received for publication April 29, 1955.

${ }^{2} \mathrm{Mr}$. Miskus is Senior Laboratory Technician in Entomology and Parasitology at Berkeley; Mr. Erwin is Principal Laboratory Technician in Entomology and Parasitology at Berkeley; Mr. Hoskins is Professor of Entomology and Chemist in the Experi. ment Station, Berkeley.
} 
tact with the watery mass in which the residual toxicant is contained and the extraction is inefficient. This objectionable situation may be overcome almost entirely by adding enough water-soluble solvent, for example, alcohol or acetone, to give a single liquid phase, into which the residual toxicant readily passes. After addition of more water, the benzene separates more or less completely upon standing as an upper layer carrying the insecticide.

TABLE 1

COMMON OR TRADE NAMES, CHEMICAL NAMES AND FORMULAS OF ACARICIDES USED IN THESE STUDIES

\begin{tabular}{|c|c|c|}
\hline $\begin{array}{l}\text { Com- } \\
\text { pound } \\
\text { number }\end{array}$ & Chemical name and formula & $\begin{array}{l}\text { Residue } \\
\text { analysis } \\
\text { method } \\
\text { number }\end{array}$ \\
\hline 1 & $\begin{array}{l}\text { Aramite (88R), 2-(p-tert butylphenoxy) } 2^{\prime} \text {-chloroethyl-1-methyl-ethyl sulfite.. } \\
\qquad \mathrm{ClCH}_{2} \mathrm{CH}_{2} \mathrm{OS}(=\mathrm{O}) \mathrm{OCH}\left(\mathrm{CH}_{3}\right) \mathrm{CH}_{2}-\mathrm{OC}_{6} \mathrm{H}_{4} \mathrm{C}\left(\mathrm{CH}_{3}\right)_{3}\end{array}$ & 1 \\
\hline 2 & $\begin{array}{l}\text { Chlorobenzilate, 2-hydroxy-2,2-bis (4-chlorophenyl) ethyl acetate } \ldots \ldots \ldots \ldots \ldots \ldots \ldots \\
\quad \mathrm{ClC}_{6} \mathrm{H}_{4} \mathrm{C}(\mathrm{OH})\left[\mathrm{C}(=\mathrm{O}) \mathrm{OC}_{2} \mathrm{H}_{5}\right] \mathrm{C}_{6} \mathrm{H}_{4} \mathrm{Cl}\end{array}$ & 2 \\
\hline 3 & $\begin{array}{l}\text { Dimite, 4,4-dichloro- } a \text { methyl benzohydrol, or bis-( } p \text {-chlorophenyl) methyl carbinol ... } \\
\quad \mathrm{ClC}_{6} \mathrm{H}_{4} \mathrm{C}(\mathrm{OH})\left(\mathrm{CH}_{3}\right) \mathrm{C}_{6} \mathrm{H}_{4} \mathrm{Cl}\end{array}$ & 2 \\
\hline 4 & 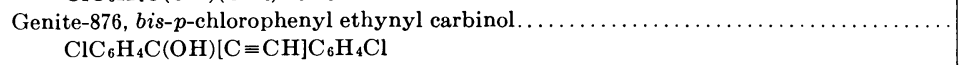 & 2 \\
\hline 5 & $\begin{array}{l}\text { Genite- } 923,2,4 \text { dichlorophenyl benzene sulfonate } \ldots \ldots \ldots \ldots \ldots \ldots \ldots \ldots \ldots \ldots \ldots \ldots \ldots \ldots \\
\quad \mathrm{Cl}, \mathrm{ClC}_{6} \mathrm{H}_{3} \mathrm{OS}(=\mathrm{O})(=\mathrm{O}) \mathrm{C}_{6} \mathrm{H}_{5}\end{array}$ & 3 \\
\hline 6 & $\begin{array}{l}\text { Ovotran, } p \text {-chlorophenyl, } p \text {-chlorobenzene sulfonate } \ldots \ldots \ldots \ldots \ldots \ldots \ldots \ldots \ldots \ldots \ldots \ldots \ldots \ldots \ldots \\
\quad \mathrm{ClC}_{6} \mathrm{H}_{4} \mathrm{OS}(=\mathrm{O})(=\mathrm{O}) \mathrm{C}_{6} \mathrm{H}_{4} \mathrm{Cl}\end{array}$ & 3 \\
\hline 7 & $\begin{array}{l}\text { Diazinon, O,O-diethyl-O-[2-isopropyl-6 methyl-4-pyrimidinyl] thiophosphate } \ldots \ldots \ldots \ldots \\
\quad\left(\mathrm{C}_{2} \mathrm{H}_{5} \mathrm{O}\right)_{2} \mathrm{P}(=\mathrm{S})-\mathrm{O}-\mathrm{C}_{4} \mathrm{~N}_{2} \mathrm{CH}\left(\mathrm{CH}_{3}\right)_{2},\left(\mathrm{CH}_{3}\right)\end{array}$ & 4 \\
\hline 8 & $\begin{array}{l}\text { OMPA (Schradan, Pestox } 3) \text {, Octamethyl pyrophosphoramide; bis-(bis dimethyl amino)- } \\
\text { phosphonous anhydride } \ldots \ldots \ldots \ldots \ldots \ldots \ldots \ldots \ldots \ldots \ldots \ldots \ldots \ldots \ldots \ldots \ldots \ldots \ldots \ldots \ldots \ldots \ldots \ldots \ldots \ldots \ldots \\
\\
\quad\left[\left(\mathrm{CH}_{3}\right)_{2} \mathrm{~N}\right]_{2} \mathrm{P}(=\mathrm{O})-\mathrm{O}-\mathrm{P}(=\mathrm{O})\left[\mathrm{N}\left(\mathrm{CH}_{3}\right)_{2}\right]_{2}\end{array}$ & 6 \\
\hline 9 & $\begin{array}{l}\text { Malathion (4049), O,O-dimethyl-S-(1,2-dicarboxyethyl) dithiophosphate } \ldots \ldots \ldots \ldots \ldots \ldots \\
\qquad\left(\mathrm{CH}_{3} \mathrm{O}\right)_{2} \mathrm{P}(=\mathrm{S})-\mathrm{SCH}\left[\mathrm{C}(=\mathrm{O}) \mathrm{OC}_{2} \mathrm{H}_{5}\right] \mathrm{CH}_{2} \mathrm{C}(=\mathrm{O}) \mathrm{OC}_{2} \mathrm{H}_{5}\end{array}$ & 5 \\
\hline 10 & Kolofog a a sulfur-bentonite mixture containing $30 \% \mathrm{~S} \ldots \ldots \ldots \ldots \ldots \ldots \ldots \ldots \ldots \ldots \ldots \ldots \ldots$ & . \\
\hline 11 & $\begin{array}{l}\text { Karathane } e^{\mathrm{a}}, 2,4 \text { dinitro, 6-capryl-phenyl crotonate } \ldots \ldots \ldots \ldots \ldots \ldots \ldots \ldots \ldots \ldots \ldots \\
\qquad \mathrm{CH}_{3} \mathrm{CH}=\mathrm{CH}-\mathrm{C}(=\mathrm{O}) \mathrm{O}\left[\mathrm{CH}_{3} \mathrm{CH}\left(\mathrm{CH}_{2}\right)_{5} \mathrm{CH}_{3}\right] \mathrm{C}_{6} \mathrm{H}_{2}\left(\mathrm{NO}_{2}\right)_{2}\end{array}$ & .. \\
\hline 12 & $\begin{array}{l}\text { Neotran }{ }^{\mathrm{a}} \text {, di- } p \text {-chloro-diphenoxymethane } \ldots \ldots \ldots \ldots \ldots \ldots \ldots \ldots \ldots \ldots \ldots \ldots \ldots \ldots \ldots \ldots \ldots \\
\quad \mathrm{ClC}_{6} \mathrm{H}_{4} \mathrm{OCH}_{2} \mathrm{OC}_{6} \mathrm{H}_{4} \mathrm{Cl}\end{array}$ & . \\
\hline 13 & $\begin{array}{l}\text { Mitox }{ }^{\mathrm{a}}, p \text {-chlorophenyl- } p \text {-chlorophenyl sulfide } \ldots \ldots \ldots \ldots \ldots \ldots \ldots \ldots \ldots \ldots \ldots \ldots \ldots \ldots \ldots \ldots \\
\mathrm{ClC}_{6} \mathrm{H}_{4} \mathrm{CH}_{2} \mathrm{SC}_{6} \mathrm{H}_{4} \mathrm{Cl}\end{array}$ & .. \\
\hline 14 & $\begin{array}{l}\text { Systox a, O,O-diethyl, O-2-athyl mercapto-ethyl thionophosphate and thiolisomer } \ldots \ldots \ldots \\
\left(\mathrm{C}_{2} \mathrm{H}_{5} \mathrm{O}\right)_{2} \mathrm{P}(=\mathrm{S}) \mathrm{O}-\mathrm{CH}_{2} \mathrm{CH}_{2} \mathrm{SCH}_{2} \mathrm{CH}_{3} \text { plus }\left(\mathrm{C}_{2} \mathrm{H}_{5} \mathrm{O}\right)_{2} \mathrm{P}(=\mathrm{O}) \mathrm{S}-\mathrm{CH}_{2} \mathrm{CH}_{2} \mathrm{SCH}_{2} \mathrm{CH}_{3}\end{array}$ & . \\
\hline
\end{tabular}

a Acaricide used in pest control studies (Madsen and Borden, 1956; Summers, 1956) and flavor evaluations Hinreiner and Simone, 1956), but not included in residue analyses.

It is not necessary to recover all the benzene, for the residue may be assumed to be distributed uniformly between that which is recovered and that which remains emulsified. The total toxicant in the sample may be calculated then by proportion from that found in the recovered benzene or in a portion thereof. An important precaution is the addition of sufficient water to reduce the solubility of the benzene to practically zero in the aqueous phase.

After extensive experiments, the following procedure was adopted for use with all fruits. In the case of fresh fruits, 2,000 grams, selected at random from larger samples from the plots, were chopped to a fine mush in a Buffalo food chopper and removed completely to a $21 / 2$-gallon jar by aid of a 1:1 mixture of c.p. benzene and 95 per cent ethyl alcohol. With malathion 


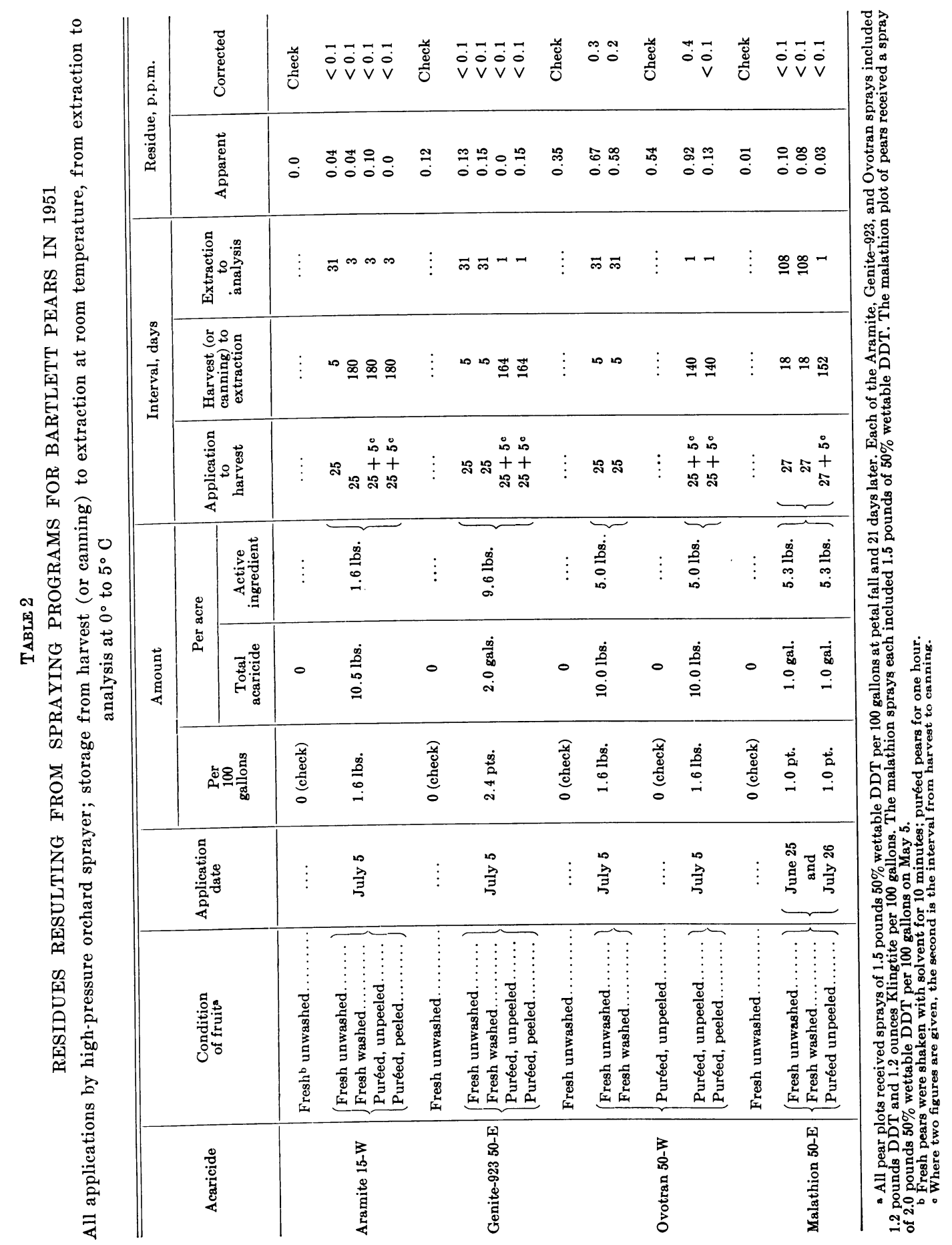


and OMPA residues, carbon tetrachloride and chloroform, respectively, were used instead of benzene, as required by the analytical method. The total volume of this mixed solvent was made up to 4 liters, and the whole mass was shaken or rolled mechanically for 1 hour.

In testing canned fruits, 1,000 grams of pears or peaches, taken at random from a number of cans, were subdivided in a Waring blender and placed in a shaking jar with 2 liters of the same 1:1 benzene-alcohol solvent. Applesauce or puréed fruits were extracted without further subdivision.

In all cases, at the end of the period, the mixture was diluted approximately $2 \frac{1}{2}$-fold with water, whereupon most of the benzene readily separated as an upper layer. In some of the early work, the ratios were varied somewhat and the fresh pears of the 1951 season were stripped with benzene alone.

Purification. In addition to the contaminating acaricides, the solvent removes many substances, collectively called "extractives," which usually must be removed before proceeding with the analysis. As noted in the descriptions of the analytical methods, some of these methods automatically destroy or exclude interfering extractives.

This is not the case with Dimite, Genite-876, Genite-923, Ovotran, Systox, and Diazinon. Extracts thought to contain any of these substances were purified by passage through the alumina-wax column developed in the insect toxicology laboratory and described in detail elsewhere (Erwin, Schiller, and Hoskins, 1955). The completeness of extraction of toxicants from samples and of passage through the wax column has been checked, both by recovery of known additions and by successive extractions of normally contaminated samples. The efficiencies of the two processes vary with the toxicant and the sample but agree in indicating that 80 per cent or more of the total contaminant is accounted for.

To minimize changes during the unavoidably long period between extraction and analysis of some samples, all extracts were stored in glass at $0-5^{\circ} \mathrm{C}$, in the dark.

Analysis. The extracts, after passage through a column when necessary, were treated by appropriate analytical procedure:

1. Aramite. A colorimetric method (Gunther, et al., 1951) involves hydrolysis of acaricide with formation of ethylene oxide which is distilled out, leaving behind the extractives. Treatment with lepidine in diethylene glycol gives a blue color when read in a colorimeter at $610 \mathrm{~m} \mu$.

2. Chlorobenzilate, Genite-876, Dimite. For Chlorobenzilate and Genite- 876 the Schechter-Haller nitration procedure (Schechter, et al, 1945) involving strong nitration, reduction, and coupling with a strong base gives a red color when read at $538 \mathrm{~m} \mu$. The procedure can be applied to Dimite when read at $530 \mathrm{~m} \mu$.

3. Genite-923 and Ovotran. A modification of the method for Ovotran published by Kutschinski and Luce (1952) involves hydrolysis to 4-chlorophenol or 2,4-di-chlorophenol, which are converted to a red compound with 4aminoantipyrine and potassium ferricyanide and read in a colorimeter at $500 \mathrm{~m} \mu$.

4. Diazinon was bioassayed by the procedure of Hoskins, Witt, and Erwin 


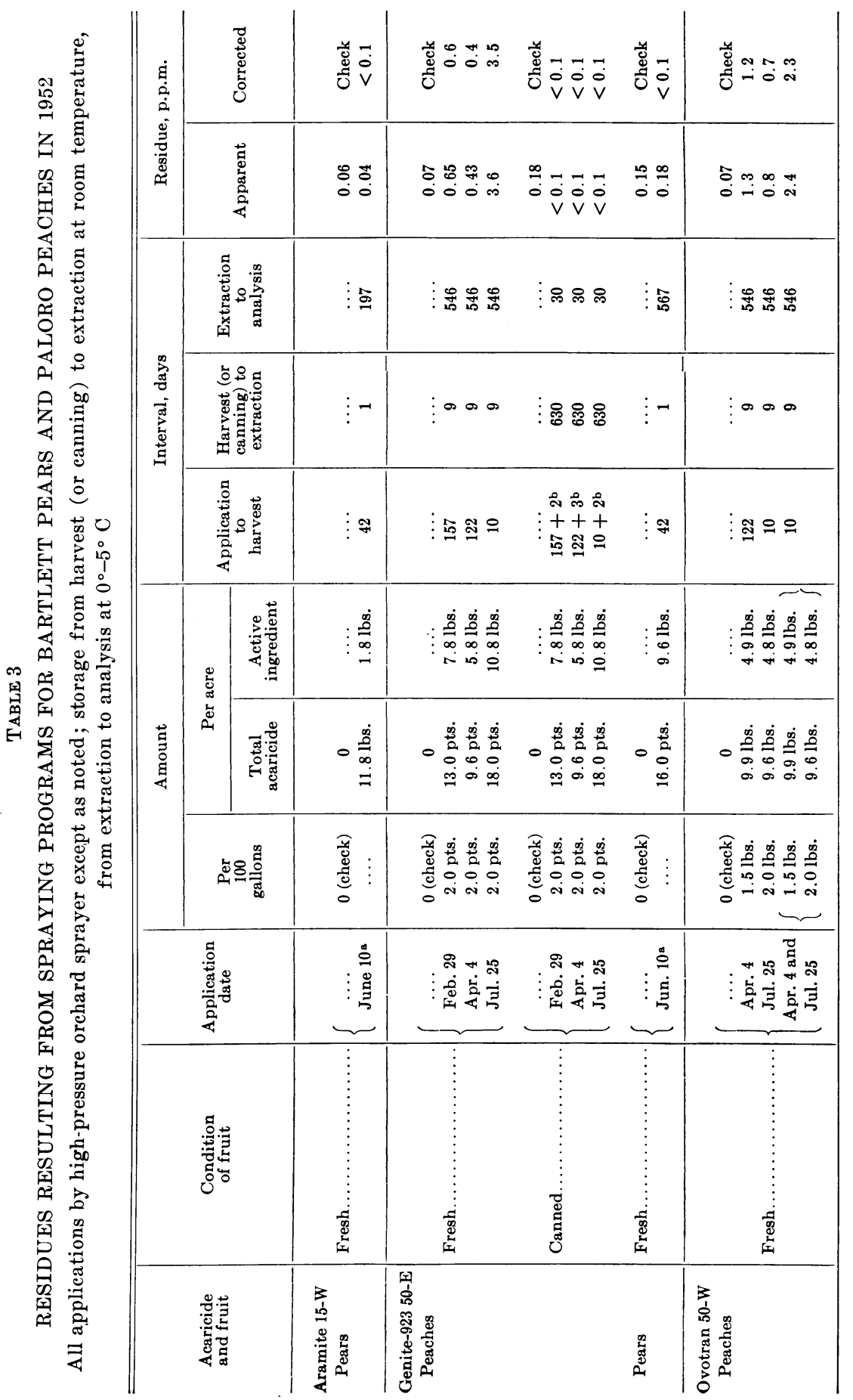




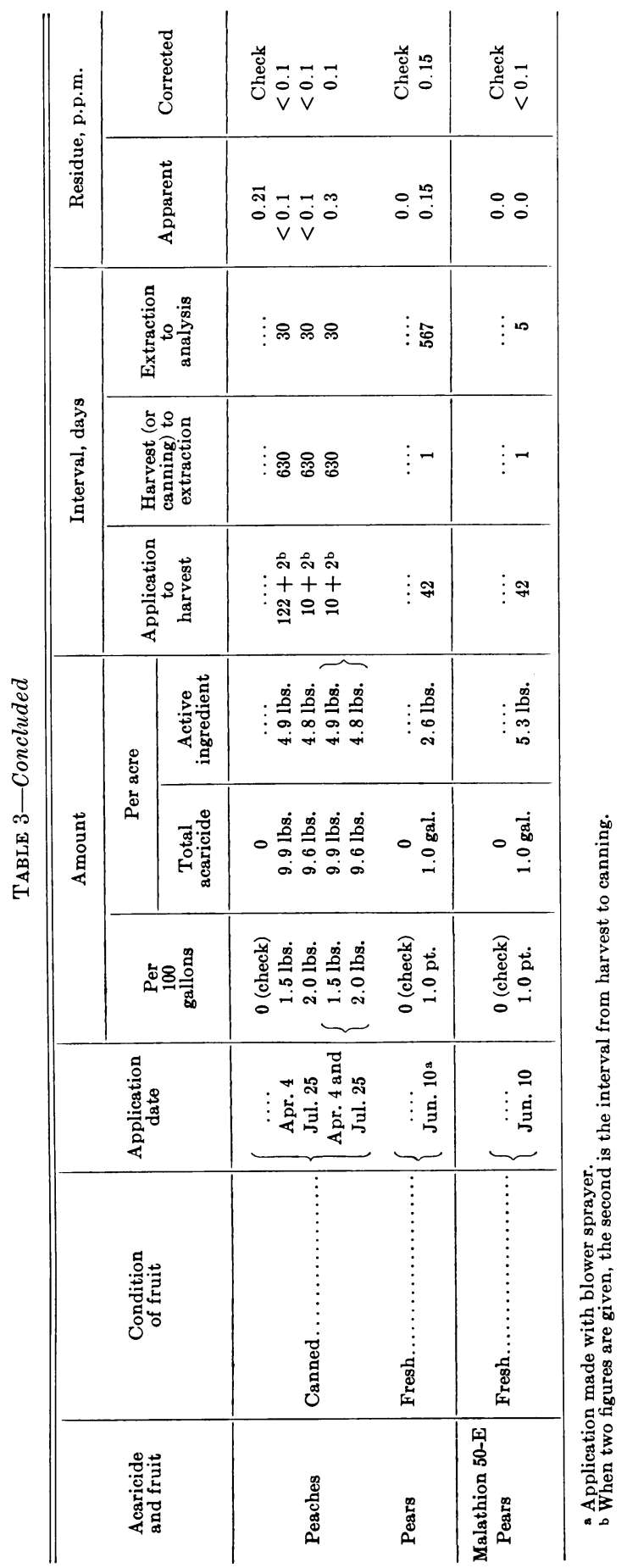




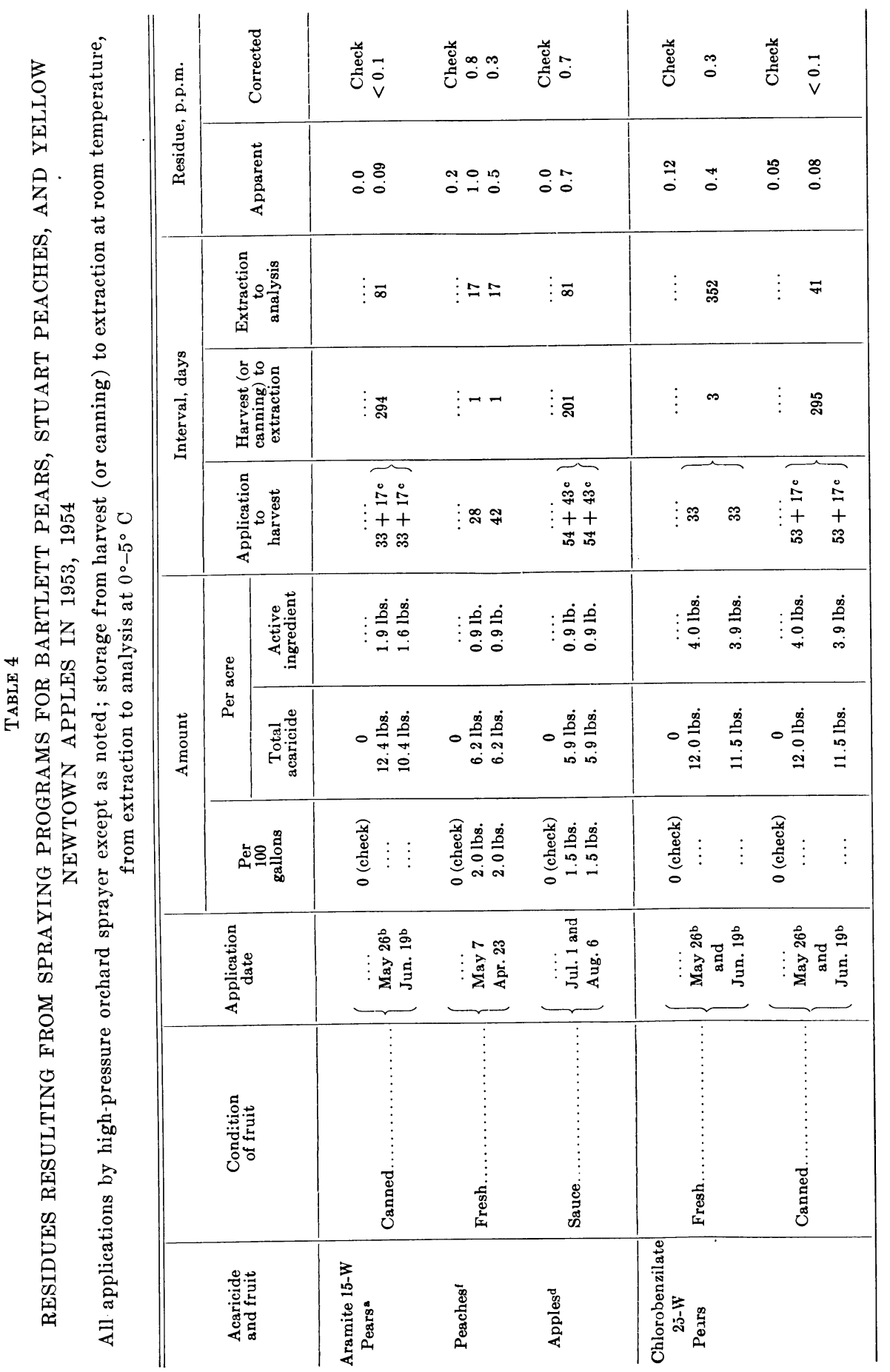




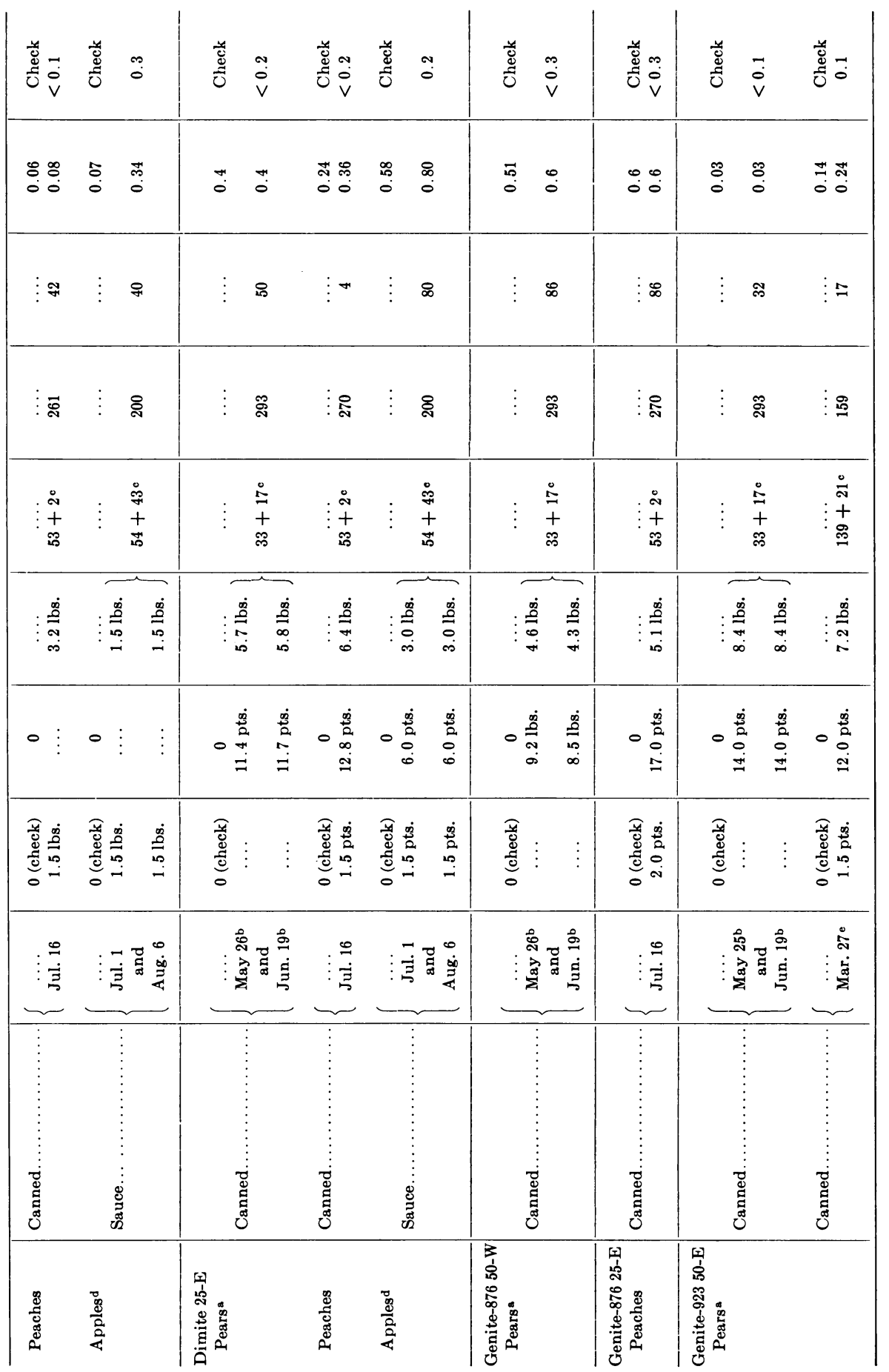




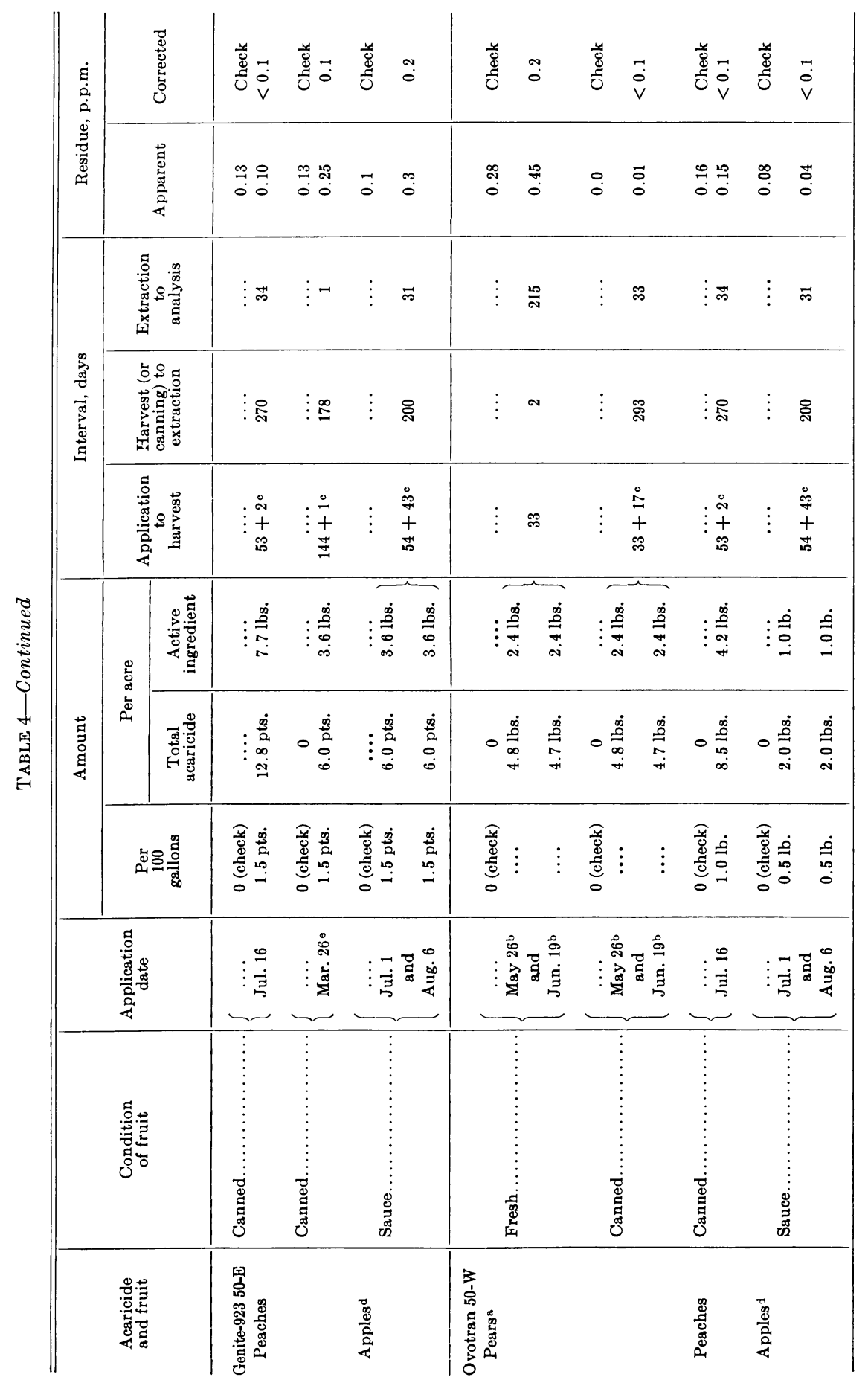




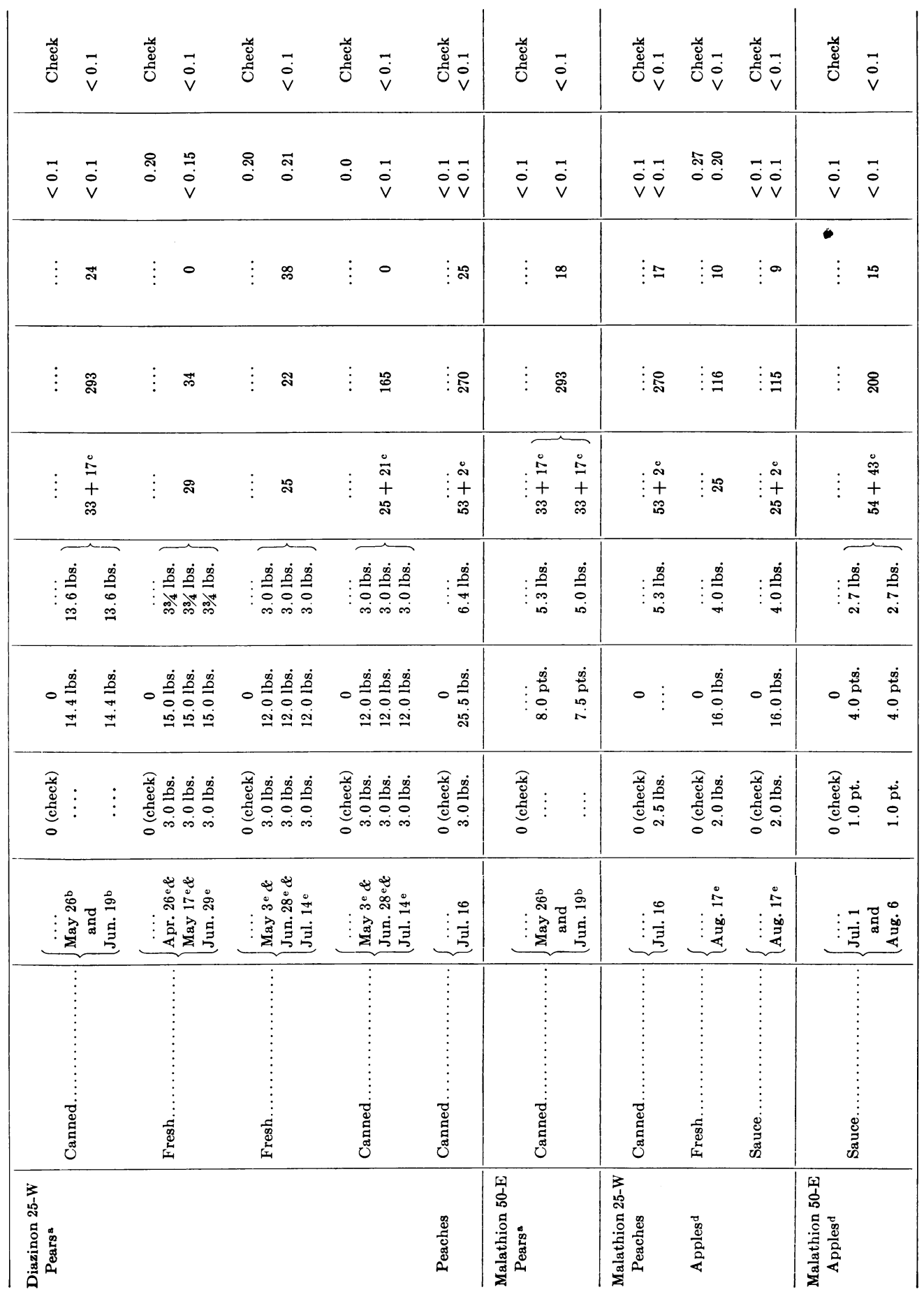




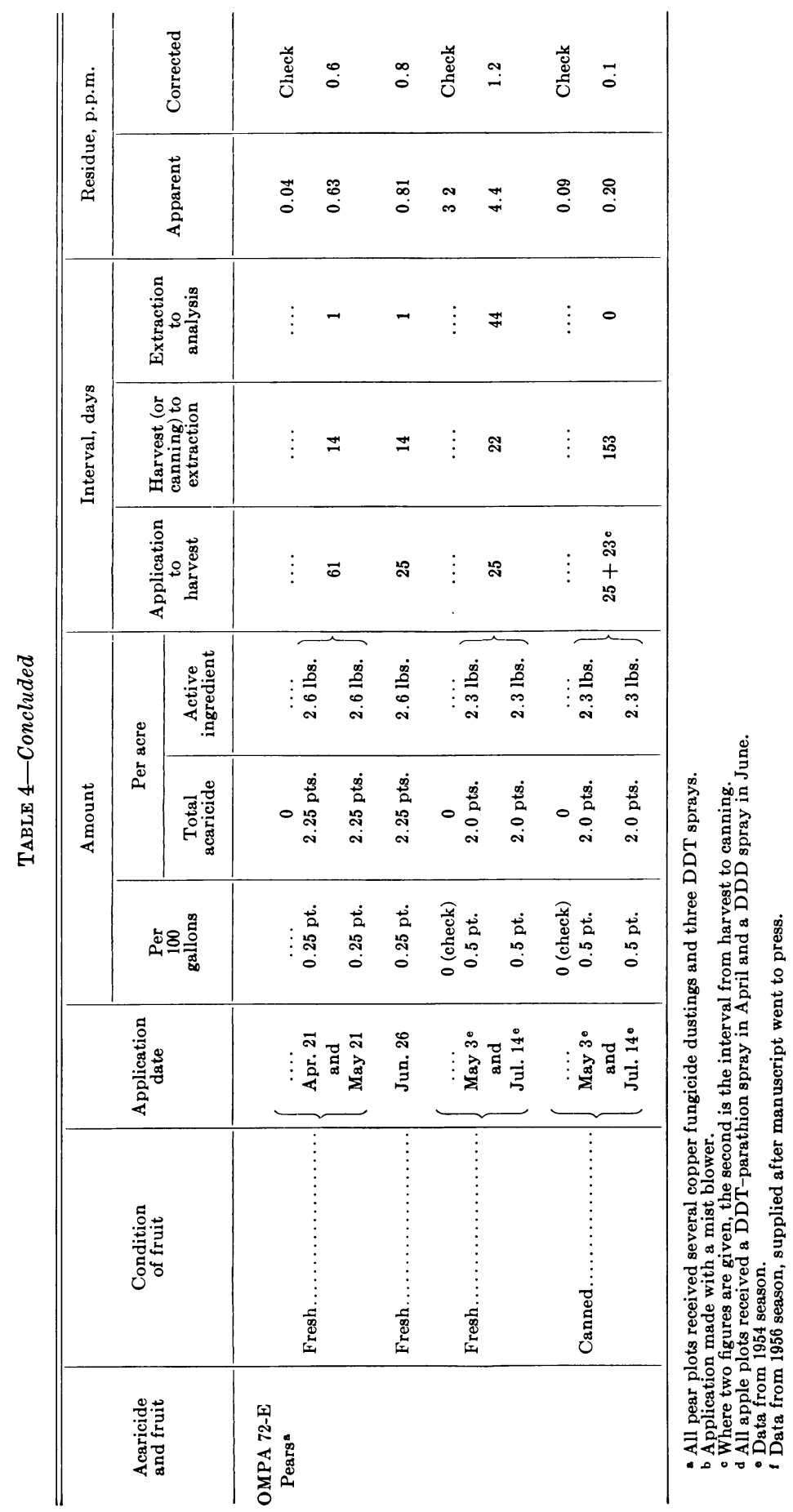


(1952), which uses houseflies exposed to the toxicant spread on the interior surface of a small vial.

5. Malathion. A tentative method suggested by American Cyanamid Company $(1954 a, 1954 b)$ includes alkaline decomposition to a water-soluble derivative, which eliminates most extractives. A yellow color is then formed with copper sulfate and read at $418 \mathrm{~m} \mu$.

6. OMPA. Alkaline hydrolysis and reëxtraction with chloroform eliminates most extractives. Blue color developed with phosphomolybdate by the method of Allen (1940) is read at $600 \mathrm{~m} \mu$. Correction for organic phosphate in untreated fruit is necessary, but is small in fruits so far tested.

In all cases blank runs were made with untreated fruit from the same orchard in order to allow for false readings due either to the reagents or to unknown substances in the fruit. In no case did such values exceed a few tenths of a part per million, except in one instance with OMPA (table 4), in which both the sample and the check were hydrolyzed in an irregular manner, which probably affected them equally. The data in the last column of tables 2 to 4 are corrected for blanks.

The minimum contamination which can be reliably determined is influenced by the sensitivity of the method of analysis, and the extent of interference by extractives from the contaminated material, and also by the size of sample taken when results are expressed in parts per million as in the present case. Under the conditions used the colorimetric methods all gave reproducible results with somewhat less than 0.1 p.p.m., but this figure has been taken as a conservative measure of the minimum detectable. Hence data that actually indicate smaller amounts in the "apparent" column are given as < 0.1 p.p.m. in the "corrected" column. Larger residues are rounded off to the nearest tenth. In a few cases in which the blank indicated several tenths of a part per million contamination, the sensitivity has been taken arbitrarily, but conservatively, as half the blank reading ; for example, with Genite-876 on peaches (table 4) the blank and a sample each gave apparent contamination of 0.6 p.p.m. The corrected residue is given as $<0.3$ p.p.m. In the case of Diazinon, which was determined by bioassay, the amounts giving 50 per cent mortality were used to calculate minima detectable, even though smaller amounts did cause mortality. In the present cases, the corrected sensitivity comes out as less than 0.1 p.p.m.

\section{RESULTS}

The residues resulting from application of Aramite, Genite-923, Ovotran, and malathion to pears in 195124 to 27 days before harvest are shown in table 2 (p. 48). In some cases, the reading from treated plots was equal to or slightly less than that for check fruit, but such residues have been designated as less than 0.1 p.p.m. in accordance with the sensitivity assigned to the analytical procedures for the four chemicals concerned. Only Ovotran gave clear evidence of exceeding this level in the case of pears, both fresh and canned without peeling.

The results for the 1952 season (table 3) confirm those for 1951 in the case of pears. With fresh peaches, which were not analyzed in 1951, there 
were relatively heavy residues of Genite-923 and of Ovotran, even when application was made early in the season. Such a result probably is to be expected because of the hairy nature of the peach surface, which would tend to hold any material placed upon it. Late application, ten days before harvest, decidedly increased the residue and, with the Ovotran plot, caused some ( 0.1 p.p.m. after correction for blank) to carry over into the canned peaches. Since such application is not made in actual control work, this result is not of practical importance. Kutschinski and Luce (1952) have reported somewhat heavier residues on peaches sprayed with Ovotran at various times before harvest.

The more extensive 1953 and 1954 results (table 4) agree with those for the earlier years in showing less than 0.1 p.p.m. Aramite, Genite-923, and Ovotran in canned pears and equally low residues of Genite-923 and Ovotran in canned peaches, with the exception of 0.1 p.p.m. Genite-923 in canned peaches in 1954. New features are the relatively heavy residue of Aramite in fresh peaches $(0.8$ p.p.m. $)$ and in applesauce $(0.7$ p.p.m. $)$ and of Genite-923 in applesauce (0.2 p.p.m.). Data from Nangatuck Chemical Company (1954) show considerably lower Aramite residues on fresh pears than on fresh apples, in agreement with the similar difference between the canned products shown in table 4 . Ovotran, on the other hand, was less than 0.1 p.p.m. in applesauce. The low residues of malathion found in all three seasons are in agreement with results obtained by the American Cyanamid Company (1954b) with apples from various parts of the country.

Among materials determined for the first time in 1953-54, the chlorinated hydrocarbon Chlorobenzilate gave residues above 0.1 p.p.m. on fresh pears and the organic phosphate OMPA gave residues of 0.6 to 1.2 p.p.m. on fresh pears and 0.1 p.p.m. in canned pears. Residues approximating the 0.3 p.p.m. Chlorobenzilate on fresh pears (table 3) 1 month after spraying have been reported by Geigy Agricultural Chemicals (1953). On the other hand, residues of these three materials in canned fruits were below the detectable limit, and the toxicants Genite-876, Diazinon, and malathion, in no case exceeded 0.1 p.p.m. in canned fruits.

\section{LITERATURE CITED}

Allen, R. J. L.

1940. The estimation of phosphorus. Biochem. Jour. 34:858-65.

American Cynanamid Company

1954a. Colorimetric method for the determination of malathion in the technical grade product and in insecticidal preparations (carbon tetrachloride method). Analytical Research Laboratory. 4 pp. Mimeo.

$1954 b$. Malathion residues-apples. Analytical Research Laboratory. 4 pp. Mimeo.

Erwin, W. R., D. Schiller, and W. M. Hoskins

1955. Pesticide residue analysis. Preassay purification of tissue extracts by wax column. Jour. Agr. and Food Chem. 3:676-79.

Geigy Agricultural Chemicals

1953. Chlorobenzilate residues. $6 \mathrm{pp}$. Mimeo.

Gunther, F. A., R. C. Blinn, M. J. Kolbezen, and J. H. Barkley

1951. Microestimation of 2-( $p$-tertbutyl-phenoxy) isopropyl-2-chloroethyl sulfite residues. Analyt. Chem. 23:1835-42. 
HINREINER, E., and M. SIMONE

1956. Effects of acaricides on flavor of almonds and canned fruits. Hilgardia 26:35-45. Hoskins, W. M.

1949. Deposit and residue of recent insecticides resulting from various control practices in California. Jour. Econ. Ent. 43:966-73.

Hoskins, W. M., J. M. WiTT, and W. R. ERwin

1952. Bioassay of 1.2.3.4.5.6-hexachlorocyclohexane (lindane). Analyt. Chem. 24:55560 .

Kutschinski, A. H., and E. N. LuCE

1952. Determination of $p$-chlorphenyl-p-chlorobenzene sulfonate in spray residues on fresh fruits. Analyt. Chem. 24:188-90.

MAdsen, H. F., and A. D. Borden

1956. Field tests of acaricides for control of mites on pears and apples. Hilgardia $26: 7-18$.

Naugatuck Chemical Company

1954. Aramite residues on various crops. $22 \mathrm{pp}$. Mimeo.

Schechter, M. S., S. B. Solomon, R. A. Hayes, and H. L. Haller

1945. Colorimetric determination of DDT. Color test for related compounds. Indust. and Eingin. Chem., Analyt. Ed. 17:704-9.

SUMMERs, F. M.

1956. Field tests of acaricides for control of spider mites on almonds and peaches. Hilgardia 26:19-34. 


\title{
RESIDUAL SOIL INSECTICIDES FOR THE CONTROL OF WIREWORMS AFFECTING VEGETABLE CROPS ${ }^{1}$
}

\author{
W. hARRY LANGe and ELMER C. CARLSON ${ }^{2}$
}

\section{INTRODUCTION}

THE USE of residual soil insecticides is a common practice for wireworm control, not only giving an initial control, but also remaining biologically active in the soil for a number of years. These writers have been engaged since 1947 in an over-all program of wireworm control in which the use of residual soil insecticides is one phase of the problem. In addition to determining effective rates of these chemicals against wireworms, it seems highly desirable to ascertain if they are absorbed by root vegetables, and if they cause off-flavors or other degrading effects in the marketable portions of vegetables.

The 1952-1953 experiments presented in this paper were primarily designed to coördinate all three objectives of wireworm control, translocation, and possible degrading effects. The results of chemical absorption are presented in the paper on residue analyses by Erwin, Miskus, and Hoskins (1956), and the effects on flavors are discussed by Hinreiner and Simone (1956).

In making certain conclusions the present writers have drawn upon the results of earlier tests. It should also be mentioned that natural infestations of wireworms were not present in all of the field plots and for this reason soil was removed from the plots at intervals of time following application and the residual effectiveness tested by means of a laboratory bioassay method utilizing the Pacific Coast wireworm, Limonius canus (LeConte).

It is only within the last ten years that the control of certain soil-inhabiting arthropods has been placed on a practical and economical basis. The appearance of dichloropropane-dichloropropene mixture in 1943 (Carter, 1943) and ethylene dibromide in 1944, made it possible to control certain soil pests and laid the groundwork for the use of DDT and related compounds. Reviews of soil insecticide uses can be found by reference to Gough (1945), Lange (1947), Lilly (1951), and Slawson (1954).

It is difficult to make general recommendations for the control of wireworms or other soil-inhabiting pests because of the many variables that must be considered. Some of these factors are the species involved, time insecticide is applied in relation to activity of insect, stages of insect development at time of application, cultural practices used, soil type or other variable physical and chemical soil characteristics, rates applied, nature of the soil biota, and many others. Methods of application of insecticides will be greatly influenced in each section of the country by these and other factors.

${ }^{1}$ Received for publication April 29, 1955.

${ }^{2} \mathrm{Mr}$. Lange is Associate Professor of Entomology and Associate Entomologist in the Experiment Station, Davis; Mr. Carlson is Associate Specialist in the Experiment Station, Davis. 


\section{METHODS OF INSECTICIDE APPLICATION}

The methods of applying chemicals for control of wireworms and other soil-dwelling pests can be generally classified as follows: (1) soil fumigation, (2) strip treatments, such as the use of sprays, dusts, or granular material in rows or in fertilizers, (3) dipping or drenching plants prior to, or just after planting, (4) application with irrigation, as in overhead sprinkling, (5) seed treatments, and (6) residual soil treatments.

While the experiments discussed in this paper are all the results of residual-soil-treatment method, a brief review of the information on other methods may be useful.

The soil fumigant most widely used in California for control of wireworms is ethylene dibromide. Information on this fumigant can be found in articles by Lange (1945), Cook (1949), Stone (1949), and Cook, Lane, and Stone (1948). In California, thousands of acres have been treated with this compound. In addition to wireworm control, it has the advantage of suppressing or controlling root knot nematodes under certain conditions. No serious effects of fumigants on the quality of root crops has been reported when the customary time intervals between fumigation and planting have been observed.

Wireworm control by strip methods involves the use of sprays, dusts, or granules in bands by means of attachments on planters or fertilizer applicators. They usually protect for only one crop, but have the advantage of reducing the amounts of insecticides needed at one time. The use of granular insecticides incorporated in fertilizer mixtures is a recent development. A recent review of the literature on pesticides in fertilizers can be found in an article by Watts (1951).

Dipping or drenching of plants for wireworm control is sometimes used, particularly when plants grown in seed beds are treated prior to planting in the field. Application of materials with irrigation, such as overhead sprinkling, is occasionally practical. The use of insecticide-fungicide combination seed treatments for wireworm and pre-emergence damping-off protection has come into use in recent years (Lange, Carlson, and Leach, 1949).

The use of residual chemicals for control of wireworms and other soil insects began with the use of DDT and later, benzene hexachloride. DDT has been tested by a number of investigators over considerable periods of time. This chemical has been effective for wireworm control in California, but its slow action is a disadvantage, particularly on crops such as potatoes where protection is needed during the current year of treatment. Lane, et al. (1948), pointed out its effectiveness against young larvae of Limonius spp. DDT, being cheaper and long-lasting, was recommended by Lane and Stone (1951) as a general broadcast treatment for wireworm control in irrigated lands at the rate of 10 pounds of technical DDT per acre. The present authors have found this dosage gives inadequate control in soils of high clay or organic matter content.

Arnason, Fox, and Glen (1947) found that DDT at 100 pounds of technical grade per acre was not too effective in controlling wireworms in Canada. 
The persistence of DDT in the soil was found by Fleming, Maines, and Coles (1951) to follow a sigmoid curve, showing that the loss took place slowly for the first $3 \frac{1}{2}$ years, then rapidly, then slower again. They found a close agreement between chemical and biological determinations of residues of DDT, TDE, toxaphene, and chlordane. Some differences in the percentage loss of different chemicals with time were shown by these authors.

That residual soil chemicals cause definite responses by different plants is shown in the work by Fleming (1947), Morrison et al. (1948), Stitt and Evanson (1949), Foster (1951), Allen, et al. (1951) and Fleming and Maines $(1952,1953)$. The results of long-term studies of residual soil chemicals were made in Oregon by Morrison and Crowell (1952) who found residual action with DDT, toxaphene, and chlordane, but little residual action with EPN and parathion. They further reported good control with benzene hexachloride, but tainting of certain crops. They discovered that residues of aldrin, dieldrin and heptachlor caused no serious off-flavors or other.adverse effects on produce grown in soil treated with these compounds.

A long-term experiment-1946-1953-testing the effectiveness of a number of chlorinated hydrocarbon insecticides against the sugar beet wireworm, Limonius californicus Mann., was reported by Stone and Foley (1953). DDT gave good control at 10 pounds per acre for 4 years and at 20 pounds per acre for 5 years. BHC (technical benzene hexachloride) and lindane at $1 / 2$ pound of gamma isomer per acre controlled wireworms for 3 years. Dieldrin and aldrin were shown to have possibilities, but methoxychlor was ineffective. That elaterids may show differential responses to soil insecticides was indicated when DDT did not control Melanotus longulus Lec., but chlordane was effective. Foliage applications of DDT and plowing under tomato crop residues was shown to control wireworms in initial experiments.

\section{7-1951 TESTS}

The first series of field soil treatments testing the residual nature of chlorinated hydrocarbons was initiated June 4, 1947, at Davis in a Yolo clay loam soil. In this soil type it was shown that 20 to 40 pounds of DDT and 1 to 2 pounds of BHC were necessary to obtain good wireworm control when tested over a 4-year period. Additional tests were made at Davis and at other northern California localities during this period using a number of different residual chemicals.

Variations in results - due to the variable factors in even one localityshowed how difficult it was to determine minimum effective dosages of soil insecticides. Such circumstances as soil texture, organic matter, method and thoroughness of mixing, dosage, cultural methods following application, all affected insecticide effectiveness and persistence.

Tests in 1951 also were concerned with the dispersion of several chemicals in the soil following different tillage methods (Lange and Carlson, 1955).

Preliminary checks in these early experiments indicated off-flavor only in those vegetables grown in soil treated with $\mathrm{BHC}$ and lindane. ${ }^{3}$ At rates

\footnotetext{
${ }^{3}$ Tests run in coöperation with Department of Home Economics, Davis, and National Canners Association Research Laboratory.
} 
of 1 to 2 pounds of gamma isomer from $\mathrm{BHC}$, off-flavors were recorded in fresh cantaloupes, fresh, canned, cooked, and juiced tomatoes, fresh, cooked, and canned carrots, dry and cooked lima beans, and cooked white potatoes. With lindane, off-flavors were recorded from cooked white potatoes and canned tomatoes at levels as low as $1 / 4$ to $1 / 2$ pound of actual gamma isomer content per acre.

The need for work on off-flavor effects was demonstrated when commercial field applications of benzene hexachloride in California and elsewhere resulted in pronounced off-flavors, particularly with certain root crops such as white potatoes. Off-flavors from lindane were not as pronounced, but could be detected under certain situations and dosage rates. An announcement, EP-68 (Lemmon, 1952) was made on June 11, 1952, stating that, in California, BHC should not be applied to soil where edible root crops will be grown within 2 years, and lindane should not be used as a soil treatment where white potatoes or sweet potatoes will be grown within 2 years.

\section{TEST PROCEDURES 1952-53}

Plot Design and Application Methods. During 1952-53 several residual chemicals at different rates were applied to five different soil types at three locations in northern California. The locations and soil characteristies of the plots are shown in table 1. The type of erop grown, and the production and processing information for experiments 1 through 6 are given in table 2 . The 1952 and 1953 plots on carrots (experiments 1 and 2) were 30 feet by 40 feet, or 1,200 square feet in extent, and were replicated twice for each chemical and dosage except for the untreated checks, where 4 plots were used. The insecticides were sprayed on the surface and disked in to a depth of 5 to 6 inches the same day. No natural infestation of wireworms was present. The 1952 sweet-potato plots (experiment 3 ) were 25 feet wide by 40 feet long, and replicated similarly to the carrot experiments. The chemicals were harrowed the same day to a depth of 3 inches. No natural infestation occurred. The 1953 sweet-potato plots (experiment 4) were 24 feet by 570 feet. Applications were by a power sprayer on single plots for each chemical and dosage, except in the case of the standard treatment of 5 pounds of aldrin and the untreated checks, where four replications were used. The insecticides were double-disked into the soil to a depth of 5 to 6 inches the day of application. The 1953 white-potato experiments (experiments 5 and 6 ) were 30 feet wide by 50 feet long and were replicated four times for each chemical and dosage level. The materials were sprayed on by hand-operated compressed-air sprayers and double-disked the day of application to a depth of 5 to 6 inches.

In addition to the six experiments listed, an additional field trial checking the field performance of lindane, aldrin, and dieldrin was conducted in a field near Lodi. Chemicals sprayed on unreplicated 2-acre plots with a power sprayer were double-disked into the soil the day of application. The extensive wireworm damage (97 per cent) made it impossible to evaluate off-flavors.

Method of Testing Residual Nature of Insecticides in the Soil. At stated 
TABLE 1

LOCATIONS AND CHARACTERISTICS OF SOILS TESTED FOR

INSECTICIDE RESIDUAL EFFECTS, 1952-53 ${ }^{a}$

\begin{tabular}{|c|c|c|c|c|c|c|c|c|}
\hline \multirow{2}{*}{$\begin{array}{c}\text { Experi- } \\
\text { ment } \\
\text { number }\end{array}$} & \multirow{2}{*}{ Location } & \multirow{2}{*}{$\mathrm{pH}$} & \multicolumn{3}{|c|}{ Mechanical analyses } & \multirow{2}{*}{$\begin{array}{l}\text { Textural } \\
\text { class }\end{array}$} & \multirow{2}{*}{$\begin{array}{l}\text { Per cent } \\
\text { organic } \\
\text { matter }\end{array}$} & \multirow{2}{*}{$\begin{array}{l}\text { Moisture } \\
\text { equiva- } \\
\text { lent }\end{array}$} \\
\hline & & & $\begin{array}{l}\text { Per cent } \\
\text { sand }\end{array}$ & $\begin{array}{l}\text { Per cent } \\
\text { silt }\end{array}$ & $\begin{array}{l}\text { Per cent } \\
\text { clay }\end{array}$ & & & \\
\hline 1 & Salinas (1952). & 7.7 & 17 & 40 & 43 & Silty clay & 3.34 & 27.5 \\
\hline 2 & Salinas (1953). & 7.7 & 17 & 40 & 43 & Silty clay & 3.34 & 27.5 \\
\hline 3 & Manteca (1952). & 6.5 & 82 & 8 & 10 & Loamy sand & 0.60 & 5.02 \\
\hline 4 & Manteca (1953). & 6.9 & 76 & 14.4 & 9.6 & Sandy loam & 0.80 & 4.84 \\
\hline 5 & Hollister (1953). & 7.4 & 73.6 & 14.5 & 11.9 & Sandy loam & 1.40 & 7.47 \\
\hline 6 & Hollister (1953). & 6.9 & 42.4 & 19.1 & 37.5 & Clay loam & 2.60 & 19.09 \\
\hline
\end{tabular}

- Most of the soil analyses were made by A. L. Brown, Department of Soils, Davis.

TABLE 2

LOCATION, TYPE OF CROP, SOIL TYPE, PRODUCTION DATA AND PROCESSING DATES FOR 1952-53 EXPERIMENTS

\begin{tabular}{|c|c|c|c|c|c|c|c|}
\hline $\begin{array}{c}\text { Experi- } \\
\text { ment } \\
\text { number }\end{array}$ & Location & Crop & Soil type & Date treated & Date planted & $\begin{array}{c}\text { Date } \\
\text { harvested }\end{array}$ & Date canned \\
\hline $1 \ldots$ & Salinas & $\begin{array}{l}\text { Imperator } \\
\text { carrots }\end{array}$ & $\begin{array}{l}\text { Salinas silty } \\
\text { clay loam }\end{array}$ & $\begin{array}{l}\text { June 10-11, } \\
1952\end{array}$ & July 8, 1952 & $\begin{array}{l}\text { October } 25 \text {, } \\
1952\end{array}$ & $\begin{array}{c}\text { October } 27- \\
29,1952\end{array}$ \\
\hline 2. & Salinas & $\begin{array}{l}\text { Imperator } \\
\text { carrots }\end{array}$ & $\begin{array}{c}\text { Salinas silty } \\
\text { clay loam }\end{array}$ & May 22,1953 & May 26,1953 & $\begin{array}{c}\text { September } \\
19,1953\end{array}$ & $\begin{array}{c}\text { October 21- } \\
23,1953\end{array}$ \\
\hline $3 \ldots$ & Manteca & $\begin{array}{l}\text { Puerto Rico } \\
\text { sweet pota- } \\
\text { toes }\end{array}$ & $\begin{array}{l}\text { Dinuba loamy } \\
\text { sand }\end{array}$ & $\begin{array}{c}\text { April 29, } \\
1952\end{array}$ & May 17,1952 & $\begin{array}{l}\text { October } 31, \\
1952\end{array}$ & $\begin{array}{l}\text { December } \\
23-24,1952\end{array}$ \\
\hline $4 \ldots$ & Manteca & $\begin{array}{c}\text { Jersey sweet } \\
\text { potatoes }\end{array}$ & $\begin{array}{l}\text { Hanford fine } \\
\text { sandy loam }\end{array}$ & May 20,1953 & May 27,1953 & $\begin{array}{c}\text { October 7- } \\
14,1953\end{array}$ & $\begin{array}{c}\text { October } 29, \\
1953\end{array}$ \\
\hline $\mathbf{5} \ldots \ldots \ldots$ & Hollister & $\begin{array}{l}\text { Russet white } \\
\text { potatoes }\end{array}$ & $\begin{array}{l}\text { Yolo sandy } \\
\text { losm }\end{array}$ & April 21,1953 & May 15,1953 & $\begin{array}{c}\text { September } \\
12,1953\end{array}$ & ....... \\
\hline $6 \ldots$ & Hollister & $\begin{array}{l}\text { Russet white } \\
\text { potatoes }\end{array}$ & Yolo clay loam & April 21, 1953 & May 20,1953 & $\begin{array}{l}\text { November 6, } \\
\quad 1953\end{array}$ & . \\
\hline
\end{tabular}

intervals a total of 25 soil samples were removed by means of a trowel thrust into the soil to a depth of from 5 to 6 inches and pooled from each plot in the several experiments. The samples were brought into the laboratory and a bioassay method utilizing larvae of Limonius canus was used to determine the amounts of active chemicals in the different samples.

The soil samples brought into the laboratory were kept separate for all wireworm tests. Every replication of each treatment was canned individually, in 4-ounce salve cans. Soil was taken at random from each replicated sample and screened through a 14-mesh screen into 5 salve cans per replication. The minimum number of cans per treatment was 10 , the maximum 20 , depending upon the number of field replications. Type of treatment, replica- 
tion, and date were written on each salve can, and each was filled three quarters full of soil. To prevent contamination, all soil samples were canned with extreme care within a few days of soil sampling.

After filling the cans with soil, approximately one-fifth teaspoon cracked field corn was placed in each salve can. This food was put in the center and buried thoroughly in the soil. Distilled water was then added to each salve can in amounts varying according to initial moisture content and soil type. Enough water was added to bring each up to only 10 to 12 per cent moisture by weight of soil-not up to field capacity.

Method of Counting Wireworms. Wireworms were baited in the field, collected by hand, and kept at $55^{\circ}$ to $60^{\circ} \mathrm{F}$ in crocks of soil with food. Field locations were selected to obtain a preponderance of either the Pacific Coast wireworm, Limonius canus (Lec.) or the sugar-beet wireworm, L. californicus (Mann.), and these were stored separately. In these tests active Limonius canus larvae were used and sick or molting individuals were discarded. Only one wireworm was introduced into each salve can, since some cannibalism does occur when more than one are present in confinement.

The laboratory wireworm test cans were handled carefully throughout, replaced in the original containers (holding three dozen), and placed in a refrigerator or cold room at $58^{\circ}$ to $60^{\circ} \mathrm{F}$. The wireworms were still active at this temperature, but it was low enough to simulate field conditions.

Wireworm counts for each test series were then made at 2-week intervals after their introduction. Appropriate count sheets allowed a quick check as to the number of live worms, moribund (sick and seriously affected) worms, and dead worms. As long as the check or control mortality remained under 10 per cent, counts were continued for the number of weeks necessary to obtain 90 per cent mortality or better.

When the wireworm counts were completed, the data for each treatment were summarized in tables giving the percentage of dead worms and percentage of total mortality (moribund and dead worms). The percentage total mortality was obtained for each counting interval, and later used in histograms which also recorded the number of worms actually dead. This was permissible since the truly moribund worms do not usually recover even when held for extended periods of time. A mean total mortality was computed for all replications and count intervals for each treatment. This had the advantage of introducing a factor for velocity of insecticidal action which is not adequately shown in final mortality figures.

\section{RESULTS}

Experiment 1. Carrots. Soil was collected at 30, 120, and 446 days after treatment and tested against larvae of Limonius canus in the laboratory. At the 30-day count the most effective in total mortality materials were lindane at 5 pounds, aldrin at 10 pounds, dieldrin at 3 and 5 pounds, and heptachlor at 10 pounds. When evaluated in terms of actual kill instead of total mortality (dead and moribund) lindane at 5 pounds, aldrin at 10 pounds, and heptachlor at 10 pounds were the most effective. When examined 120 days after application there was a general reduction in effectiveness, although 

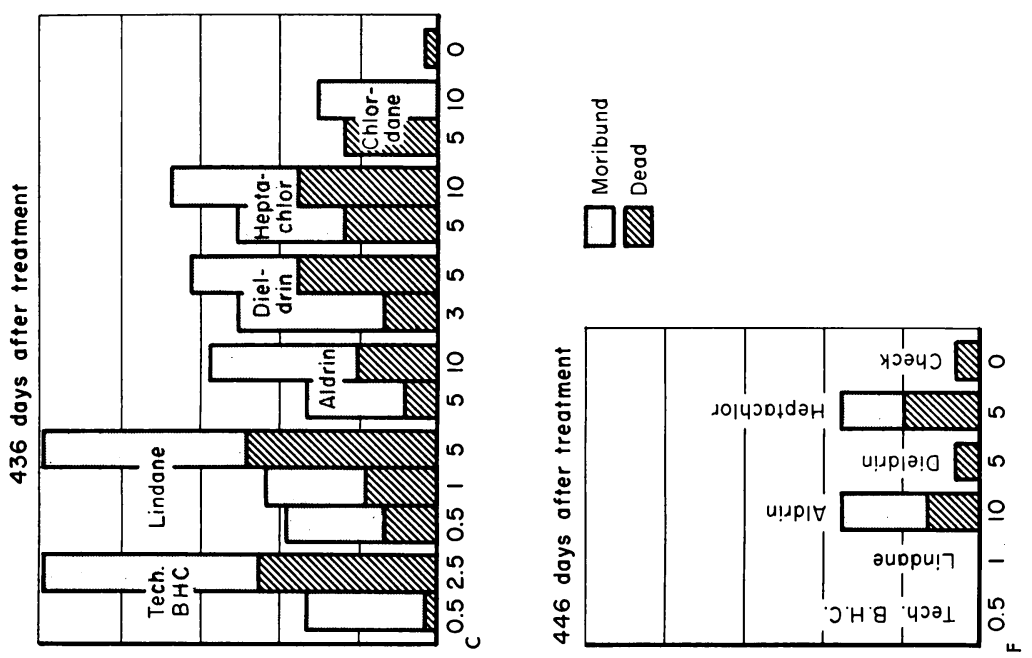

.

讯

ฐٓ

员

用离

두에

$\pi 2$

0

別范

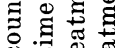

$\rightarrow \pm$

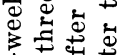

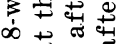

तृ

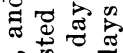

0 is 0

$0+\%$

명 엄

बे क ส
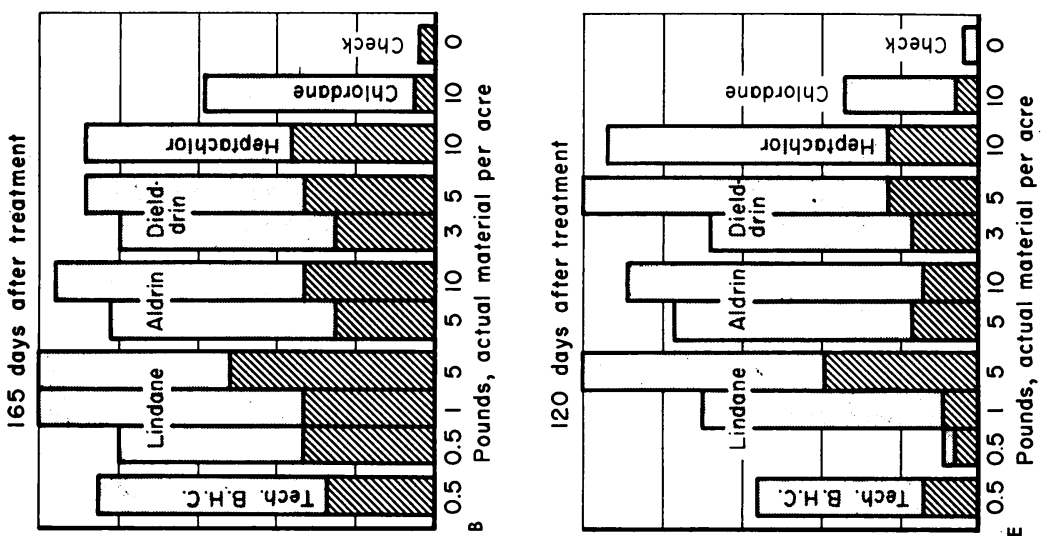

410

월

สี نें

至

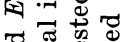

สี

a

คी

จ

ปซ⿱乛⿻)

क षै

焉

ठै की

휴

의 운

o 0
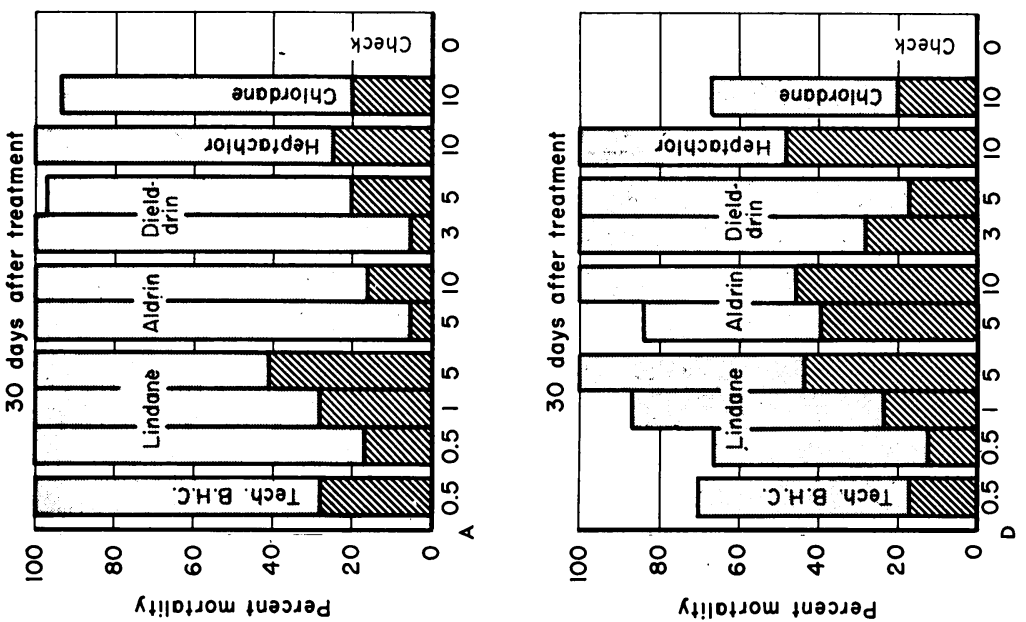

유웛

席范

के क

ते

फक्ष

कान्न है

क

कo

证

뭉

ह

¿

守声

啳

ह

:

事额

․ 중

so:

庄 
lindane at 5 pounds and dieldrin at 5 pounds remained 100 per cent effective. Soil removed 446 days after spraying gave little indication of a residual effect in this silty clay loam soil, although aldrin at 10 pounds and heptachlor at 5 pounds affected an average of about 35 per cent of the worms during an 8 -week exposure period. These data are summarized in figure $1, D, E$, and $F$.

Experiment 3. Sweet Potatoes. Soil was collected at intervals of 30 days, 165 days, and 436 days after treatment and tested in the laboratory against the wireworm, Limonius canus, with the techniques already discussed. Moribund and dead wireworms were counted at 2 , 4 , and 6 weeks following their introduction for the soil samples removed at 30 and 165 days, and an additional count at 8 weeks for the sample removed at 436 days after application. The 30-day test indicated 100 per cent mortality (moribund plus dead) with $1 / 2$ pound of BHC, $1 / 2,1$, and 5 pounds of lindane, 5 and 10 pounds of aldrin, 3 pounds of dieldrin, and 10 pounds of heptachlor. Dieldrin at 5 , and chlordane at 10 pounds approached complete mortality. Based on actual dead wireworms, lindane, BHC, and heptachlor showed superiority. At 165 days after treatment, all materials except chlordane affected 80 per cent or more of the wireworms. Lindane at 5 pounds gave the highest kill, followed by lindane at $1 / 2$ and 1 pound, aldrin at 10 pounds, dieldrin at 5 pounds, and heptachlor at 10 pounds. Lindane at $1 / 2$ and 1 pound, aldrin at 5 pounds, and chlordane at 5 and 10 pounds showed greatly reduced activity in comparison with the 165-day test. These data are graphically shown in figure $1, A, B, C$.

Field Experiment at Lodi. White Potatoes. Results of the chemical applications in the Lodi white-potato experiment were obtained at time of harvest by digging potatoes from the center rows in each plot and examining random samples for wireworm damage. Potatoes from the untreated area gave an average of 97 per cent damage. Dieldrin reduced damage to 8.5 per cent, followed by aldrin at 25 and 31 per cent, and lindane at 70.1 per cent. In terms of per cent reduction in the number of wireworm holes in comparison with the untreated check, all treatments except lindane gave a 90 per cent decrease, or better. When evaluated with respect to total damage (one hole or more), however, only dieldrin at 3.75 pounds per acre gave over a 90 per cent decrease. This means that in the aldrin plots many potatoes had 1 or 2 holes. These data are summarized in table 3.

\section{RESULTS}

Experiment 2. Carrots. Soil from this experiment was collected the day of applying chemicals and 120 days after treatments. The initial kill and residual nature of the chemicals were tested in the laboratory by the methods already discussed. Soil collected the day of treatment showed 100 per cent mortality with isodrin at 5 pounds per acre, endrin at 3 pounds and 5 pounds, and lindane at 1 pound. A 90 per cent mortality or better was obtained for isodrin at 3 pounds, aldrin at 5 pounds, dieldrin at 5 pounds, and heptachlor at 5 pounds. A check at the end of 120 days again showed considerable reduction in insecticidal efficiency in this heavy soil textural class. Endrin at 5 pounds remained effective and, to a lesser degree, so did isodrin at 3 and 5 pounds, endrin at 3 pounds, and aldrin and heptachlor at 5 
pounds. Dieldrin at 5 pounds did not remain effective in this particular experiment. These data are graphically shown in figure $2, A$, and $B$.

Experiment 4. Sweet Potatoes. Soil was collected 29 and 140 days after treatment and tested in the laboratory, utilizing larvae of Limonius canus. At 29 days after treatment 100 per cent mortality was obtained with 5 pounds of isodrin, 5 pounds of endrin, 5 pounds of aldrin, and 1 pound of lindane. With the exception of 3 pounds of heptachlor a 90 per cent, or better, mortality was obtained with 3 pounds of isodrin, 3 pounds of endrin, 3 pounds of aldrin, 3 pounds of dieldrin, and 1/2 pound of lindane. In terms of actual kill of wireworms, isodrin at 5 pounds gave the highest mortality followed closely by all rates of the other chemicals except 3 pounds of heptachlor, which fell below in this particular test.

TABLE 3

RESULTS OF SOIL INSECTICIDE APPLICATIONS FOR THE CONTROL OF Limonius canus, LODI, ON NOVEMBER 11, 1952a

\begin{tabular}{|c|c|c|c|c|c|c|c|}
\hline \multirow{2}{*}{$\begin{array}{l}\text { Insecticide and rate } \\
\text { actual chemical } \\
\text { per acre }\end{array}$} & \multicolumn{3}{|c|}{ Number potatoes examined } & \multirow{2}{*}{$\begin{array}{l}\text { Per cent } \\
\text { damaged }\end{array}$} & \multirow{2}{*}{$\begin{array}{c}\text { Average } \\
\text { number } \\
\text { worm holes } \\
\text { per potato } \\
\text { examined }\end{array}$} & \multicolumn{2}{|c|}{ Per cent reduction ${ }^{b}$} \\
\hline & Clean & Damaged & Total & & & $\begin{array}{l}\text { In number } \\
\text { worm holes }\end{array}$ & $\begin{array}{l}\text { In total } \\
\text { damage }\end{array}$ \\
\hline Untreated (check). & 4 & 141 & 145 & 97.2 & 7.3 & $\ldots$ & 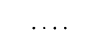 \\
\hline Lindane $0.25 \mathrm{lb} .$. & 35 & 84 & 119 & 70.6 & 3.5 & 52.7 & 27.4 \\
\hline Aldrin 3.5 lbs.... & 70 & 32 & 102 & 31.4 & 0.7 & 91.0 & 67.7 \\
\hline Aldrin 4.4 lbs.. & 75 & 25 & 100 & 25.0 & 0.5 & 93.8 & 74.3 \\
\hline Dieldrin 3.75 lbs.. & 97 & 9 & 106 & 8.5 & 0.2 & 97.8 & 91.3 \\
\hline
\end{tabular}

a Soil treated May 9, 1952; chemicals sprayed on surface and disked into upper 6 inches of soil. Potatoes harvested November 11, 1952.

b Decrease in number of worm holes in potatoes and in total damage in comparison with potatoes from untreated check.

At the 140-day observation period, endrin at 5 pounds, aldrin at 5 pounds, and lindane at $1 / 2$ and 1 pound gave 100 per cent mortality. Based on actual kill, endrin at 5 pounds, isodrin at 5 pounds, and lindane at $1 / 2$ pound were superior. As before, heptachlor at 3 pounds gave the lowest per cent mortality. These data are presented in figure $2, C$ and $D$.

An evaluation of the field performance of the materials used in experiment number 4 at Manteca was possible as a natural infestation occurred. Jersey sweet potatoes were dug from each plot at the time of harvest and examined for wireworm damage.

In this experiment isodrin at 5 pounds per acre gave the best protection from wireworm attack, reducing worminess from 72 per cent in the untreated plots to 4.7 per cent where treated. Isodrin at this level was followed in effectiveness by aldrin at 5 pounds, lindane at 1 pound, and endrin at 5 pounds. Isodrin and endrin at 1 pound per acre and endrin at 3 pounds gave poor protection under these particular conditions. Isodrin at 3 pounds, dieldrin at 3 pounds, 3 pounds of heptachlor, and $1 / 2$ pound of lindane gave fair to good protection in this experiment. Based on the index of severity, which takes into account relative extent of damage, aldrin at 5 pounds had the lowest rating $(0.06)$, followed by isodrin at 5 pounds $(0.09)$, and endrin at 5 pounds $(0.10)$. These data are summarized in table 4 . 
Experiments 5 and 6. White Potatoes. A duplicate of soil applications was made in each of two fields at Hollister. In the case of experiment 6 the soil was contaminated with DDT, but in experiment 5 both laboratory and field evaluations were made.

Soil from experiment 5 was obtained 4 and 144 days after treatment and tested against larvae of Limonius canus in the laboratory using the tech-
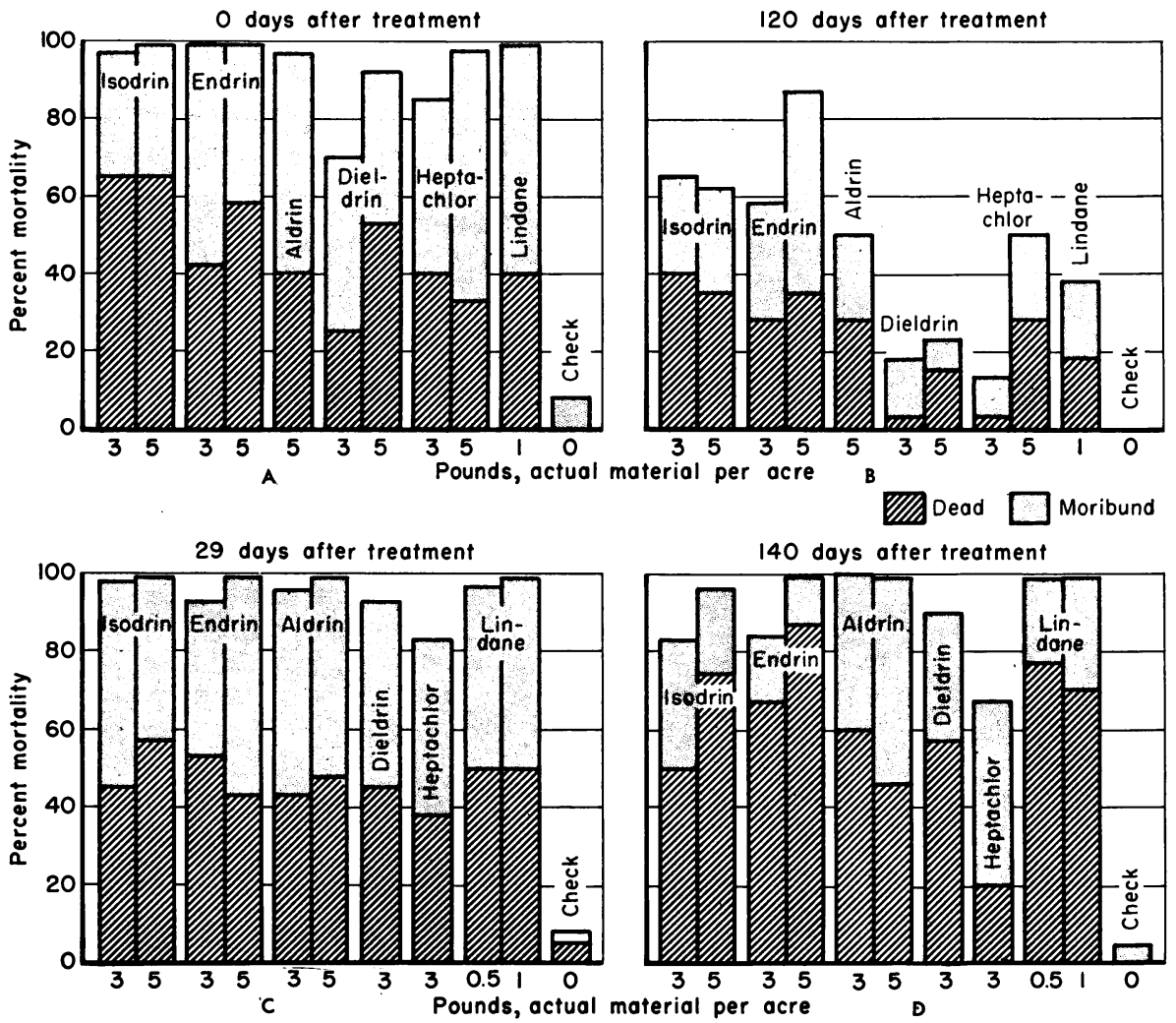

Fig. 2. Mean wireworm mortalities obtained from 2-, 4-, 6-, and 8-week laboratory bioassay tests for several chemicals in two soil types and tested at two intervals following treatment. $A$ and $B$ : Salinas experiment 2, treated May 22, 1953, and checked the same day of application and 120 days after treatment. $C$ and $D:$ Manteca experiment 4, treated May 20, 1953, and tested 29 and 140 days after treatment.

niques already given. The results of the laboratory tests are shown in figure $3, A$ and $B$. The highest mortality at 4 days after spraying was shown with 5 pounds of parathion, followed by lindane at 1 pound, heptachlor at 3 pounds, and aldrin at 5 pounds. DDT at 10 pounds and aldrin at 2 pounds were relatively ineffective. At 144 days after spraying, parathion dropped to about one third of its original effectiveness. Lindane at 1 pound, endrin at 3 pounds, and aldrin at 5 pounds gave 90 per cent mortality, or better.

Field performance data for experiment 5 are shown in table 5 . 


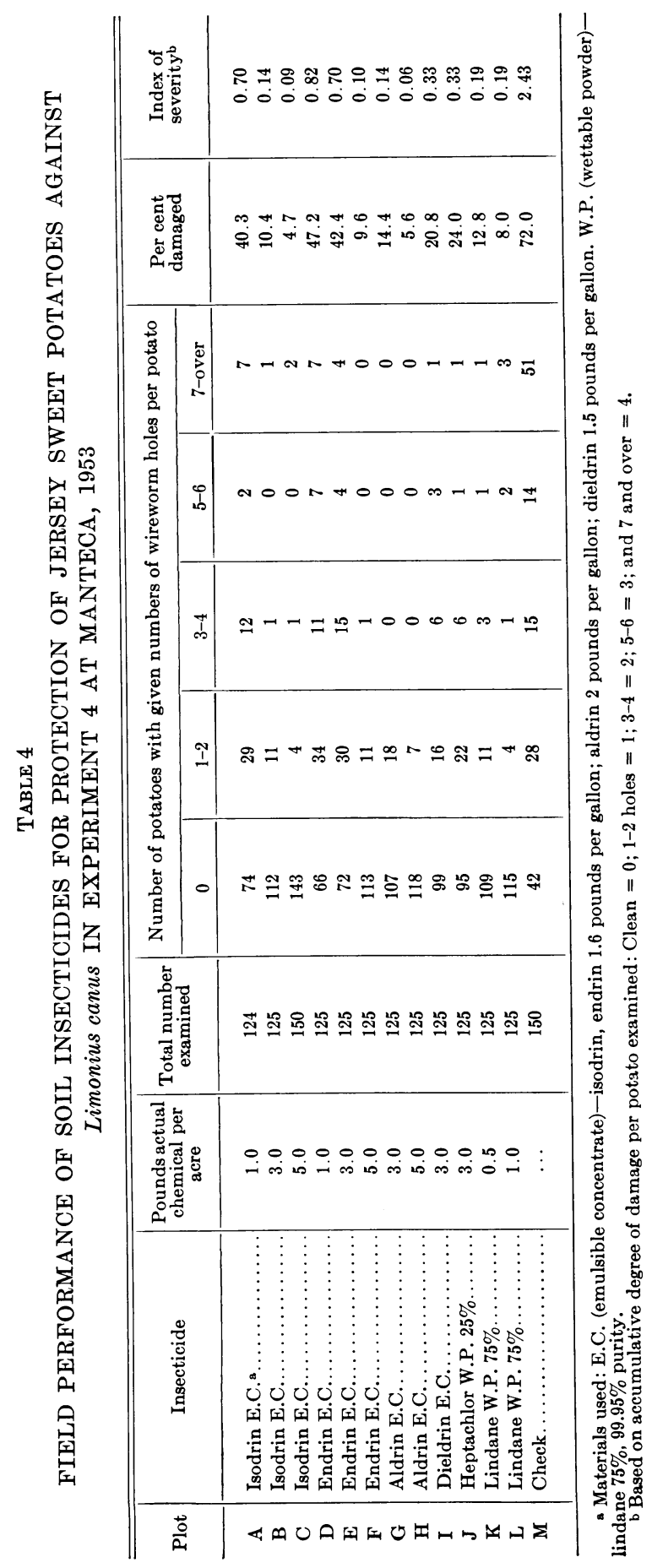




\section{CONCLUSIONS}

1947-1951 Tests. The difficulty of determining minimum effective dosages of soil insecticides for wireworm control was evident in this initial work. Factors such as soil texture, amount of organic matter, method and extent of incorporating insecticides in soil, and cultural methods following application,
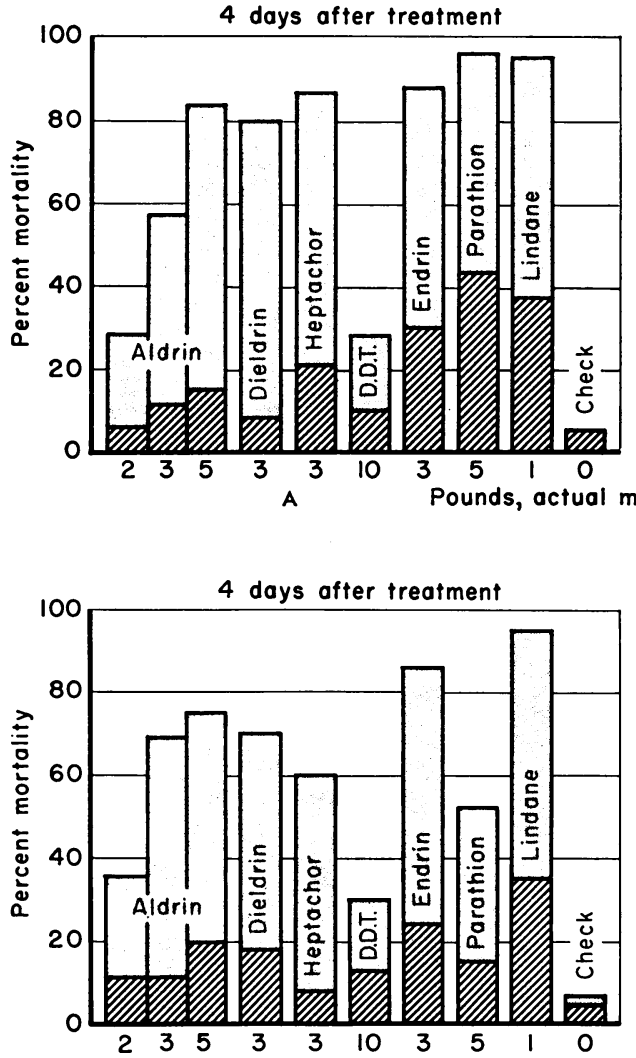

144 days after treatment

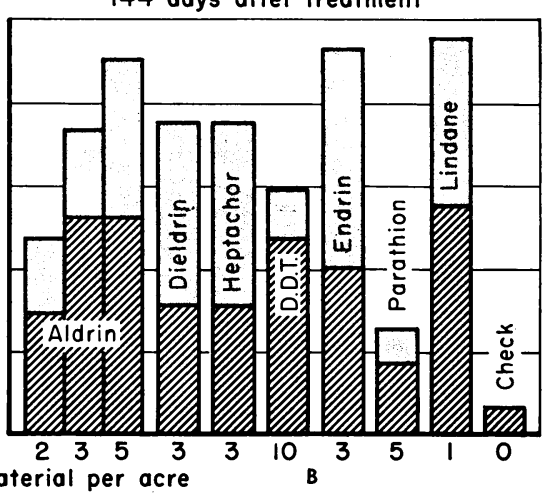

WDead $\square$ Moribund

152 days after treatment

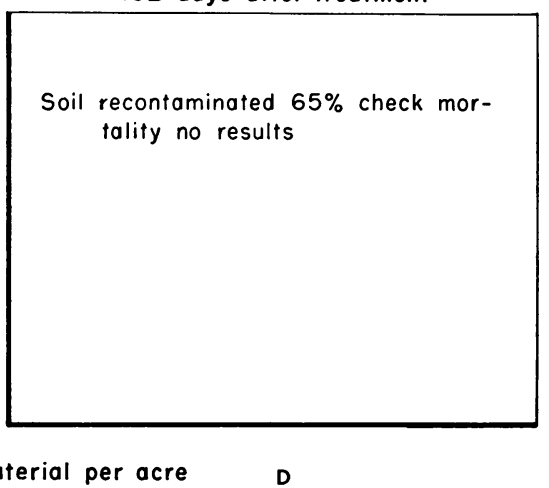

Fig. 3. Mean wireworm mortalities obtained from 2,- 4-, and 6-week laboratory bioassay tests for several chemicals in two soil types and tested at one and two intervals after treatment. $A$ and $B$ : Hollister experiment 5, treated April 21, 1953, and soil tested 4 and 144 days after treatment. $C$ and $D$ : Hollister experiment 6, treated April 21, 1953, and tested 4 days after treatment.

all were instrumental in determining results in any particular experiment. A special series of trials indicated that disking and rototilling were more effective in dispersing chemicals in soil than was harrowing. Even with good mixing, twice as much of a chemical remained in the topmost $2 \frac{1}{2}$ inches than in the next lower $2 \frac{1}{2}$ inches. Benzene hexachloride and lindane were found to give off-flavors to many fresh and processed vegetables when used as soil treatments.

1952-1953 Tests. While the difficulties of correlating laboratory and field 
investigations are clearly shown in these experiments, each furnished valuable data in determining the practical use of the chemicals under field conditions. Parathion, for example, may give excellent control in the laboratory (figure $3, A$ ), but, at practical levels, is not sufficiently residual in the soil to protect potatoes from wireworm attack (table 5).

The present method of removing field-treated soil and testing it in the laboratory has the advantage of ascertaining the decline of chemicals under natural conditions. The nature of the decline, however, is usually not known because of the complexity of heterogeneous factors influencing each experi-

TABLE 5

FIELD PERFORMANCE OF SOIL INSECTICIDES FOR PROTECTION OF RUSSET WHITE POTATOES AGAINST Limonius canus IN EXPERIMENT NUMBER 5 AT HOLLISTER, 1953

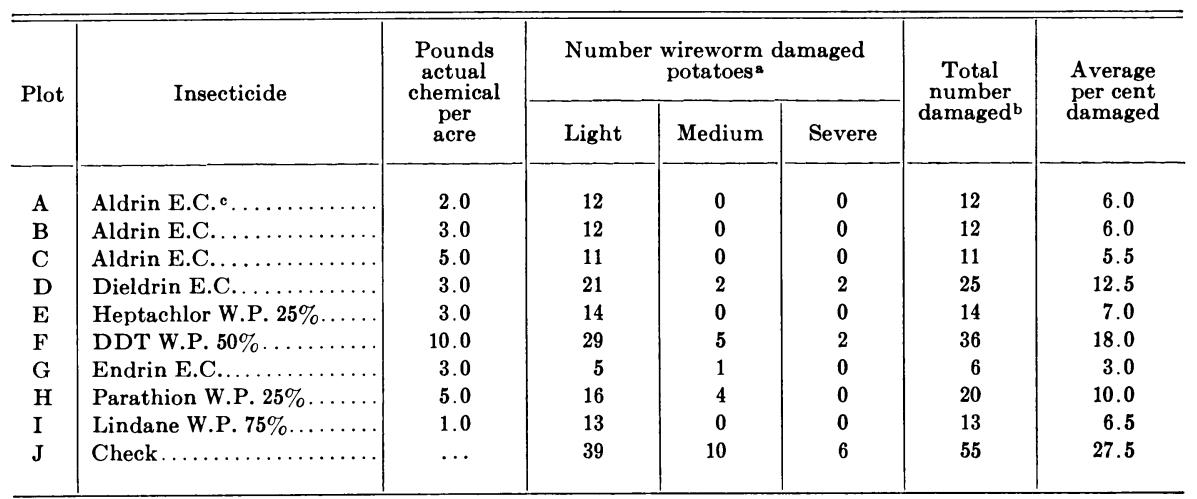

a Light 1-2 holes per potato; medium 3-5; severe 6 and over.

b Examined 200 potatoes per treatment; 50 in each of 4 replications.

c Materials used: E.C. (emulsible concentrate)-aldrin 2 pounds per gallon; dieldrin 1.5 pounds per gallon; endrin 1.6 pounds per gallon; lindane $99.95 \%$ purity.

ment. The method has further disadvantages which stem from the difficulty in obtaining adequate and randomized soil samples from field plots, and from the necessary limitations in the magnitude of tests that can be run. The difficulty of adequate mixing in the soil is probably one of the first problems encountered in conducting field tests.

In these trials it is difficult to relate insecticidal efficiency with textural classifications of the soil, but it is apparent that there was a distinct difference between a clay loam soil at Salinas, having a clay content of 43 per cent and 27.5 moisture equivalent, and the lighter soils. An example of this kind is shown in figure $1, A$ to $C$ and $D$ to $F$, in which the Salinas soil can be compared with a loamy sand from Manteca with 10 per cent clay, and moisture equivalent of 5.02. With lindane, for example, it took almost 5 pounds at Salinas to equal the control obtained with 0.5 pound at Manteca. With aldrin, dieldrin, and heptachlor, however, no great differences between the effectiveness in the two soil types was noted at the 30-day interval after treatment. At the next two observation dates, however, it was very apparent that insecticidal activity dropped off very rapidly in the Salinas soil (figure $1, B, C, E, F)$. 
In the 1953 tests the decrease in biological activity in the Salinas clay loam soil (figure $2, A$ and $B$ ) as compared with a sandy loam soil at Manteca is clearly shown. These trials indicate that it might be necessary to greatly increase the dosage of most soil insecticides in soils of high clay or organicmatter content to obtain adequate control of wireworms beyond a six-month interval.

In these trials adverse effects on growth were observable only with the 21/2-pound dosage of BHC at Manteca on sweet potatoes. Aboveground effects were a definite reduction in vine growth. Belowground effects were gigantism

TABLE 6

EFFECTIVE RATES OF CERTAIN SOIL INSECTICIDES AND THEIR RESIDUAL NATURE IN SOIL, NORTHERN CALIFORNIA, 1947-1953a

\begin{tabular}{|c|c|c|}
\hline Insecticide $^{b}$ & $\begin{array}{l}\text { Effective dosage } \\
\text { range per acre } \\
\text { (pounds actual) }\end{array}$ & $\begin{array}{c}\text { Persistence as } \\
\text { determined by } \\
\text { biological } \\
\text { activity (years) }\end{array}$ \\
\hline DDT $\ldots \ldots \ldots \ldots \ldots \ldots$ & $10-40 \mathrm{c}$ & 4.5 \\
\hline Chlordane.............. & $5-10$ & $1.0-2.0$ \\
\hline 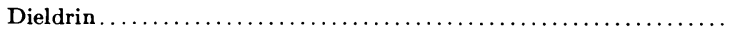 & $2-5$ & $2.0-2.5$ \\
\hline 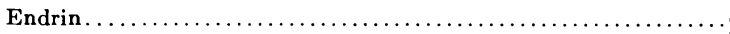 & $2-5$ & ?d \\
\hline Isodrin $\ldots \ldots \ldots \ldots \ldots \ldots \ldots$ & $2-5$ & ?d \\
\hline Heptachlor...... & $2-5$ & $1.0-2.0^{\mathrm{d}}$ \\
\hline BHC................. & $0.25-1.0$ (gamma) & $1.0-2.5$ \\
\hline
\end{tabular}

a Based upon field and laboratory tests using an approximate LD-50 value.

b In these tests DDD at 20 pounds per acre, parathion at 5 pounds, and methoxychlor at 20 pounds were not found effective.

c 20 pounds of DDT in five locations indicated that about 60 per cent remained 4.5 years in clay soils.

d Complete residual nature still under investigation.

of the tubers and reduction in number of potatoes. The same dosage at Salinas on carrots had no apparent effect on growth or yields.

General Conclusions 1947-1953. On the basis of all trials (1947-1953) it is possible to suggest in table 6 an effective dosage range for wireworm control with a number of soil insecticides and to predict the length of time each will remain biologically active in the soil.

In general, the lower rates are suggested for light soils and the heavier rates for heavy soils. The choice of a chemical will be determined to some extent by the crop to follow. BHC and lindane cannot be used prior to planting a root crop. Certain materials such as DDT are slow acting and usually have to be applied several months prior to the time when protection of a crop is needed.

These experiments indicate that the soil insecticides tested might be grouped according to performance for the control of wireworms (Limonius spp.), as follows:

1. Lindane, $\mathrm{BHC}$, endrin, isodrin. These have given rapid control of wireworms, yet have shown enough residual action to give protection during the crop season. Lindane and BHC are effective in amounts of $1 / 2$ to 1 pound of gamma isomer per acre. Endrin and isodrin produce the same velocity of action as lindane when used in amounts of 3 to 5 pounds per 
acre. Field performances to date show no constant difference between endrin and isodrin, although laboratory tests show endrin to be more effective.

2. Aldrin, heptachlor. These are equal in performance. Their velocity of action appears slower than endrin or isodrin, and faster than dieldrin.

3. DDT, dieldrin. These materials seem more residual in the soil, and may be as effective in controlling wireworms where they can be applied several months before planting. Both of these chemicals are slower acting on wireworms than lindane, $\mathrm{BHC}$, isodrin, endrin, aldrin, and heptachlor and as indicated in table 5 they do not show to their best advantage in many instances when compared during a one-year period after treatment.

4. Parathion, chlordane. In this group are chlordane and parathion as these chemicals often give excellent immediate control, but under most conditions, as is indicated in figures 1 and 3, they do not persist long enough in their insecticidal activity to give adequate control.

\section{ACKNOWLEDGMENTS}

The present work has been supported in part by grants-in-aid from the Shell Chemical Corporation and the Velsicol Corporation, and the authors are greatly indebted to these companies and their representatives for assistance. In addition to many coöperative farmers the writers would like to acknowledge the assistance of Farm Advisors J. R. Underhill and R. D. McCallum of San Joaquin County and San Benito County, respectively, who made the field tests possible. The tests at Salinas were made possible by R. L. Adams, formerly with the Grower-Shipper Vegetable Association. Dr. A. L. Brown of the Soils Department at Davis has helped in supplying analyses of the soils used in the experiments. Dr. J. E. Knott of the Vegetable Crops Department, Davis, has supplied land for experimental plots and coöperated in many other ways to facilitate our work.

\section{LITERATURE CITED}

Allen, N., F. F. Bondy, J. F. Bullock, and E. E. HAll

1951. Effect of soil treatments with DDT, benzene hexachloride, and toxaphene on tobacco, cotton, and cowpeas. U. S. Dept. Agr. Tech. Bul. 1047:1-22.

Arnason, A. P., W. B. Fox, and R. Glen

1947. A preliminary test of DDT and benzene hexachloride for the control of wireworms in a Saskatchewan potato field. Canad. Ent. 79:174-80.

CARTER, W.

1943. A promising new soil amendment and disinfectant. Science $97: 383-84$.

Cook, W. C., M. C. Lane, and M. W. Stone

1948. Wireworm control in irrigated lands with ethylene dibromide. U. S. Bur. Ent. and Pl. Quart. EC-6:1-8.

Cook, W. C.

1949. Comparative studies of three soil fumigants for wireworm control. U. S. Dept. Agr. Tech. Bul. 980:1-22.

ERwin, W. R., R. P. Miskus, and W. M. Hoskins

1956. Harvest residues of insecticides in vegetable and field crops resulting from foliage and soil application. Hilgardia 26:86-106. 
Fleming, W. E.

1947. Effect on plants of DDT applied to the soil for the destruction of Japanese beetle larvae. U. S. Bur. Ent. and Pl. Quart. E-737: 1-20.

Fleming, W. E., and W. W. Maines

1952. Effect of DDT and chlordane applied to control Japanese beetle larvae on the yield of grass, rye, soybeans, and corn. U. S. Bur. Ent. and Pl. Quart. E-839: $1-9$.

1953. Effect of chlorinated organic compounds on plants grown in treated soil. U. S. Bur. Ent. and Pl. Quart. E-872:1-7.

Fleming, W. E., W. W. Maines, and L. W. Coles

1951. Persistence of chlorinated hydrocarbon insecticides in turf treated to control the Japanese beetle. U. S. Bur. Ent. and Pl. Quart. E-829:1-6.

Foster, A. C.

1951. Some plant responses to certain insecticides in the soil. U. S. Dept. Agr. Cir. $862: 1-41$.

Govgh, H. C.

1945. A review of the literature on soil insecticides. Impl. Inst. of Ent. London. 161 pp.

HiNREiner, E., and M. Simone

1956. Effects of soil insecticides on flavor of vegetable crops. Hilgardia 26:76-85.

LANE, M. C., and M. W. Stone

1951. DDT for control of wireworms in irrigated lands. U. S. Bur. Ent. and Pl. Quart. EC-19:1-4.

Lane, M. C., M. W. Stone, H. P. Lanchester, E. W. Jones, and K. E. Gibson

1948. Studies with DDT as a control for wireworms in irrigated land-progress report. U. S. Bur. Ent. and Pl. Quart. E-765:1-9.

LANGE, W. H., JR.

1945. Ethylene dibromide and dichloropropane-dichloropropene mixture for wireworm control. Jour. Econ. Ent. 38:643-45.

1947. New developments in soil insecticides. Agr. Chem. 2:20-23, 68-69.

Lange, W. H., JR., E. C. Carlson, and L. D. Leach

1949. Seed treatments for wireworm control with particular reference to the use of lindane. Jour. Econ. Ent. 42:942-55.

Lange, W. H., JR., and E. C. Carlson

1955. Zonal dispersion of chemicals in soil following several tillage methods. Jour. Econ. Ent. 48:61-67.

LEMMON, A. B.

1952. Bureau of Chemistry. State Department of Agriculture. EP-68. 1 p. mimeo.

LILLY, J. H.

1951. Insecticides for the control of soil insects. Proc. Sixth Ann. Hybrid Corn Industry Research Conference. Amer. Seed Trade Assoc. Pub. 6:53-65.

MoRrison, H. E., and H. H. Crowell

1952. Soil insecticide studies in Oregon. Jour. Econ. Ent. 45:1002-10.

Morrison, H. E., H. H. Crowell, S. E. Crumb, JR., and R. W. Lauderdale

1948. The effects of certain new soil insecticides on plants. Jour. Econ. Ent. 41:374-78.

SLAWSON, H. H.

1954. Effects of insecticides on soil. Agr. Chem. 9:43.

STITT, L. L., and J. Evanson

1949. Phytotoxicity and off-quality of vegetables grown in soil treated with insecticides. Jour. Econ. Ent. 42:614-17.

STONE, M. W.

1949. Control of wireworms in California with the soil fumigants chlorinated propanepropylene and ethylene dibromide. U. S. Bur. Ent. and Pl. Quart. E-786:1-21.

Stone, M. W., and F. B. Foley

1953. Field experiments with insecticides for the control of wireworms in irrigated lands. Jour. Econ. Ent. 46:1075-83.

W ATTS, J. G.

1951. Soil insect control in Southeast by mixtures of pesticides and fertilizers. Agr. Chem. 6:36-38, 115-17. 


\title{
EFFECTS OF SOIL INSECTICIDES ON FLAVOR OF VEGETABLE CROPS ${ }^{1}$
}

\author{
ELIY HINREINER and MARION SIMONE ${ }^{2}$
}

\section{LITERATURE ON SOIL INSECTICIDES}

DURING THE past decade many investigations have been made on the effect of benzene hexachloride on the flavor of food crops. Similar studies with other soil insecticides have also been reported. Because of the quite pronounced "musty" or "earthy" flavor often imparted to foods by benzene hexachloride, its effect on many different crops under widely varied conditions has been readily observed.

This flavor difficulty was one of the prime factors in stimulating research into the effect of other soil insecticides on crop flavor. Even when the dosage level has been as low as $1 / 2$ pound per acre, a number of authors have reported that potatoes and other root crops grown in soil treated with $\mathrm{BHC}$ (technical benzene hexachloride) customarily have a disagreeable flavor when cooked (Gilpin and Geissenhainer, 1953; Dawson, et al., 1953 ; Jameson and Peacock, 1953; Jameson and Tanner, 1951 ; Rusin and Andronova, 1953 ; Maclinn, Reed, and Campbell, 1950 ; Rodriguez and Gould, 1950 ; Greenwood and Tice, 1949; and Stitt and Evanson, 1949).

However, there is disagreement over whether the use of preparations containing higher proportions of the $\gamma$-isomers of benzene hexachloride than in the technical product result in less off-flavor or not. Stitt and Evanson (1949), working with two benzene hexachloride preparations of 37 per cent and 99 per cent $\gamma$-isomer content; Maclinn, Reed, and Campbell (1950), Rodriguez and Gould (1950), and Greenwood and Tice (1949), comparing BHC with lindane (99 per cent or higher $\gamma$-isomer content), all report substantially less off-flavor in crops grown in soils treated with lindane than those treated with $\mathrm{BHC}$.

On the other hand, Jameson and Peacock (1953) found that pure $\gamma$ benzene hexachloride and technical $\gamma$-benzene hexachloride (90 per cent) tainted potatoes to the same degree. Gilpin, et al. (1953) observed musty off-flavors in peanuts grown in soils treated with BHC and with lindane.

In the most thorough study of this question to date, Dawson, et al. (1953) grew potatoes, tomatoes, and lima beans in soils treated with: pure $\alpha-, \beta-, \gamma-$ and $\delta$-isomers of benzene hexachloride; with a mixture of isomers; with commercial lindane; and with BHC. Small differences in degree of off-flavor were noted, but the results varied considerably from crop to crop. The $\gamma$ isomer seemed to cause slightly less off-flavor generally than the $\beta$ - and $\delta$-isomers.

Whether a treated food is consumed fresh or canned further complicates the picture. When 36 varieties of peaches were sprayed with a technical

\footnotetext{
${ }^{1}$ Received for publication April 29, 1955.

${ }^{2}$ Miss Hinreiner was Assistant Professor of Food Technology and Assistant Food Technologist in the Experiment Station, Davis; resigned June 30, 1956; Miss Simone is Senior Laboratory Technician, Department of Food Technology, Davis.
} 
benzene hexachloride preparation no off-flavors in the fresh or frozen fruit were reported by Bailey, Esselen, and Wheeler (1949), but when the same fruit was canned, all but four varieties had detectable off-flavors. Similarly, Cochran and Van Blaricom (1950) found that fewer applications of benzene hexachloride caused an off-flavor when canned peaches were eaten than when they were eaten fresh or frozen.

That this may be due to isomerization or decomposition of the insecticide during thermal processing was suggested by the work of Brittin and Fairing (1950), who added various insecticides to peaches, pears, peas, green beans, and soup in quantities ranging from 0.01 to 10.0 p.p.m. before canning. They found that foods to which small quantities of the 98 per cent $\gamma$-isomer of benzene hexachloride had been added developed a flavor after processing similar to that of the foods treated with the crude preparation.

Another variable affecting the degree of off-flavor in insecticide-treated crops is the amount of time elapsing between the treatment of the soil and the growing, harvesting, or processing of the crop. Most investigators have found a definite off-flavor not only when crops were planted in soil immediately after soil was treated with benzene hexachloride preparations, but also when grown in the soil a year after treatment.

However, the intensity of the off-flavor does diminish with time (Greenwood and Tice, 1949; Maclinn, Reed, and Campbell, 1950; Zweede, 1953). Jameson and Tanner (1951) have even developed a formula expressing "degree of taint" in potatoes as a function of the dosage level (pounds of benzene hexachloride per acre) and the time elapsed since application. They found that at $2 \frac{1}{2}$ pounds per acre benzene hexachloride gave a slight offflavor which became negligible after 30 months had elapsed. At 4 pounds per acre, potatoes grown during the first 18 months thereafter had a decided off-flavor; an occasional taint appeared in the next 18-month period; no offflavors were noted in crops grown after 3 years.

Lindane spray and dust treatments on cucumbers for pickling appeared to cause off-flavor in the pickles only when the insecticide was applied immediately before harvesting (Ditman, et al., 1953).

On the other hand, BHC and lindane applied as dusts to cotton, squash, and cucumbers have been reported to affect adversely the flavor of peanuts and potatoes grown subsequently in the same plots (Reynolds, Gilpin, and Hornstein, 1953; Reid and Cuthbert, 1953).

Turner (1950) has attempted to counteract the persistence of benzene hexachloride in the soil by application of activated charcoal or lime, but none of his methods are economically practical. Similar experiments using activated carbon were reported by Wheeler (1953).

Maclinn, Reed, and Campbell (1950) investigated the persistence of the effect on flavor of various vegetables of a number of soil insecticides. Chlordane gave an off-flavor in the first, but not the second year's crop. Parathion, contrary to normal expectation, gave greater off-flavor in crops the second season after use. Greenwood and Tice (1949) also stated that the presence of off-flavors in chlordane-treated crops was not clearly indicated.

Rodriguez and Gould (1950) grew potatoes and tomatoes in acid and alkaline soil treated with BHC. Experienced judges detected off-flavors in 
the canned vegetables - of greater intensity with $\mathrm{BHC}$ than with lindanebut found no correlation between intensity of off-flavor and $\mathrm{pH}$ of soil.

Less extensive reports have been made on effect on flavor of soil insecticides other than benzene hexachloride. Parathion has been reported responsible for off-flavor in commercial tomato juice (Coetzee, Burger, and Hugo, 1953), in tomatoes (Gould, et al., 1951), and reduced flavor quality in fresh peas, pole beans, and bush beans (Stitt and Evanson, 1949). When used as a spray, however, on citrus fruits and peaches, parathion caused negligible flavor differences, and residue analyses on the fruit gave extremely low figures (Olsen, Stearns, and Hendrickson, 1952; Smith, Jones, and Rigney, 1949; Smith, Jones, and Calvin, 1950 ; Griffiths, Reitz, and Olsen, 1950 ; and Cochran and Van Blaricom, 1950).

The effect of chlordane soil treatments on the flavor of a number of vegetables has been reported. No significant differences were noted with sweet potatoes (Gilpin and Geissenhainer, 1953), white potatoes (Greenwood and Tice, 1949), carrots, peas, beans, or cucumbers (Stitt and Evanson, 1949). Spray treatments on peaches and oranges also gave no noticeable offflavors to fresh, frozen, or canned peaches (Smith, Jones, and Rigney, 1949 ; Smith, Jones, and Calvin, 1950; Cochran and Van Blaricom, 1950) or to orange juice (Griffiths, Reitz, and Olsen, 1950).

Under some conditions spraying with chlordane was reported to have an undesirable effect on the flavor of tomatoes, carrots, potatoes, and lima beans (Gould, et al., 1951).

Rusin and Andronova (1953, 1954) and Gould, et al. (1951) have claimed adverse flavor effects from the use of DDT on various food crops. Generally, however, flavor differences due to use of this insecticide appear to be negligible (Gilpin and Geissenhainer, 1953).

Gilpin, et al. (1953) report that the flavor of peanuts was not affected by soil and foliage dust treatments with dieldrin or aldrin. An enormous amount of flavor-evaluation work has been done on fruits and vegetables treated with these two insecticides and the information has been compiled by the Shell Chemical Corporation (1954), but practically none of these data have been published elsewhere. These insecticides also do not appear to cause serious off-flavors under most conditions of use.

\section{ORGANOLEPTIC TESTS}

Vegetables Tested. The investigations reported here record flavor tests made on canned and fresh carrots and sweet potatoes grown in soils treated with aldrin, BHC, lindane, chlordane, dieldrin, endrin, heptachlor, and isodrin. Fresh white potatoes grown in soils treated by aldrin, dieldrin, endrin, heptachlor, lindane, DDT, and parathion were also tested.

Complete data on the dosage levels, treatments, and handling of the crops are summarized by Lange and Carlson (1956). Residue analyses made on samples of the potatoes and carrots used in the taste experiments are given by Erwin, Miskus, and Hoskins (1956).

Preparation of Samples. Except for the white potatoes, all samples were tested both fresh and at intervals after canning. 
Sweet potatoes were ripened after harvest according to a special schedule of about a month at the Gerber Products Company in Oakland. The samples to be canned were blanched, peeled, and diced. The thoroughly mixed batches of diced potatoes were placed in No. $2 \frac{1}{2}$ eans to a fill weight of $22.0 \pm 0.1$ ounces, and 8 ounces of 1 per cent sodium chloride brine was added before closure and cooking.

The carrots were also canned as dice after first being topped and lyepeeled. The fill weights were $18.5 \pm 0.1$ ounces of carrots plus 10.5 ounces of 1 per cent brine for the 1952 pack, and 19.5 ounces of carrots plus 9 ounces of brine in 1953 and 1954. All of the canning was done in the pilot plant of the Department of Food Technology at Davis. The samples were stored at room temperature for at least one month before testing.

The flavor analyses were performed by panels of selected judges in the manner described by Hinreiner and Simone (1956) for testing acaricidetreated fruits and nuts. It was necessary to cook the fresh vegetables, of course, before serving. Carrots were scraped, sliced, and cooked until soft in a small (and uniform) amount of salted water. They were served hot with a little of the cooking liquid accompanying each sample. Potatoes, both white and sweet, were baked in their skins; the insides were scooped out, mashed without the addition of salt or butter, and served hot. The canned vegetables were also warmed before tasting and served with some of the hot can liquid. It was not considered necessary to further subdivide the diced vegetables by passing them through a food grinder, as in the case of the pears and peaches.

In several cases a whole spectrum of different dosage levels of the same insecticide-treated vegetable was available from the entomological experiments, and time was too limited to taste all of them. It was the usual practice-once a given treatment had been found not to differ significantly from the control sample-to assume that no lower dosages of the same chemical would influence flavor. Nor were dosages tested at levels higher than that found to give a statistically significant difference in taste.

\section{DISCUSSION OF RESULTS}

Unfortunately, the many variables involved in an experiment of this kind make it impossible to conclude from the data obtained precisely which dosage levels of a given insecticide are "safe" and which are likely to give undesirable flavors. Too much depends upon the soil type, irrigation practices, the particular crop, whether it is eaten fresh or canned, sensitivity of the taster, and many other factors. The experimenter can only consider the average performance of an insecticide during the course of many trials as a basis for predicting its tendency to cause flavor problems.

The data of these experiments clearly confirm the verdict of most other investigators with respect to BHC. Even at the fairly low dosage level of $1 / 2$ pound per acre it caused severe off-flavors in canned carrots and sweet potatoes. The off-flavors were less intense in the fresh vegetables, but still noticeable to a significant number of judges (tables 1 and 2).

Lindane also caused off-flavors in canned vegetables. At 1 pound per acre, 
TABLE 1

RESULTS OF TRIANGULAR TESTS FOR OFF-FLAVORS IN CARROTS GROWN IN INSECTICIDE-TREATED SOILS, 1952, 1953, 1954

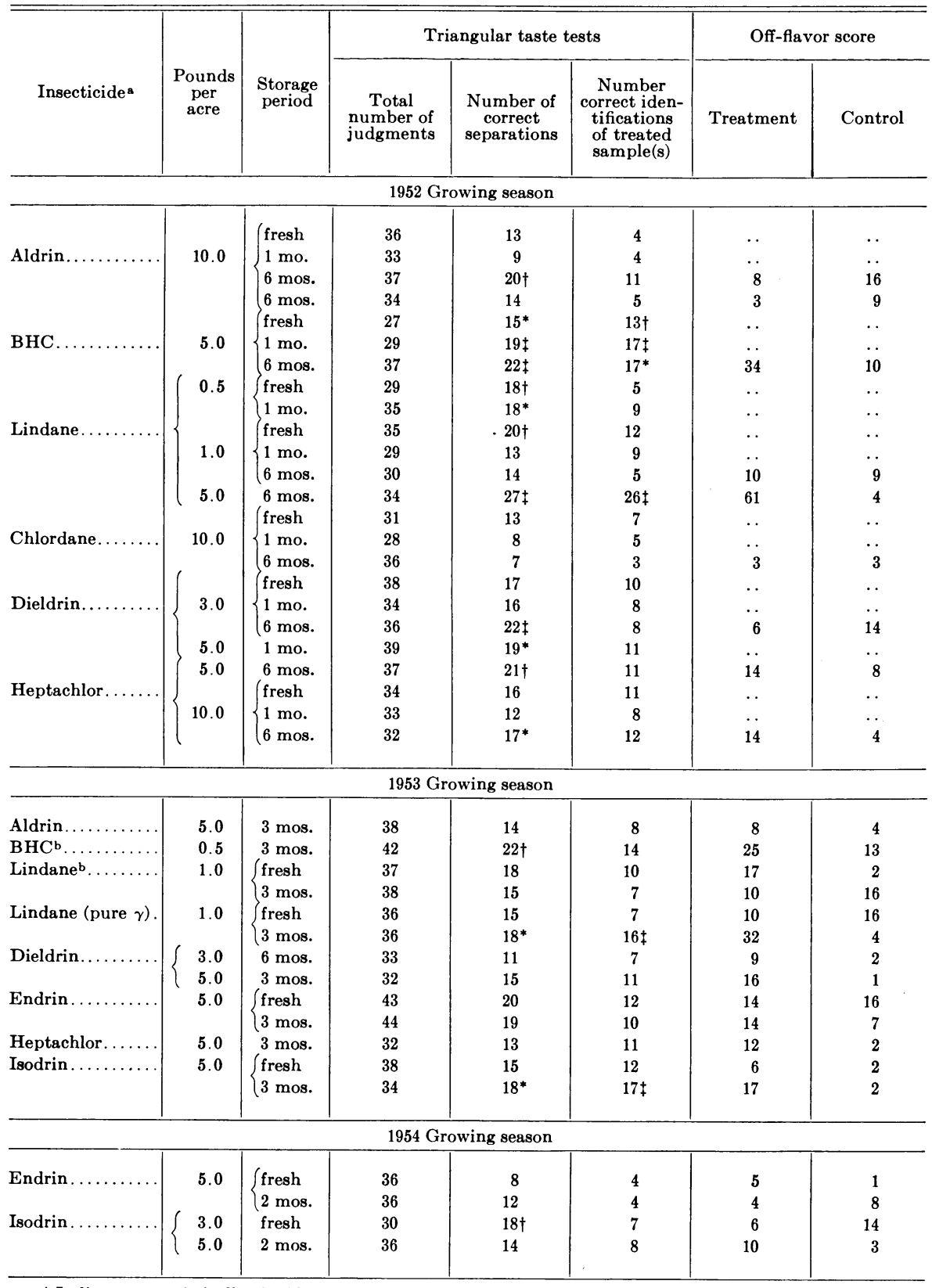

* Indicates a statistically significant result at the 95 per cent probability level.

t Indicates a statistically significant result at the 99 per cent probability level.

† Indicates a statistically significant result at the 99.9 per cent probability level.

a For dates of treatment, planting, harvesting and canning, see Lange and Carlson (1956), table 2.

b Treatment applied to soil in 1952 . 
TABLE 2

RESULTS OF TRIANGULAR TESTS FOR OFF-FLAVORS IN SWEET POTATOES GROWN IN INSECTICIDE-TREATED SOILS, 1952, 1953, 1954

\begin{tabular}{|c|c|c|c|c|c|c|c|}
\hline \multirow[b]{2}{*}{ Insecticide ${ }^{\mathbf{a}}$} & \multirow[b]{2}{*}{$\begin{array}{l}\text { Pounds } \\
\text { per } \\
\text { acre }\end{array}$} & \multirow[b]{2}{*}{$\begin{array}{c}\text { Storage } \\
\text { period }\end{array}$} & \multicolumn{3}{|c|}{ Triangular taste tests } & \multicolumn{2}{|c|}{ Off-flavor score } \\
\hline & & & $\begin{array}{c}\text { Total } \\
\text { number of } \\
\text { judgments }\end{array}$ & $\begin{array}{l}\text { Number of } \\
\text { correct } \\
\text { separations }\end{array}$ & $\begin{array}{c}\text { Number } \\
\text { correct iden- } \\
\text { tifications } \\
\text { of treated } \\
\text { sample(s) }\end{array}$ & Treatment & Control \\
\hline \multicolumn{8}{|c|}{1952 Growing season } \\
\hline \multirow{5}{*}{ Aldrin...$\ldots \ldots \ldots$} & 5.0 & Fresh & 30 & 15 & 9 & .. & .. \\
\hline & & Fresh & 40 & 19 & 8 & . & .. \\
\hline & 10.0 & $\{1 \mathrm{mo}$. & 30 & 9 & 4 & 7 & 8 \\
\hline & & $6 \mathrm{mos}$ & 30 & 12 & 4 & 3 & 8 \\
\hline & & Fresh & 36 & $19^{*}$ & 7 & .. & .. \\
\hline \multirow[t]{5}{*}{ BHC............ } & 0.5 & $\{1 \mathrm{mo}$. & 35 & $26 \ddagger$ & $24 \ddagger$ & 76 & 2 \\
\hline & & $6 \mathrm{mos}$ & 36 & $23 \ddagger$ & $20 \ddagger$ & 38 & 1 \\
\hline & 2.5 & Fresh & 31 & $22 \ddagger$ & $16^{*}$ & . & .. \\
\hline & & Fresh & 35 & $18^{*}$ & 9 & . & . \\
\hline & 0.5 & $\{1 \mathrm{mo}$. & 30 & $18 \dagger$ & $15 \dagger$ & 36 & 6 \\
\hline \multirow[t]{5}{*}{ Lindane......... } & & $6 \mathrm{mos}$ & 41 & $22 \dagger$ & 13 & 29 & 18 \\
\hline & 1.0 & Fresh & 36 & 11 & 6 & . & . \\
\hline & & $1 \mathrm{mo}$ & 38 & $21 \dagger$ & $19 \ddagger$ & 52 & 4 \\
\hline & 10.0 & $6 \mathrm{mos}$ & 37 & 9 & 4 & 0 & 7 \\
\hline & & Fresh & 35 & 14 & 4 & . & .. \\
\hline \multirow[t]{4}{*}{ Chlordane........ } & 20.0 & $1 \mathrm{mo}$ & 37 & 16 & 8 & 13 & 16 \\
\hline & & $6 \mathrm{mos}$. & 32 & $17^{*}$ & 11 & 12 & 5 \\
\hline & & $6 \mathrm{mos}$. & 31 & $16^{*}$ & $12^{*}$ & 13 & 4 \\
\hline & 3.0 & $1 \mathrm{mo}$ & 35 & 11 & 6 & 8 & 7 \\
\hline \multirow[t]{4}{*}{ Dieldrin. } & & $(1 \mathrm{mo}$ & 35 & $19 \dagger$ & 11 & 18 & 10 \\
\hline & 5.0 & $\{6 \mathrm{mos}$ & 31 & 9 & 7 & 16 & $\mathbf{0}$ \\
\hline & & $6 \mathrm{mos}$ & 37 & 14 & 8 & 10 & 4 \\
\hline & & Fresh & 34 & 16 & 7 & .. & .. \\
\hline \multirow[t]{2}{*}{ Heptachlor....... } & 10.0 & $\{1 \mathrm{mo}$ & 36 & 15 & 10 & 16 & 8 \\
\hline & & $6 \mathrm{mos}$ & 37 & 13 & 7 & 7 & 5 \\
\hline
\end{tabular}

1953 Growing season

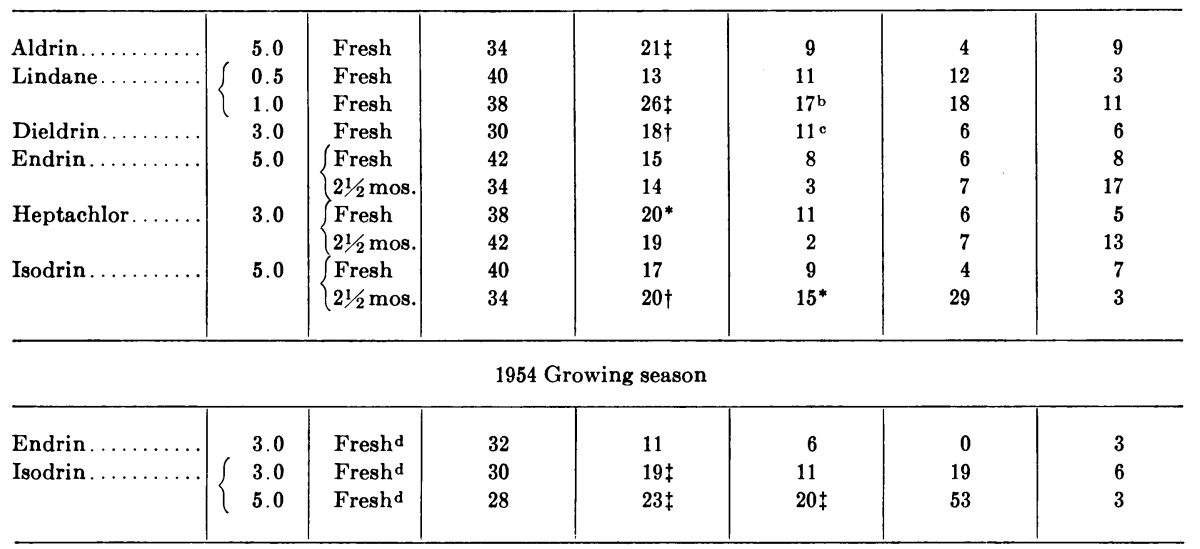

* $t$ t See footnotes, table 1.

a For lates of treatment, planting, harvesting and canning, see Lange and Carlson (1956), table 2.

b Noti seable difference in color between sample and control.

c Noticeable difference in sweetness between sample and control.

d Sweet potatoes were not canned in 1954 . 
even though the pure $\gamma$-isomer (99.9 per cent) was used, fresh white potatoes were significantly off-flavored, but the fresh sweet potato and carrot samples treated with lindane, though they sometimes were significantly different from the controls, exhibited no undesirable flavors. There did not seem to be any appreciable advantage to using the 99.9 per cent pure $\gamma$-isomer preparation over ordinary lindane. For canned sweet potatoes at least, lindane was

TABLE 3

RESULTS OF TRIANGULAR TESTS FOR OFF-FLAVORS IN FRESH WHITE POTATOES GROWN IN INSECTICIDE-TREATED SOILS,

1953 AND 1954

\begin{tabular}{|c|c|c|c|c|c|c|c|}
\hline \multirow[b]{2}{*}{ Insecticide ${ }^{\mathrm{a}}$} & \multirow[b]{2}{*}{$\begin{array}{l}\text { Pounds } \\
\text { per } \\
\text { acre }\end{array}$} & \multirow[b]{2}{*}{$\begin{array}{l}\text { Storage } \\
\text { period }\end{array}$} & \multicolumn{3}{|c|}{ Triangular taste tests } & \multicolumn{2}{|c|}{ Off-flavor score } \\
\hline & & & $\begin{array}{c}\text { Total } \\
\text { number of } \\
\text { judgments }\end{array}$ & $\begin{array}{l}\text { Number of } \\
\text { correct } \\
\text { separations }\end{array}$ & $\begin{array}{l}\text { Number } \\
\text { correct iden- } \\
\text { tifications } \\
\text { of treated } \\
\text { sample(s) }\end{array}$ & Treatment & Control \\
\hline
\end{tabular}

1953 Growing season

\begin{tabular}{|c|c|c|c|c|c|c|c|}
\hline Aldrin $\ldots . . \ldots \ldots$ & 5.0 & $\ldots$ & 48 & 20 & 9 & 9 & 13 \\
\hline Dieldrin ......... & 3.0 & $\ldots$ & 40 & 18 & 10 & 12 & 8 \\
\hline Endrin .......... & 3.0 & $\ldots$ & 40 & $21^{*}$ & 12 & 12 & 7 \\
\hline Lindane (pure $\gamma$ ). & 1.0 & $\ldots$ & 30 & $18 \ddagger$ & $15 \ddagger$ & 26 & 5 \\
\hline DDT $\ldots \ldots \ldots \ldots$ & 10.0 & $\ldots$ & 42 & 20 & 10 & 9 & 15 \\
\hline
\end{tabular}

1954 Growing season

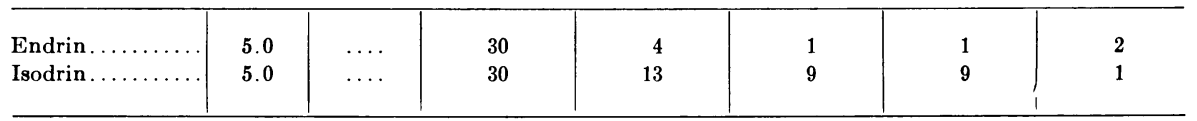

* $\ddagger$ See footnotes, table 1 .

- For dates of treatment, planting, and harvesting, see Lange and Carlson (1956), table 2.

a negligible improvement over technical benzene hexachloride. The off-flavors seemed to be slightly less objectionable, but not enough to warrant the use of lindane on vegetables to be canned.

A single experiment was made to test the persistence of lindane and benzene hexachloride in the soil after a year had elapsed between application and growing. In this experiment, soils were treated with benzene hexachloride at $1 / 2$ pound per acre and with lindane at 1 pound per acre in 1952, and carrots were grown in both the 1952 and 1953 seasons. The first year's crop was decidedly off-flavored in both instances. The second year's crop from the soil treated with BHC had about as serious an off-flavor as the first year's, but the carrots from lindane-treated soil a year after treatment did not seem to be appreciably affected by the pesticide.

Neither aldrin nor dieldrin was observed to present flavor problems in these experiments when used at reasonable dosages. Even when used at 10 pounds per acre there is only one instance in which the data show a significant difference in flavor between an aldrin-treated sample and a control (sweet potatoes, canned 6 months), and this seems to be an accident since a 
re-evaluation did not confirm the first result (see table 2). A similar phenomenon occurred with dieldrin at 3 pounds per acre, except that here there was clearly no off-flavor involved, since if anything, the treated sweet-potato sample was preferred (see table 2). However, a repetition of this tasting also failed to confirm the finding of a difference. At 5 pounds per acre, under some conditions, carrots and sweet potatoes grown in dieldrin-treated soil showed statistically significant flavor differences in the treated samples. The taint was slight, however, and would probably not be noticed by uncritical tasters in a normal meal situation.

None of the three root crops grown in soil treated with endrin at 5 pounds per acre were affected in flavor when tasted as either fresh or canned. Isodrin-treated fresh sweet potatoes, in 1954, and canned sweet potatoes and canned carrots, in 1953, however, had a detectably different and apparently undesirable flavor to the panel (tables 1 and 2). Somewhat surprisingly, fresh white potatoes grown in soil treated with this pesticide seemed to be affected very little, if at all (table 3 ).

Chlordane and heptachlor, even at the relatively high levels of 20 and 10 pounds per acre, did not produce serious flavor difficulties on the crops tested. A tendency for slight off-flavors to develop after storage of the canned product for 6 months or longer was noticed, but even in this case the intensity of flavor difference did not appear to be serious enough to warrant much concern.

DDT and parathion were tested on white potatoes in the 1953 season only. In neither case was there any significant difference in flavor between the treated and control potatoes when eaten fresh (table 3 ).

\section{ACKNOWLEDGMENT}

The writers wish to express their sincere appreciation to Mr. Sherman Leonard, Associate Specialist in the Department of Food Technology, and to the members of his staff, for their processing of the carrot samples used in these tests.

\section{LITERATURE CITED}

BAILEy, J. S., W. B. Esselin, JR., and E. H. WheELER

1949. Off-flavors in peaches sprayed with benzene hexachloride. Jour. Econ. Ent. 42: 774-76.

Brittin, W. A., and J. D. FAIRING

1950. Insecticides in canned foods. Assoc. Off. Agr. Chem. Jour. 33:599-607.

Cochran, J. H., and L. O. VAN Blaricom

1950. Insecticides vs. flavor. Food Packer 31:30-31, 59, 61-62, 64.

Coetzee, W. H. K., I. J. Burger, and J. F. DU T. Hugo

1953. Foreign taste in tomato juice caused by parathion sprays on plants. Farming in So. Africa 28:298.

Dawson, F. H., G. L. Gilpin, M. F. Kirkpatrick, and C. A. Weigel

1953. Flavor of selected vegetables grown in soil treated with isomers of benzene hexachloride. Jour. Agr. Food Chem. 1:399-403.

Ditman, L. P., F. C. Stark, C. E. Cox, and H. S. Todp

1953. Spraying and dusting for pickles. Canning Trade 75:7-8.

ERwin, W. R., R. P. Miskus, and W. M. Hoskins

1956. Harvest residues of insecticides in vegetable and field crops resulting from foliage and soil application. Hilgardia 26:86-106. 
Gilpin, G. L., E. H. Dawson, E. L. Geissenhainer, and E. H. Reynolds

1953. Flavor of peanuts and peanut products as affected by certain insecticides used in growing peanut crops. Food Technol. 7:132-35.

Gilpin, G. L., and E. L. Geissenhainer

1953. Flavor of sweet potatoes as affected by certain agricultural chemicals used as insecticides. Food Technol. 7:137-38.

Gould, W. A., J. P. Sleesman, R. W. Rings, M. Lynn, F. Krantz, and H. D. Brown

1951. Flavor evaluations of canned fruits and vegetables treated with newer organic insecticides. Food Technol. $5: 129-33$.

Greenwood, M. L., and J. M. Tice

1949. Palatability tests on potatoes grown in soil treated with the insecticides benzene hexachloride, chlordane, and chlorinated camphene. Jour. Agr. Res. 78:477-82.

Griffiths, J. T., JR., H. J. Reitz, and R. W. Olsen

1950. Off-flavors produced in Florida orange juice after application of new organic pesticides. Agr. Chemicals 5:41-43, 99.

Hinreiner, E., and M. Simone

1956. Effects of acaricides on flavor of almonds and canned fruits. Hilgardia 26:35-45.

JAmeson, H. R., and C. C. TANNER.

1951. Taint in potatoes grown on land treated with crude benzene hexachloride against wireworm. Jour. Sci. Food Agr. 2:171-75.

JAmeson, H. R., and F. C. PEACoCK

1953. Taint in potatoes grown on land treated with technical $\gamma$-benzene hexachloride or pure $\gamma$-benzene hexachloride. Jour. Sci. Food Agr. 4:102-4.

Lange, W. H., and E. C. Carlson

1956. Residual soil insecticides for the control of wireworms affecting vegetable crops. Hilgardia $26: 60-75$.

Maclinn, W. A., J. P. Reed, and J. C. Campbell

1950. Flavor of potatoes as influenced by organic insecticides. Amer. Potato Jour. 27 : 207-13.

Olsen, R. W., C. R. Stearns, JR., and R. Hendrickson

1952. Examination of citrus juices processed from parathion-sprayed fruit. Food Technol. 6:350-51.

ReID, W. J., JR., and F. P. Cuthbert, JR.

1953. Tests of insecticides for control of the pickleworm and associated insects on cucumbers and squash-1948-51. U. S. Bur. Ent. and Pl. Quarantine. E-856:1-34.

Reynolds, H., G. L. Gilsin, and I. Hornstein

1953. Palatability and chemical studies on peanuts grown in rotation with cotton dusted with insecticides containing benzene hexachloride. Jour. Agr. Food Chem. $1: 772-76$.

Rodriguez, J. G., and W. A. Gould

1950. Effect of technical benzene hexachloride and lindane on the flavor of tomatoes and potatoes. Jour. Econ. Ent. 43:498-503.

Rusin, N. M., and G. P. Androvna

1953. Organoleptic properties of food products treated with DDT or benzene hexachloride. Gigiena i Sanit. 2:27-32.

1954. Hygienic evaluation of food products treated with benzene hexachloride or DDT. Gigiena i Sanit. 6:34-99.

Shell Chemical Corporation

1954. Agricultural handbook for aldrin and dieldrin. Denver, Colo. Mimeo.

Smith, C. F., I. D. Jones, and J. A. Rigney

1949. Effect of insecticides on the flavor of peaches-1948. Jour. Econ. Ent. 42:61823.

Smith, C.F., I. D. Jones, and L. D. Calvin

1950. Effect of insecticides on the flavor of peaches-1949. Jour. Econ. Ent. 43:17981.

STITT, L. L., and J. Evanson

1949. Phytotoxicity and off-quality of vegetables grown in soil treated with insecticides. Jour. Econ. Ent. 42:614-17. 
TURNer, $\mathrm{N}$.

1950. Counteracting the effect of benzene hexachloride on flavor of potatoes. Jour. Econ. Ent. 43:109.

WHEELER, N. W.

1953. Activated carbon and the lowly potato. Taste and Odor Control Jour. 19:1-4.

ZWEEDE, A. K.

1953. Flavor changes following the use of insecticides. Mededelingen van het Instituut voor Bewaring en Verwerking van Tuinbouw-producten-Wageningen (Nederland) $16: 349-56$. 


\title{
HARVEST RESIDUES OF INSECTICIDES IN VEGETABLE AND FIELD CROPS RESULTING FROM FOLIAGE AND SOIL APPICATION ${ }^{1}$
}

\author{
W. R. ERWIN, R. P. MISKUS, and W. M. HOSKINS ${ }^{2}$
}

REsidues of insecticides on vegetables and forage crops may result not only from direct application, which usually gives chiefly surface contamination, but also from treatment of the soil either before or after planting time. Absorption of these chemicals will give rise to internal contamination. Since much of the material intended for application to the aerial part of the plant actually reaches the soil and may be carried to the roots during subsequent irrigation or cultivation, it is very important to determine the total contamination of truck and field crops whenever insecticides have been used in any manner.

This report covers work on residues resulting from field applications from the 1951 to 1954 seasons (Lange and Carlson, 1956) with a few data from earlier soil treatments. For convenience, the results are divided according to whether application was made to the growing plants or to the soil, including seed treatment in the latter eategory. Flavor evaluations on many samples grown in 1952 and 1953 were made by the taste panel of the Department of Food Technology at Davis (Hinreiner and Simone, 1956).

\section{NAMES AND FORMULAS OF INSECTICIDES TESTED}

The names and formulas of all insecticides are collected in table 1, together with reference to the analytical methods described later in this report.

The insecticides fall into four general groups:

1. DDT and related compounds

2. Benzene hexachloride technical and relatively pure gamma isomer 3. The polycyclical chlorinated hydrocarbons of the chlordane family 4. Organic phosphates of two general types

\section{METHODS OF EXTRACTION, PURIFICATION, and ANALYSIS}

Purification and Extraction. To remove adhering soil which might contain much insecticide, samples of all root crops and others that grow largely underground-for example asparagus-were very carefully scrubbed with a firm brush in a warm solution of Labtone detergent and then rinsed in clear warm water before chopping in a Buffalo chopper. The extraction of all contaminating insecticide from plant material necessitates preliminary subdivision to a fine state and use of a single-phase solvent that makes genuine contact with the watery tissues. A 50:50 mixture of benzene and ethyl alcohol has been successful with most insecticides and was used in a

\footnotetext{
${ }^{1}$ Received for publication April 29, 1955.

${ }^{2} \mathrm{Mr}$. Erwin is Principal Laboratory Technician in Entomology and Parasitology at Berkeley; Mr. Miskus is Senior Laboratory Technician in Entomology and Parasitology at Berkeley; Mr. Hoskins is Professor of Entomology and Chemist in the Experiment Station, Berkeley.
} 


\section{TABLE 1}

\section{COMMON OR TRADE NAMES, CHEMICAL NAMES, AND FORMULAS OF INSECTICIDES USED IN THESE STUDIES}

All materials used were commerical products

\begin{tabular}{|c|c|c|}
\hline $\begin{array}{l}\text { Com- } \\
\text { pound } \\
\text { number }\end{array}$ & Chemical name and formula & $\begin{array}{l}\text { Residue } \\
\text { analysis } \\
\text { method } \\
\text { number }\end{array}$ \\
\hline 1 & 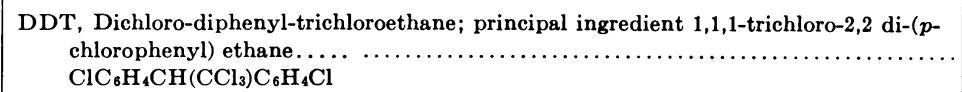 & 1 \\
\hline 2 & $\begin{array}{l}\text { Perthane (Q-137), Di-( } p \text {-ethyl phenyl) dichloroethane; principal ingredient 1,1, Dichloro- } \\
2,2-(p \text {-ethyl phenyl) ethane } \ldots \ldots \ldots \ldots \ldots \ldots \ldots \ldots \ldots \ldots \ldots \ldots \ldots \ldots \ldots \ldots \ldots \ldots \ldots \ldots \ldots \ldots \ldots \ldots \ldots\end{array}$ & 6 \\
\hline 3 & 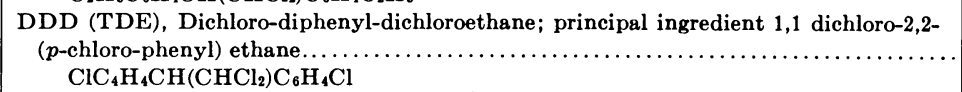 & 1 \\
\hline 4 & 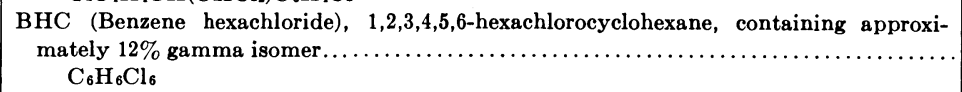 & 5 or 6 \\
\hline 5 & $\begin{array}{l}\text { Lindane (gamma isomer of benzene hexachloride), one of the geometric isomers of BHC. } \\
\quad \mathrm{C}_{6} \mathrm{H}_{6} \mathrm{Cl}_{6}\end{array}$ & 5 or 6 \\
\hline 6 & 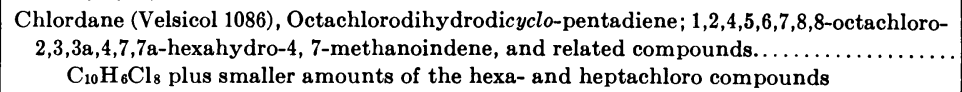 & 6 \\
\hline 7 & $\begin{array}{l}\text { Heptachlor, } 1,4,5,6,7,8,8 \text {-heptachloro-3a,4,7,7a-tetrahydro- } 4,7 \text { methanoindene (about } 67 \text { per } \\
\text { cent), plus related compounds } \ldots \ldots \ldots \ldots \ldots \ldots \ldots \ldots \ldots \ldots \ldots \ldots \ldots \ldots \ldots \ldots \ldots \ldots \\
\mathrm{C}_{10} \mathrm{H}_{5} \mathrm{Cl}_{7}\end{array}$ & 6 \\
\hline 8 & $\begin{array}{l}\text { Aldrin (Compound 118) } 1,2,3,4,10,10 \text {-hexachloro-1,4,4a,5,8,8a-hexahydro-1: } 4,5: 8 \text {-endo-exo- } \\
\text { dimethanonaphthalene } \ldots \ldots \ldots \ldots \ldots \ldots \ldots \ldots \ldots \ldots \ldots \ldots \ldots \ldots \ldots \ldots \ldots \ldots \ldots \ldots \ldots \\
\mathrm{C}_{12} \mathrm{H}_{8} \mathrm{Cl}_{8}\end{array}$ & 5 or 6 \\
\hline 9 & 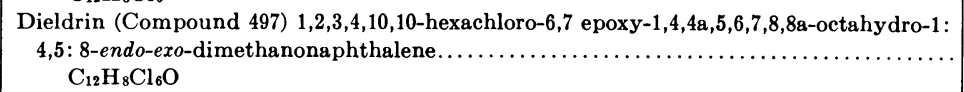 & 6 \\
\hline 10 & $\begin{array}{l}\text { Isodrin }-\mathrm{A} \text { geometrical isomer of aldrin } \ldots \ldots \ldots \ldots \ldots \ldots \ldots \ldots \ldots \ldots \ldots \ldots \ldots \ldots \ldots \ldots \ldots \ldots \ldots \ldots \\
\quad \mathrm{C}_{12} \mathrm{H}_{8} \mathrm{Cl}_{6}\end{array}$ & 6 \\
\hline 11 & $\begin{array}{l}\text { Endrin }-\mathrm{A} \text { geometrical isomer of dieldrin } \ldots \ldots \ldots \ldots \ldots \ldots \ldots \ldots \ldots \ldots \ldots \ldots \ldots \ldots \ldots \ldots \ldots \ldots \ldots \ldots \ldots \\
\quad \mathrm{C}_{12} \mathrm{H}_{8} \mathrm{Cl}_{6} \mathrm{O}\end{array}$ & 6 \\
\hline 12 & 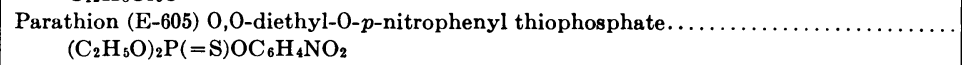 & 2 \\
\hline 13 & $\begin{array}{l}\text { Metacide-methyl parathion, O, O-dimethyl-0-p-nitrophenyl thiophosphate..................... } \\
\quad\left(\mathrm{CH}_{3} \mathrm{O}\right)_{2} \mathrm{P}(=\mathrm{S}) \mathrm{OC}_{6} \mathrm{H}_{4} \mathrm{NO}_{2}\end{array}$ & 2 \\
\hline 14 & $\begin{array}{l}\text { Malathion (4049), S-(1, 2-dicarboxy ethyl)-0, 0-dimethyl dithiophosphate...................... } \\
\quad\left(\mathrm{CH}_{3} \mathrm{O}\right)_{2} \mathrm{P}(=\mathrm{S}) \mathrm{SCH}\left[\mathrm{C}(=\mathrm{O}) \mathrm{OC}_{2} \mathrm{H}_{5}\right] \mathrm{CH}_{2} \mathrm{C}(=\mathrm{O}) \mathrm{OC}_{2} \mathrm{H}_{5}\end{array}$ & 3 \\
\hline 15 & 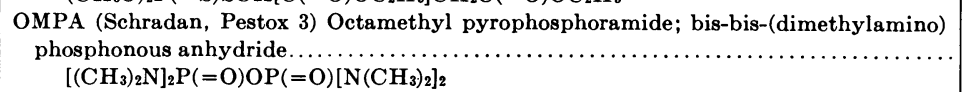 & 4 \\
\hline 16 & $\begin{array}{l}\text { Ethylene dibromide } \\
\quad \mathrm{BrCH}_{2}-\mathrm{CH}_{2} \mathrm{Br}\end{array}$ & \\
\hline 17 & $\begin{array}{l}\text { D-D mixture } \\
\text { and 1,2-dichloropropane } \\
\mathrm{ClCH}_{2} \mathrm{CHClCh} \mathrm{HCH}_{3} \text { and } \\
\mathrm{ClCH}=\mathrm{CHCH}_{2} \mathrm{Cl}\end{array}$ & \\
\hline 18 & $\begin{array}{l}\text { Toxaphenea, chlorinated camphene, containing } 67-69 \text { per cent chlorine. Approximate em- } \\
\text { pirical formula: } \\
\quad \mathrm{C}_{10} \mathrm{H}_{10} \mathrm{Cl}_{8} \\
\text { EPN } \\
\quad \mathrm{C}_{2} \mathrm{H}_{5} \mathrm{OP}(=\mathrm{S})\left[\mathrm{OC}_{6} \mathrm{H}_{4} \mathrm{NO}_{2}\right] \mathrm{C}_{6} \mathrm{H}_{5}\end{array}$ & \\
\hline
\end{tabular}

a Insecticide mentioned in report on field trials with soil insecticides (Lange and Carlson, 1956), but not included in residue analyses. 
volume approximately twice that of the chopped vegetables in all the 1952 , 1953, and 1954 analyses. However, a few insecticides such as malathion, for example, require substitution of carbon tetrachloride for the benzene. In the analyses made before 1952 benzene or petroleum ether was often used without the alcohol.

For methods of extraction, recovery of solvent, storage of extracts, purification, efficiency of recovery, and calculation of contamination, refer to report on residual acaricides on fruit (Miskus, Erwin, and Hoskins, 1956).

Analysis. The analytical methods used may be described briefly as follows:

1. DDT, DDD. The Schechter-Haller (1945) colorimetric procedure involves strong nitration, reduction and coupling with a strong base to give a blue color read at $596 \mathrm{~m} \mu$.

2. Parathion, metacide. The Averell-Norris (1948) method involves passing the benzene extract through a clay column to remove interfering impurities, reducing the nitro group to amine, diazotizing with sodium nitrite and coupling with $\mathrm{N}$-(1-naphthyl)-ethylene diamine to give a magenta color read at $520 \mathrm{~m} \mu$. This was modified by omitting passage through the column and reducing with zinc and hydrochloric acid in cyclohexane. The reduced insecticide is water-soluble and interfering impurities remain in the cyclohexane.

3. Malathion. The American Cyanamid Company's (1954a) method consists of hydrolysis in alkali to dimethyl dithiophosphate which reacts with copper to give a yellow color read at $418 \mathrm{~m} \mu$.

4. OMPA. The method of Allen (1940), modified by Ripper, et al. (1950), involves digestion of extract with perchloric acid and production of blue color, by addition of amidol and ammonium molbydate, read at $600 \mathrm{~m} \mu$.

5. Aldrin, $\mathrm{BHC}$, lindane. The extract in petroleum ether is passed through a clay column which holds back naturally occurring organic chlorine compounds. After evaporation of the eluting solvent, the aldrin is burned in a quartz tube, the volatile chloride caught in alkali and determined amperimetrically by titration with standard silver solution (Agazzi, Peltors, and Brooks, 1953).

6. Chlordane, heptachlor, aldrin, dieldrin, isodrin, endrin, perthane, and in most instances BHC and lindane, were determined by the bioassay procedure of Hoskins, et al. (1952) which uses houseflies exposed to the toxicant spread on the interior surface of a small vial.

In all cases tests were made with produce from untreated plots in order to allow for false readings due either to the reagents or interfering substances in the samples. The small corrections have been applied as indicated in the tables.

In all bioassays, the minimum contamination detectable has been calculated from the LD-50 value, even though smaller amounts were calculated from the observed mortalities by reference to the standard curve. Except for some early results-for example, lindane on celery-these are all called 0.05 p.p.m. in the "corrected" column since this figure corresponds in general to the contamination that resulted in 50 per cent mortality with the toxicants determined by bioassay. In some cases the flies showed visible distress, but either recovered or suffered too low mortality to permit calculation of nu- 
merical contamination. Such cases have been called less than 0.05 p.p.m. but are starred (*) in the "apparent" column to indicate that some toxicant was found. The limiting sensitivity for chlordane has been taken as 0.2 p.p.m. The sensitivity of the chemical method for aldrin is less than that of bioassay and is about 0.1 p.p.m., which is also the sensitivity for OMPA by phosphate analysis.

\section{RESULTS}

Insecticides Applied to Plants. Residues resulting from application directly to plants are shown in table 2 . These data may be treated briefly since the produce was not taste-tested. Fairly high initial deposits of lindane from application of 1.5 per cent dusts (11.0 p.p.m. on broccoli, 3.1 p.p.m. on cabbage) dropped to $0.2-0.3$ p.p.m. after 9 days and to less than 0.1 p.p.m. in 17 days. The same dust gave an initial deposit of 1.5 to 2.0 p.p.m. on celery, which dropped to less than 0.1 p.p.m. in 7 days. Individual spraying of artichoke plants to secure a heavy coverage led to 0.9 p.p.m. residual lindane on the partly formed heads 12 days later and 0.1 p.p.m. after 24 days.

Application of 3 per cent heptachlor, 3 per cent aldrin, or 1.5 per cent dieldrin dusts to ripe tomatoes in no case gave over 0.05 p.p.m. initial deposit. This is in conformity with the usual experience that dusts adhere very poorly to ripening tomatoes.

On 3 varieties of melon (Persian, Crenshaw, and Honeydew), residual dieldrin from either 1.5 per cent dust or dilute emulsion spray in no case exceeded 0.1 p.p.m. in the flesh after 26 to 41 days, but the outer $1 / 8$-inch rind had 0.2 to 0.4 p.p.m. indicating considerable persistence without penetration into the fruit.

A 2 per cent parathion dust gave initial deposits of 0.7 to 2.8 p.p.m. on partly formed artichoke heads and 0.9 p.p.m. on small Brussels sprouts. These all dropped to less than 0.1 p.p.m. within two weeks. Approximately the same change occurred with metacide (methyl parathion) deposits on Brussels sprouts. The rapid disappearance of parathion deposits is well illustrated by artichoke foliage upon which an initial deposit of 9.0 to 17.7 p.p.m. dropped to 0.3 p.p.m. or less within 9 days. A 2 per cent parathion dust left 0.9 p.p.m. on spinach picked and canned 5 days after application but less than 0.05 p.p.m. after 17 days.

Malathion from 4 per cent dust on artichokes was barely detectable (less than 0.2 p.p.m.) after 2 days; and a heavy initial deposit on cabbage (9.6 p.p.m.) dropped to 0.6 p.p.m. in 5 days. On honeydew melons no malathion was detectable after 37 days, as was to be expected.

Initial chlorthion deposit of 0.8-1.2 p.p.m. upon artichokes dropped in 9 days to 0.05 p.p.m. or less.

Fourteen days after application of the systemic phosphate OMPA to Brussels sprouts the residue was 8.3 p.p.m. and after 21 days it was 2.1 p.p.m. and barely detectable after 44 days. One week after sugar beets were sprayed with OMPA emulsion, the whole plant had 0.5 p.p.m. residue but less than 0.1 p.p.m. in the root. 


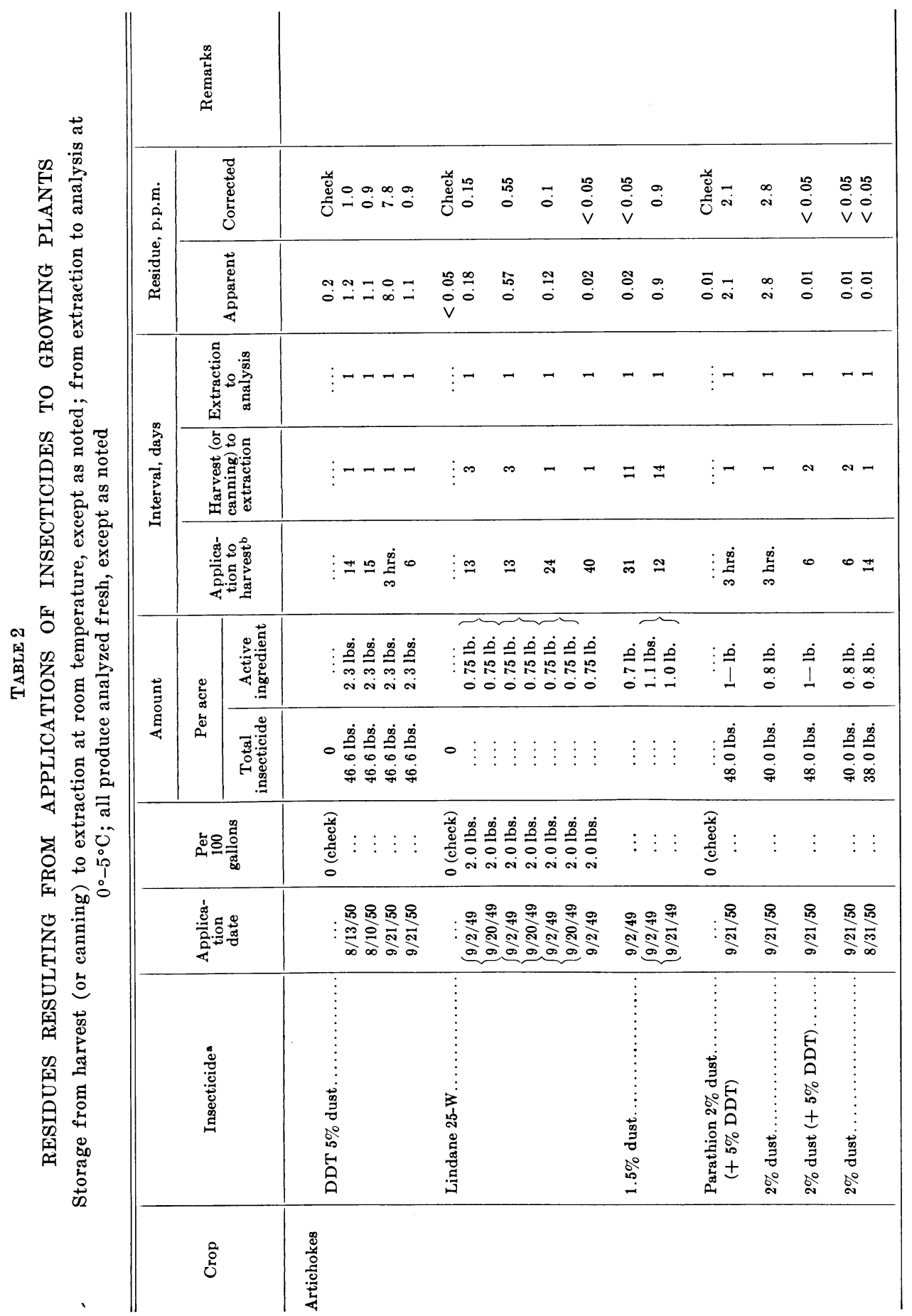




\begin{tabular}{|c|c|c|c|c|c|c|c|c|c|c|}
\hline $\begin{array}{l}\stackrel{2}{0} \\
0 \\
v\end{array}$ & $\stackrel{+0}{-0}$ & $\stackrel{8}{0}$ & $\begin{array}{l}\stackrel{8}{0} \\
\dot{0} \\
V\end{array}$ & $\stackrel{\infty}{0}$ & 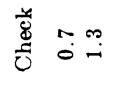 & 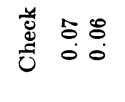 & 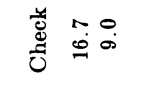 & 总 & 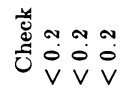 & 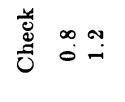 \\
\hline$\ddot{0}$ & $\stackrel{+}{-1}$ & $\stackrel{5}{0}$ & $\begin{array}{l}\ddot{0} \\
0 \\
0\end{array}$ & $\stackrel{8}{0}$ & 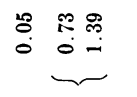 & $\begin{array}{lll}\approx & 0 & 0 \\
0 & 0 & 0 \\
0 & 0\end{array}$ & 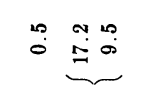 & $\underbrace{m} \underbrace{\infty}_{0} \begin{array}{ll}\infty & 0 \\
0 & 0\end{array}$ & $\begin{array}{llll}\sim & 0 & 0 & \pm \\
0 & 0 & 0 & 0 \\
V & 0 & 0\end{array}$ & 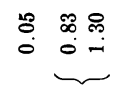 \\
\hline$\infty$ & 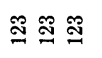 & 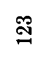 & $\cong$ & $\cong$ & $\stackrel{\infty}{=}$ & $\vdots \cong$ & $\vdots \stackrel{\infty}{\rightleftharpoons}$ & $\vdots \cong$ & ১ ৯ ৯ & 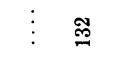 \\
\hline- & --- & - & - & - & $\vdots \quad \pi$ & $\vdots \quad-$ & $\vdots \quad+$ & $\vdots-$ & 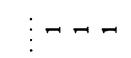 & $\vdots \quad+$ \\
\hline \pm & $\frac{\dot{m}}{\stackrel{N}{N}}-N$ & $n$ & - & 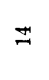 & $\vdots \quad \frac{\dot{m}}{\sharp}$ & $\vdots \quad 0$ & $\vdots \quad \frac{g}{g}$ & $\vdots$ & 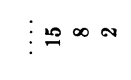 & $\vdots \quad \frac{\dot{g}}{\underline{G}}$ \\
\hline $\begin{array}{l}\stackrel{\infty}{\rho} \\
\underline{1}\end{array}$ & 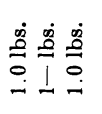 & $\stackrel{\dot{0}}{=}$ & $\stackrel{\substack{0 \\
0}}{0}$ & 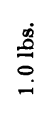 & 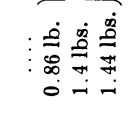 & 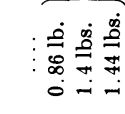 & 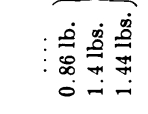 & 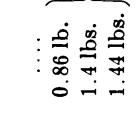 & : & 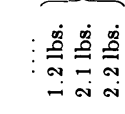 \\
\hline $\begin{array}{l}\stackrel{\infty}{0} \\
\stackrel{0}{0} \\
\dot{y}\end{array}$ & 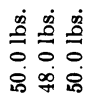 & $\begin{array}{l}\stackrel{\infty}{0} \\
\stackrel{0}{0} \\
\stackrel{\infty}{\phi}\end{array}$ & $\begin{array}{l}\stackrel{\infty}{0} \\
\stackrel{0}{0} \\
\dot{0}\end{array}$ & $\begin{array}{l}\stackrel{\dot{m}}{0} \\
\stackrel{0}{0} \\
\dot{8}\end{array}$ & 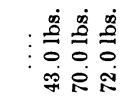 & 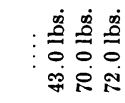 & 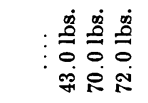 & 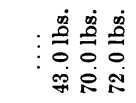 & 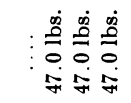 & 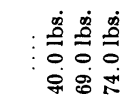 \\
\hline$\vdots$ & $\vdots$ & $\vdots$ & $\vdots$ & $\vdots$ & 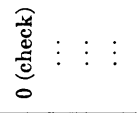 & 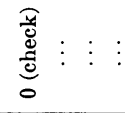 & 宽 & 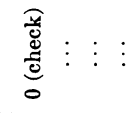 & 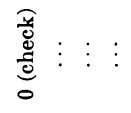 & 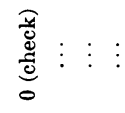 \\
\hline$\frac{p}{\infty}$ & 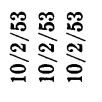 & 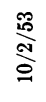 & 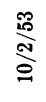 & $\frac{\mathscr{n}}{\stackrel{n}{9}}$ & : & 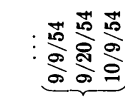 & : & : & 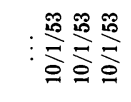 & 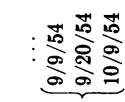 \\
\hline 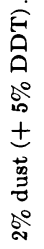 & 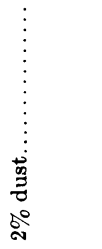 & 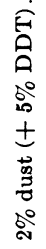 & 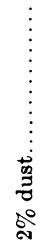 & 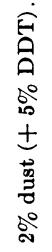 & 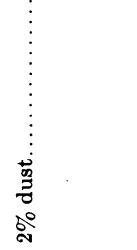 & & 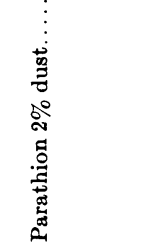 & & 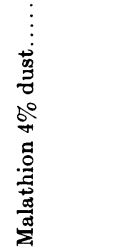 & 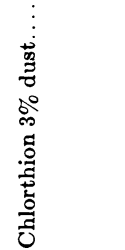 \\
\hline & & & & & & & 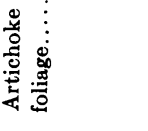 & & & \\
\hline
\end{tabular}




\begin{tabular}{|c|c|c|c|c|c|c|c|c|}
\hline \multicolumn{3}{|c|}{ 䓛 } & \multirow[b]{2}{*}{ 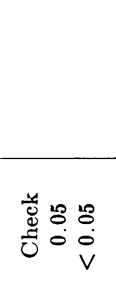 } & \multirow{2}{*}{ 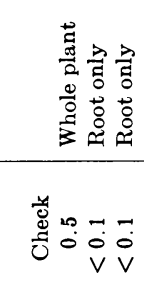 } & \multicolumn{2}{|r|}{ 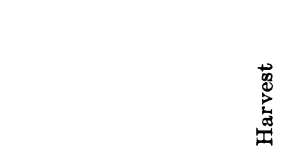 } & \multicolumn{2}{|l|}{ 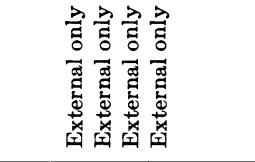 } \\
\hline \multirow{2}{*}{ 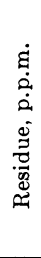 } & \multicolumn{2}{|c|}{ 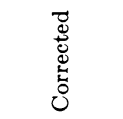 } & & & 递 & 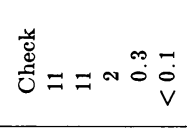 & 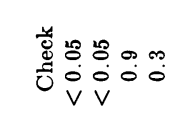 & 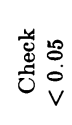 \\
\hline & \multicolumn{2}{|c|}{ 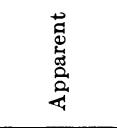 } & 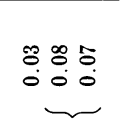 & 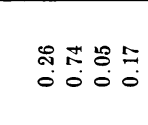 & $\begin{array}{l}\vec{i} \\
\dot{0} \\
\mathrm{v}\end{array}$ & $\stackrel{\circ}{\circ}=\approx \sim \stackrel{\infty}{\stackrel{0}{0}} \underset{v}{ }$ & 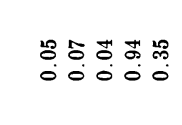 & $\stackrel{m}{0}=$ \\
\hline \multirow{3}{*}{ 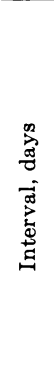 } & \multicolumn{2}{|c|}{ 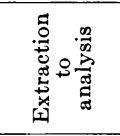 } & 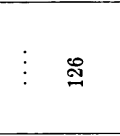 & $\rightarrow-r$ & -1 & $\vdots 00000$ & \multicolumn{2}{|l|}{$\vdots-7$ 웅ㅇ } \\
\hline & \multicolumn{2}{|c|}{ 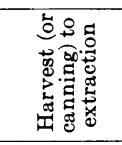 } & $\vdots \quad-$ & 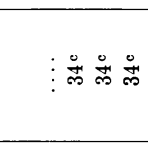 & - & $\vdots$ ニーーーー & \multicolumn{2}{|l|}{$\vdots$ 呙 } \\
\hline & \multicolumn{2}{|c|}{ 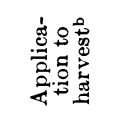 } & $\infty$ & $-n$ & "ே & $\vdots 0 \times \cos =$ & $0 \cong 0 \%$ & $=$ \\
\hline \multirow{2}{*}{ 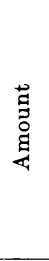 } & \multirow{2}{*}{ 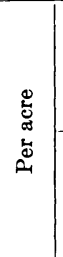 } & 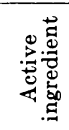 & 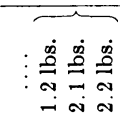 & 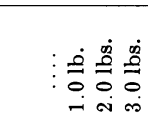 & $\stackrel{\dot{0}}{\circ}$ & 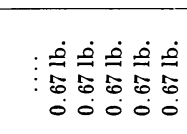 & 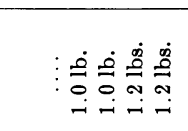 & 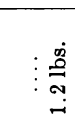 \\
\hline & & 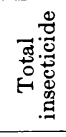 & 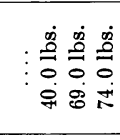 & 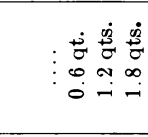 & & 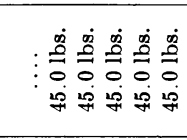 & 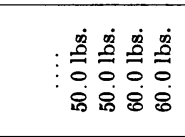 & : \\
\hline & \multicolumn{2}{|c|}{ 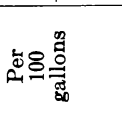 } & 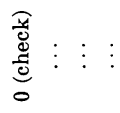 & 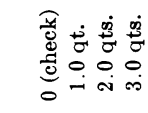 & 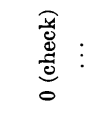 & 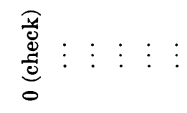 & 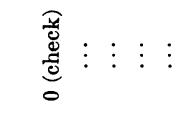 & 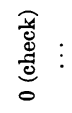 \\
\hline & \multicolumn{2}{|c|}{ 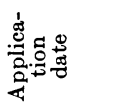 } & : & 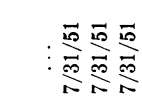 & $\sum_{i=0}^{\sqrt[10]{2}}$ & 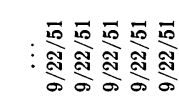 & : & $: \underset{\frac{0}{9}}{\stackrel{0}{9}}$ \\
\hline & \multicolumn{2}{|l|}{ 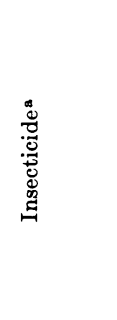 } & 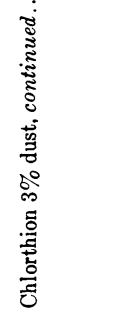 & 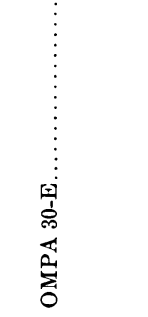 & 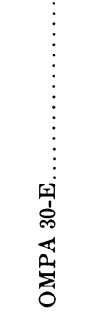 & 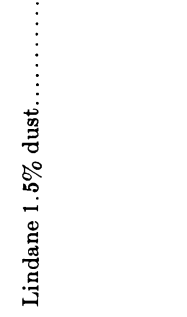 & \multicolumn{2}{|l|}{ 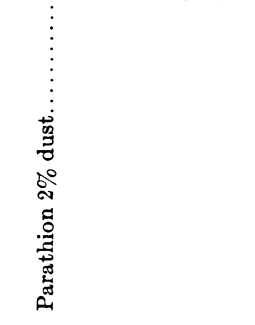 } \\
\hline \multicolumn{3}{|c|}{ نั } & 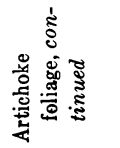 & 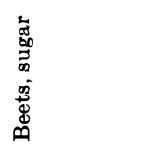 & \multicolumn{2}{|l|}{ : } & \multicolumn{2}{|l|}{ 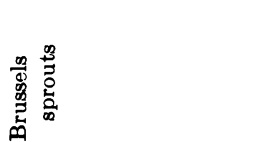 } \\
\hline
\end{tabular}




\begin{tabular}{|c|c|c|c|c|c|c|}
\hline & & & 蒂 & 兽 & 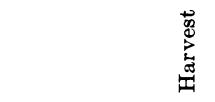 & 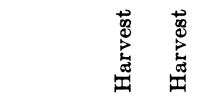 \\
\hline 苋 & 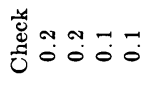 & 苞 & 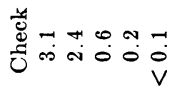 & 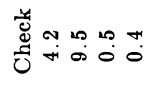 & 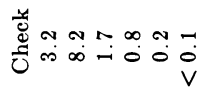 & 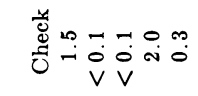 \\
\hline $\begin{array}{l}\text { 웅 유 } \\
000\end{array}$ & 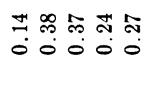 & 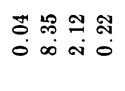 & 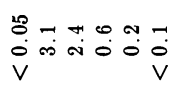 & 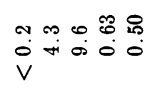 & 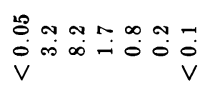 & 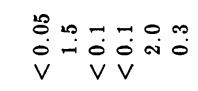 \\
\hline$\because$ & ஜ & 000 & $\vdots 00000$ & $\vdots 0000$ & $\vdots 00000$ & $\vdots 00000$ \\
\hline 战 & $\stackrel{\circ}{\sim} \infty \infty$ & $\approx \infty \infty$ & オニーー & won & $\vdots-7-7-$ & $\vdots \begin{array}{l}\vdots \\
\vdots\end{array}$ \\
\hline 00 & N N N & 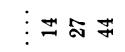 & $0 \cos 0=$ & O & $\begin{array}{l}0 \\
0\end{array}$ & ON $\infty$ ON \\
\hline 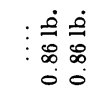 & 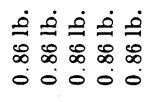 & 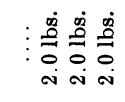 & 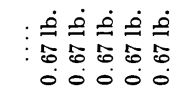 & 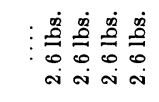 & 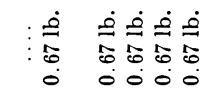 & 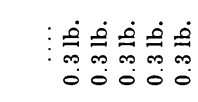 \\
\hline 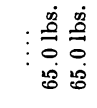 & 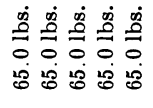 & $\vdots$ & 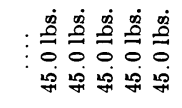 & 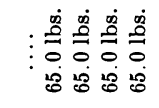 & 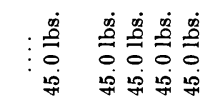 & 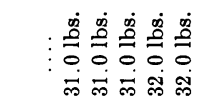 \\
\hline 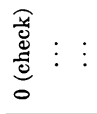 & $\vdots \vdots \vdots \vdots \vdots$ & 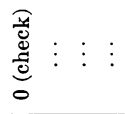 & 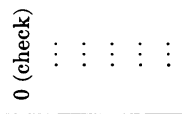 & 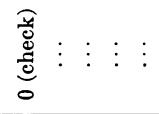 & 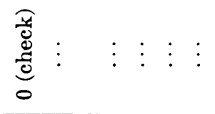 & 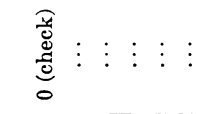 \\
\hline$\frac{a}{2} \frac{a}{20}$ & 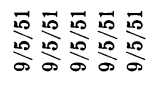 & 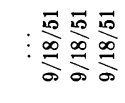 & 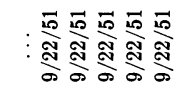 & 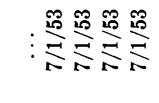 & 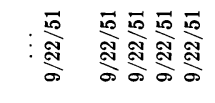 & 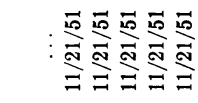 \\
\hline 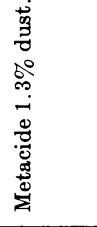 & & 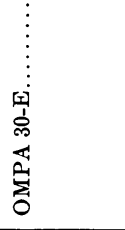 & 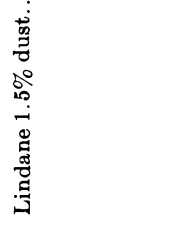 & 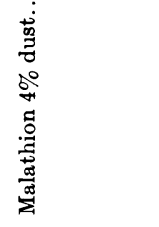 & 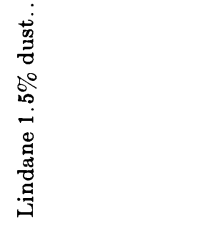 & 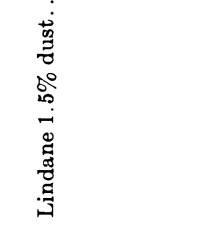 \\
\hline & & & 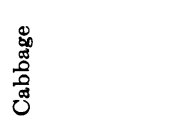 & & 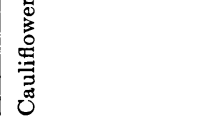 & 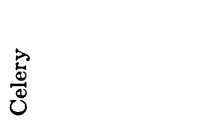 \\
\hline
\end{tabular}




\begin{tabular}{|c|c|c|c|c|c|c|c|c|c|c|}
\hline & \multicolumn{2}{|c|}{ 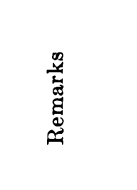 } & 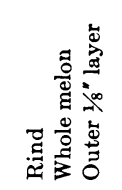 & 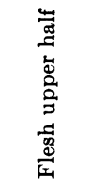 & 䓪 & 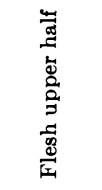 & 胥 & 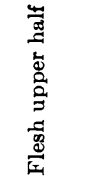 & 苞 & 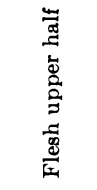 \\
\hline \multirow{2}{*}{ 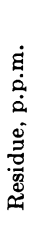 } & \multicolumn{2}{|c|}{ 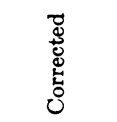 } & 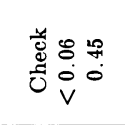 & $\begin{array}{l}\stackrel{0}{0} \\
0 \\
\mathrm{v}\end{array}$ & $\stackrel{20}{\circ}$ & $\begin{array}{l}\stackrel{8}{0} \\
0 \\
v\end{array}$ & 苋 & $\overrightarrow{0}$ & $\frac{+}{0}$ & $\frac{+}{0}$ \\
\hline & \multicolumn{2}{|c|}{ 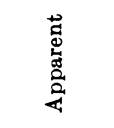 } & 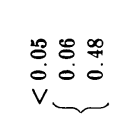 & $\stackrel{8}{\circ}$ & $\stackrel{\infty}{0}$ & $\stackrel{20}{0}$ & $\begin{array}{l}\text { : } \\
\dot{0} \\
\vee\end{array}$ & $\stackrel{\dddot{0}}{\stackrel{0}{0}}$ & $\stackrel{20}{0}$ & $\stackrel{2}{0}$ \\
\hline \multirow{3}{*}{ 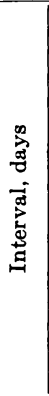 } & \multicolumn{2}{|c|}{ 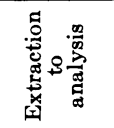 } & $\vdots 0$ & 0 & 0 & 0 & & 0 & 0 & 0 \\
\hline & \multicolumn{2}{|c|}{ 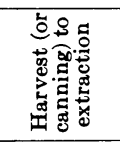 } & $\vdots-$ & - & - & 0 & & $\infty$ & $\infty$ & $\infty$ \\
\hline & \multicolumn{2}{|c|}{ 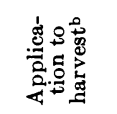 } & $\vdots$ & $F$ & $F$ & $\hat{A}$ & & $\stackrel{\text { สి }}{2}$ & $\mathscr{\sim}$ & ๙ి \\
\hline \multirow{2}{*}{ 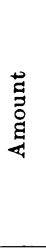 } & \multirow{2}{*}{ 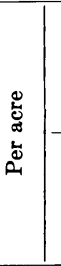 } & 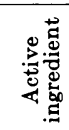 & $\overbrace{0}^{\dot{0}}$ & 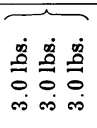 & 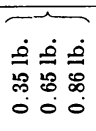 & 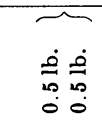 & & 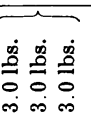 & 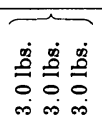 & 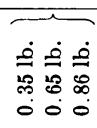 \\
\hline & & 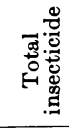 & : & : & $\vdots$ & & & $\vdots \vdots$ & $\vdots \vdots \vdots \vdots$ & \\
\hline & \multicolumn{2}{|c|}{ 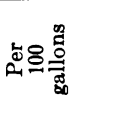 } & $\begin{array}{l}\widehat{\frac{s}{d}} \\
\frac{d}{\tilde{e}} \\
0\end{array}$ & $\vdots \quad \vdots \quad \vdots$ & $\vdots \vdots \vdots$ & $\vdots \vdots$ & $\begin{array}{l}\text { se } \\
\text { d } \\
\text { ê } \\
0\end{array}$ & $\vdots \vdots \vdots$ & $\vdots \quad \vdots \quad \vdots$ & \\
\hline & \multicolumn{2}{|c|}{ 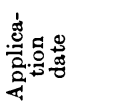 } & $\underbrace{\sqrt[5]{\frac{5}{\infty}}}$ & 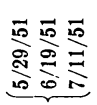 & 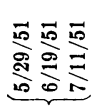 & 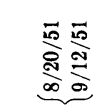 & & 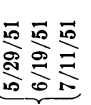 & $\underbrace{\sqrt[9]{8}}$ & 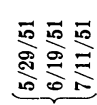 \\
\hline & \multicolumn{2}{|c|}{ 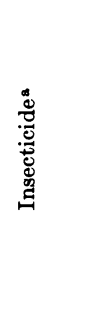 } & 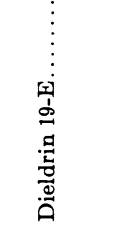 & 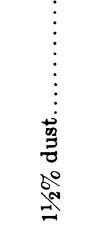 & 国 & 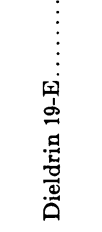 & 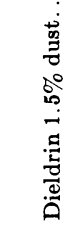 & & - & $\begin{array}{c}\vdots \\
\vdots \\
\vdots \\
\vdots \\
\vdots \\
\text { 宅 } \\
\text { d }\end{array}$ \\
\hline & \multicolumn{2}{|c|}{ 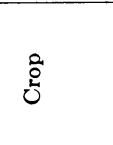 } & 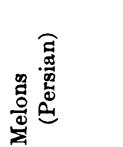 & & & 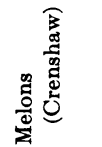 & 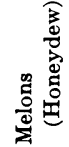 & & & \\
\hline
\end{tabular}




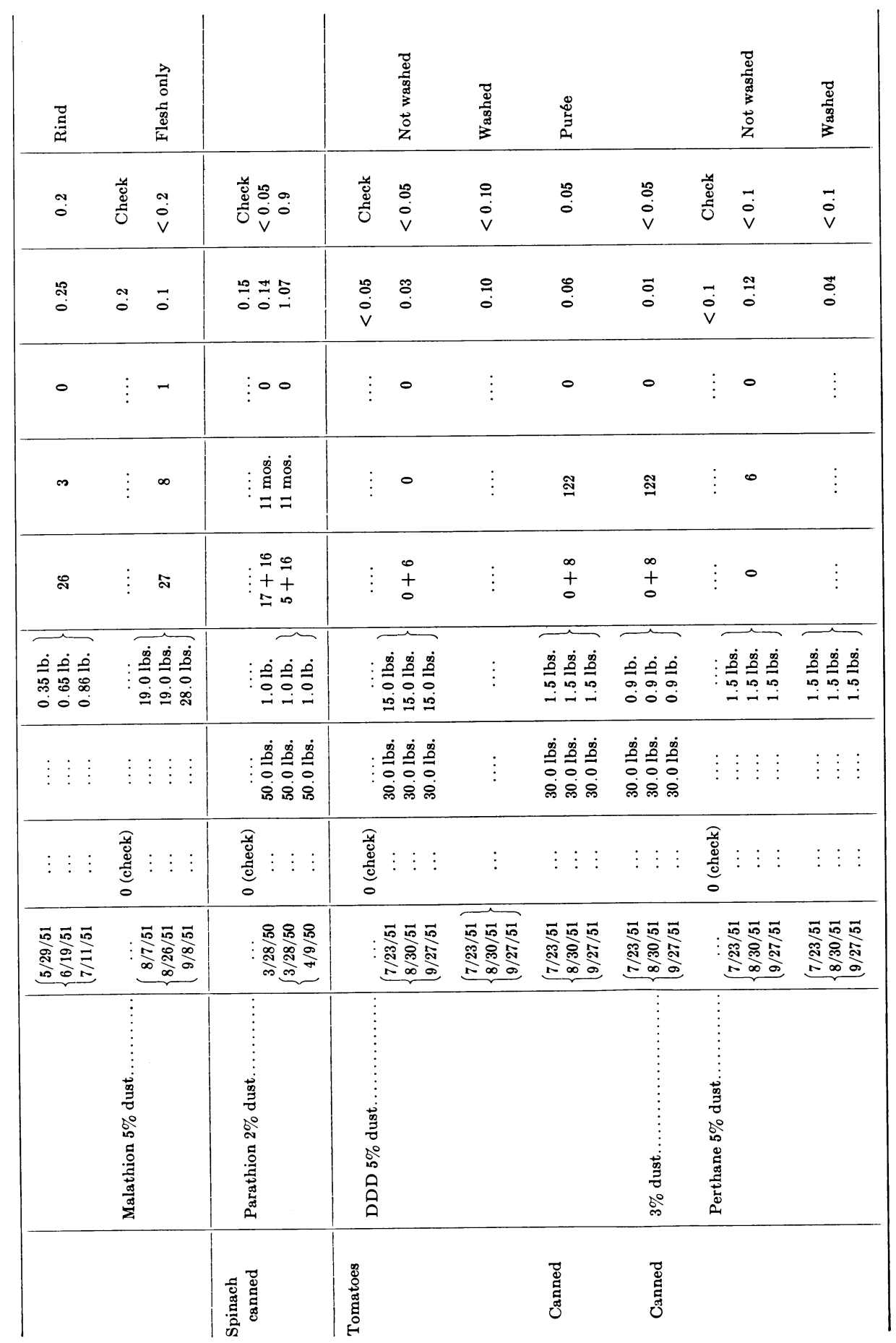




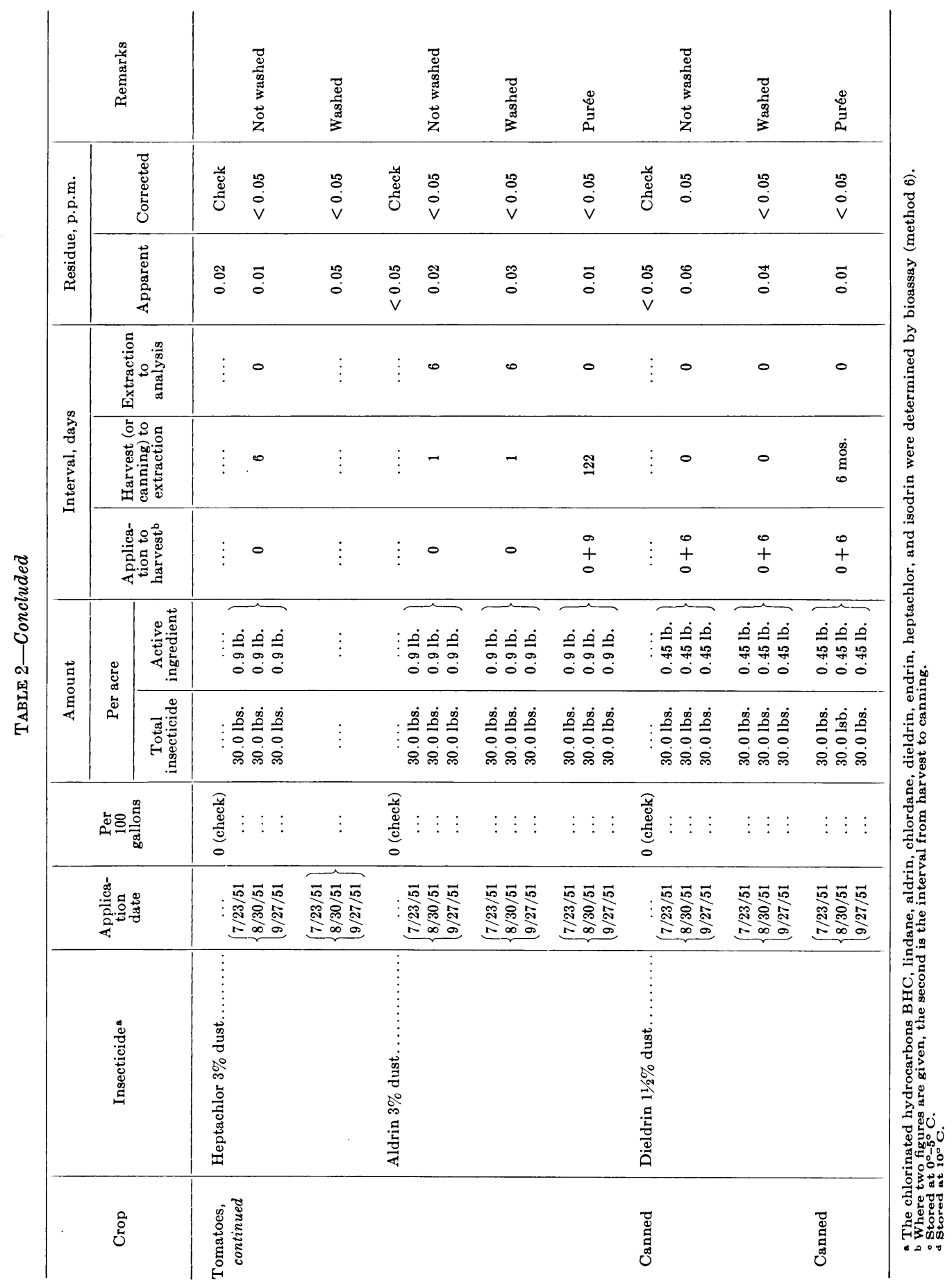


Insecticides Applied to Soils. Table 3 contains the data on residual insecticides from soil applications obtained in coöperation with taste-testing of the canned vegetables. Technical benzene hexachloride used at 25 pounds per acre caused a contamination in carrots of 0.6 p.p.m. calculated from organic chloride or 0.1 p.p.m. as gamma isomer equivalent by bioassay. After canning, bioassay indicated that less than 0.05 p.p.m. as gamma isomer equivalent could be present. The situation was precisely similar with sweet potatoes. These data forcefully illustrate the profound difference in results obtained by the nonspecific chloride determination from those by bioassay, which responds only to the toxic constituent. Neither canned asparagus from soil treated with 28 pounds BHC per acre nor canned tomatoes from treatment of 20 pounds per acre contained a detectable amount of gamma isomer equivalent.

The lindane residues were generally consistent with those from benzene hexachloride by bioassay, but the high value of 2.0 p.p.m. in fresh carrots from application of 2 pounds per acre in 1951 is out of line with all later results. However, from an application of 5 pounds per acre, carrots at harvest carried 0.4 and 0.5 p.p.m. lindane and evidence of slight toxic action from extracts after canning were noticed. Lindane at 5 pounds per acre caused no detectable residue in either fresh or canned sweet potatoes, though peelings contained 0.45 p.p.m. White potatoes were available only from a comparatively light treatment (11/3 pounds per acre), and they contained less than 0.05 p.p.m. though there was evidence of slight toxic action during the bioassay. Several analyses of the soils taken immediately after application and analyzed 43 to 57 days thereafter showed 0.05 to 0.12 p.p.m. gamma equivalent.

One pound of toxicant per acre amounts to approximately 0.7 p.p.m. in the soil-assuming uniform distribution through the top 6 inches-so the lower amounts of lindane found indicate considerable loss by volatization or degradation to nontoxic compounds. This was especially the case in the carrot plots at Salinas, where the soil was somewhat alkaline $(\mathrm{pH} 7.7)$ and contained 3.34 per cent organic matter. The results of Hornstein, et al. (1954) show the same high losses, for they found less than 0.1 p.p.m. BHC a few months after application of considerably larger amounts than were concerned in the present work. It is not surprising that fresh lima beans were not contaminated by seed treatment nor that soil treatment at the rate of $11 / 4$ pounds lindane per acre caused no detectable residue in canned tomatoes. In contrast to the marked disappearance of lindane or BHC, attention is directed to data obtained on residual DDT in the white potato plots at Hollister. Seventy-four days after application of 10 pounds actual DDT per acre, analyses showed 3.0, 4.0, 4.2, and 4.5 p.p.m., which average about 60 per cent of the applied dosage.

Among the polycyclic chlorinated insecticides, chlordane could not be detected by bioassay in fresh or canned carrots nor in canned sweet potatoes, from soil treated in each case with 10 pounds per acre. It may be noted that since bioassay is relatively insensitive for chlordane, contamination at levels lower than 0.2 p.p.m. is not ruled out. From applications of 10 pounds per acre, heptachlor could not be detected at 0.05 p.p.m. in either 


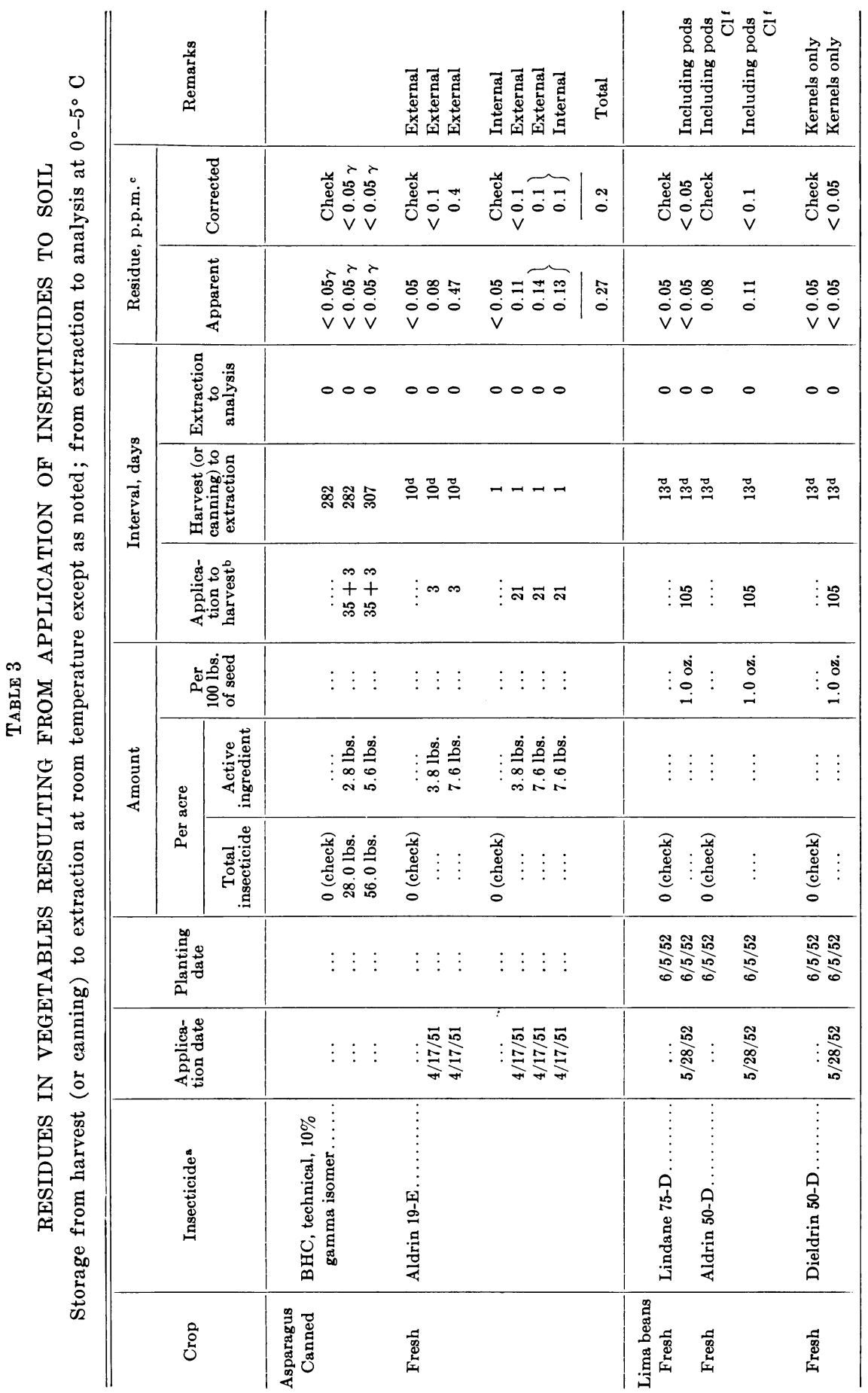




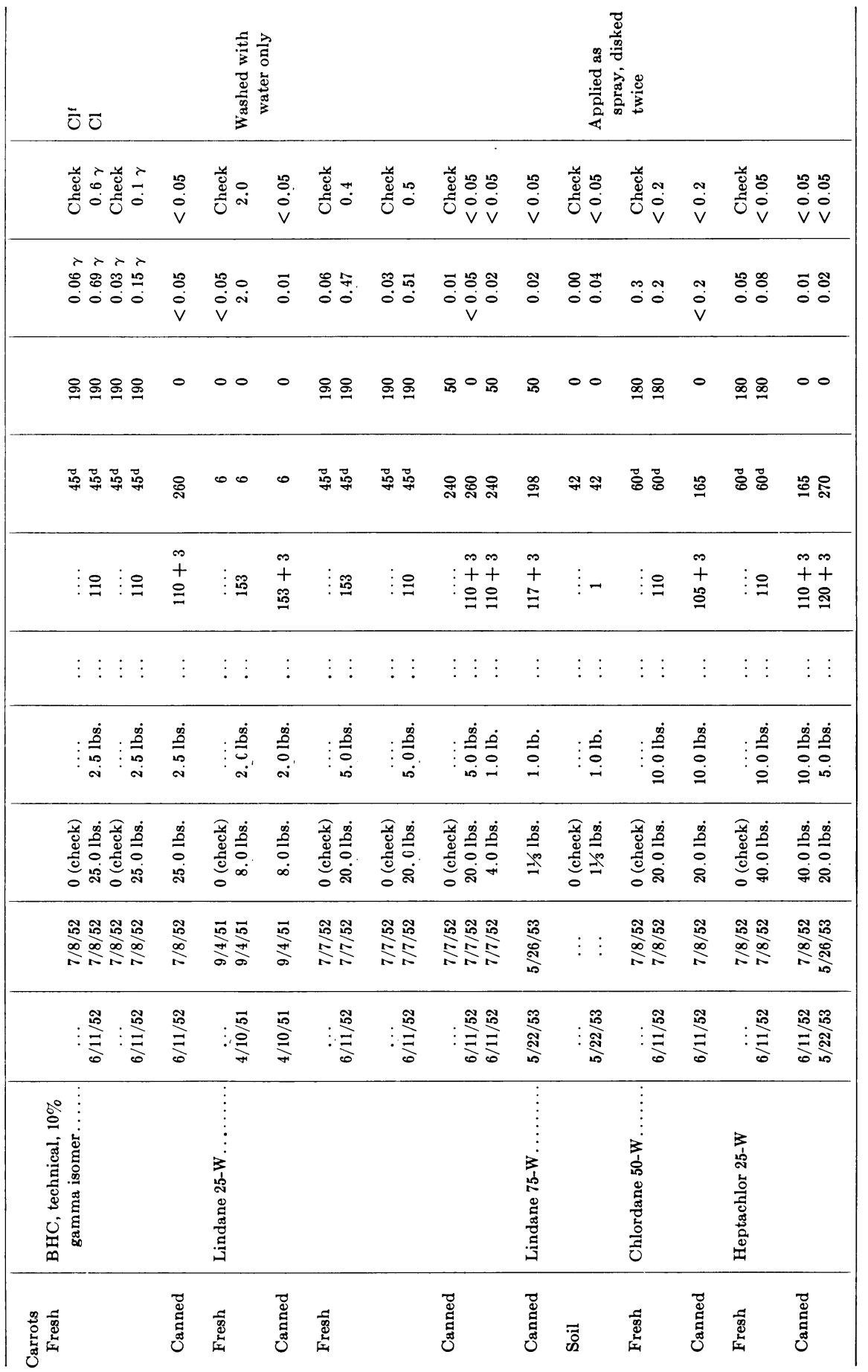




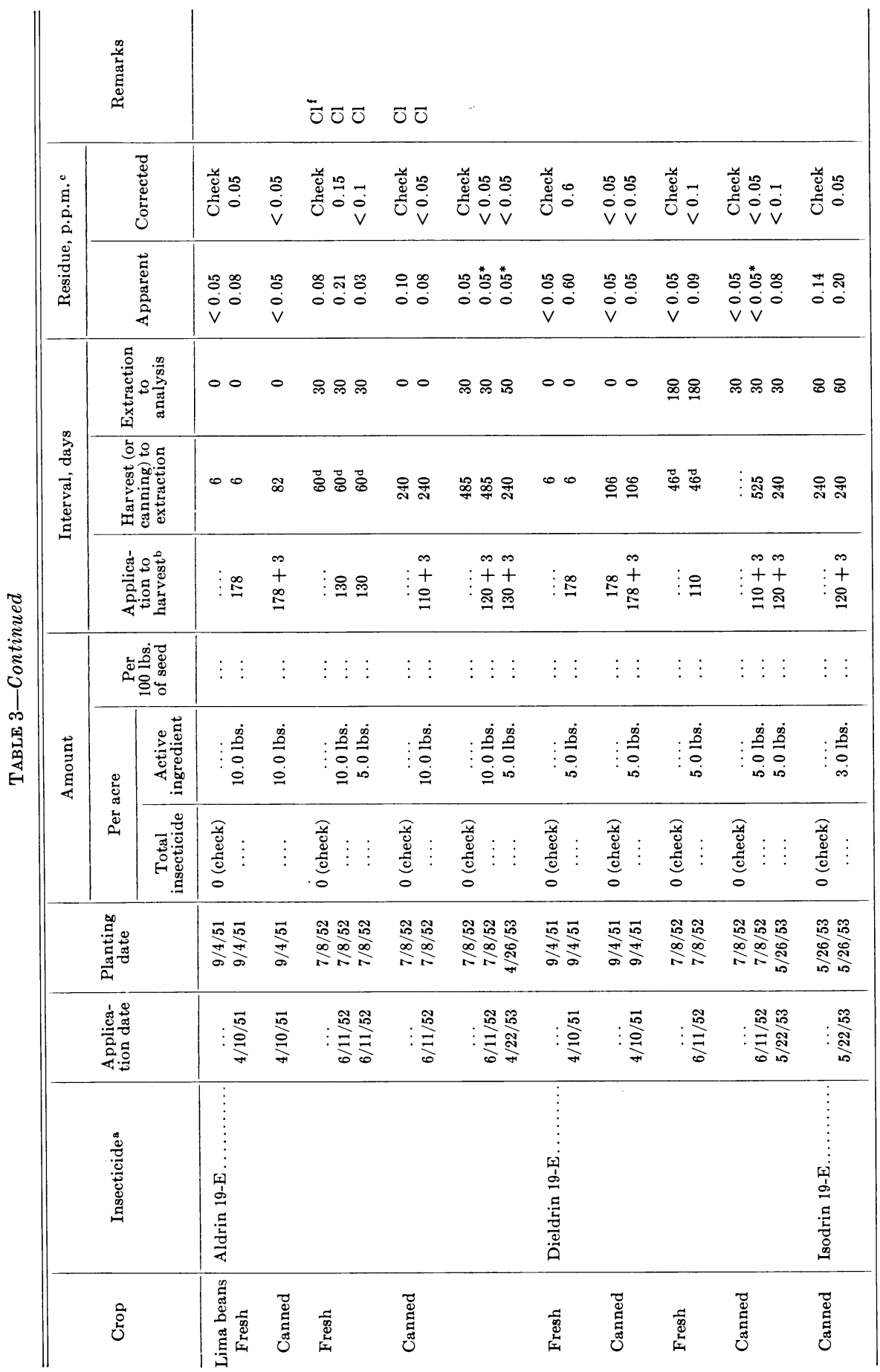




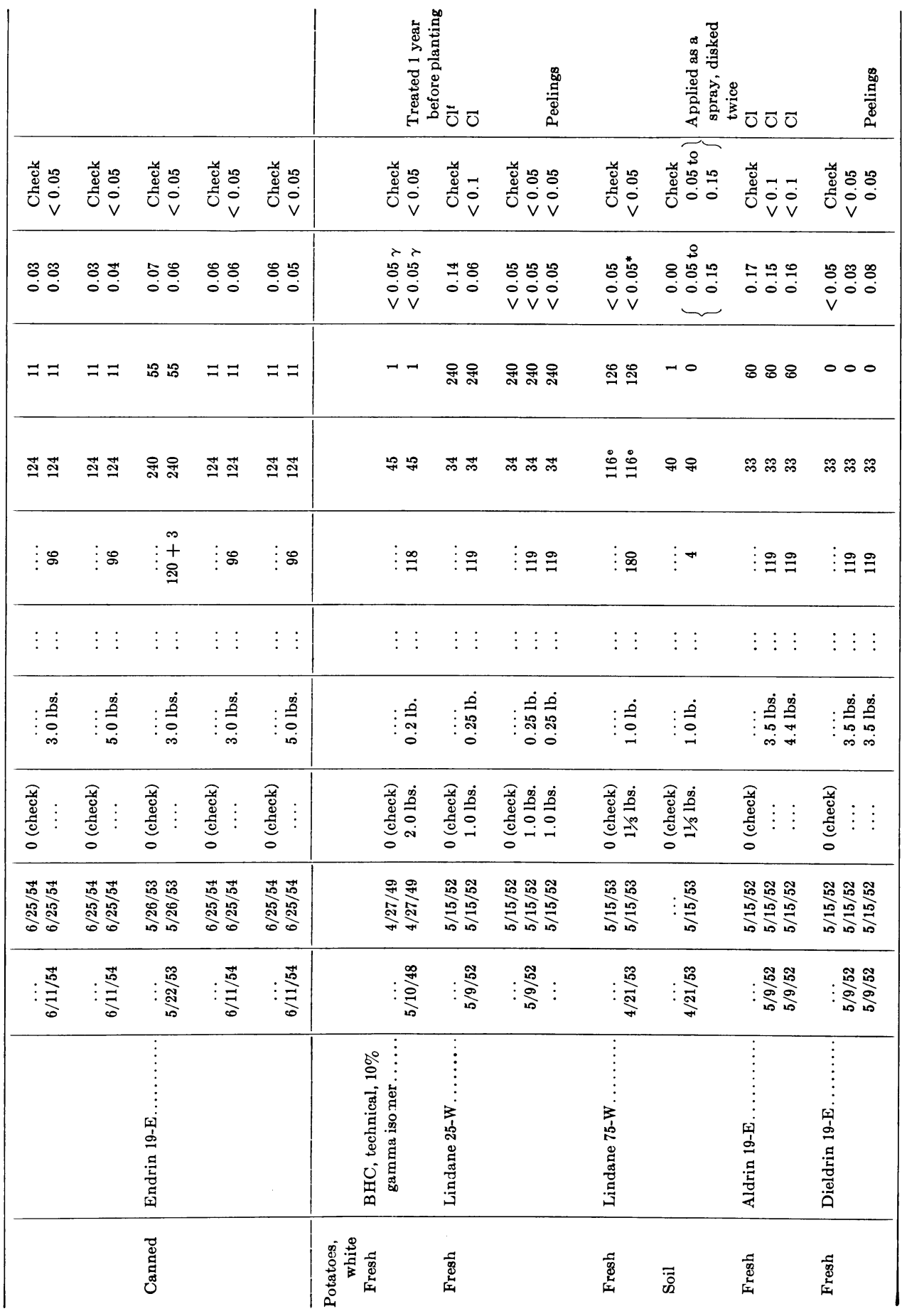




\begin{tabular}{|c|c|c|c|c|c|c|c|c|c|c|c|c|}
\hline \multicolumn{3}{|c|}{ 咅 } & & & & & & \multicolumn{5}{|c|}{$\overline{\tilde{\nu}}$} \\
\hline \multirow{2}{*}{ 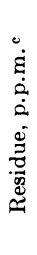 } & \multicolumn{2}{|c|}{ 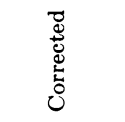 } & 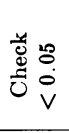 & 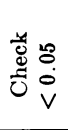 & 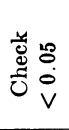 & 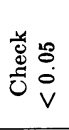 & 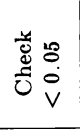 & 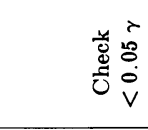 & خ & 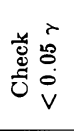 & 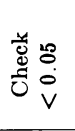 & 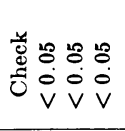 \\
\hline & \multicolumn{2}{|c|}{ 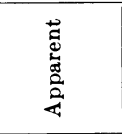 } & : & 荙 & $\begin{array}{ll}0 & \text { "艹 } \\
0 & 0\end{array}$ & $\begin{array}{ll}0 & 0 \\
0 & 0 \\
0 & 0\end{array}$ & $\begin{array}{l}0: 0 \\
0: 0 \\
0\end{array}$ & $\begin{array}{ll}r & \\
& \\
0 & \\
0 & 0 \\
0 & 0 \\
v & 0\end{array}$ & 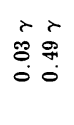 & $\begin{array}{ll} & * \\
i & * \\
0 & : 0 \\
0 & 0 \\
0 & 0 \\
V & V\end{array}$ & 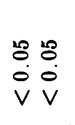 & 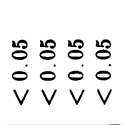 \\
\hline \multirow{3}{*}{ 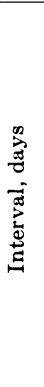 } & \multicolumn{2}{|c|}{ 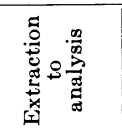 } & $\sigma r$ & $\pi r$ & $\vdots$ & 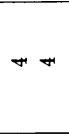 & 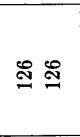 & 00 & 88 & \& & 00 & 0000 \\
\hline & \multicolumn{2}{|c|}{ 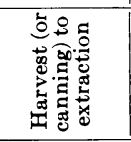 } & $\stackrel{\infty}{\infty}$ & $\stackrel{\infty}{\sim}$ & $: \stackrel{\infty}{\sim}$ & $\stackrel{\sim}{\infty} \underset{\sim}{ }$ & 这 & ํㅗㄱ : & $\Xi \Xi$ & $N$ & $\stackrel{\circ}{0}$ & 象吕吕吕 \\
\hline & \multicolumn{2}{|c|}{ 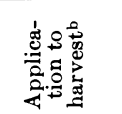 } & $\vdots \stackrel{20}{=}$ & $\stackrel{20}{=}$ & $\vdots \stackrel{2}{=}$ & $\stackrel{20}{\exists}$ & $\stackrel{\infty}{\mathscr{0}}$ & 串 & $\stackrel{\Xi}{0}$ & 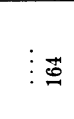 & 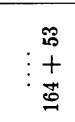 & 홍 \\
\hline \multirow{3}{*}{ 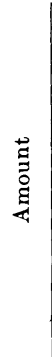 } & \multicolumn{2}{|c|}{ 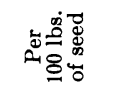 } & $\vdots \vdots$ & $\vdots \vdots$ & $\vdots \vdots$ & $\vdots \vdots$ & $\vdots \vdots$ & $\vdots \vdots$ & $\vdots \vdots$ & $\vdots \vdots$ & $\vdots \vdots$ & $\vdots \vdots \vdots \vdots$ \\
\hline & \multirow{2}{*}{ 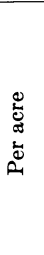 } & 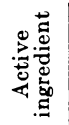 & $\vdots \stackrel{\infty}{\Rightarrow}$ & $\vdots \stackrel{\infty}{\stackrel{\infty}{=}}$ & $\vdots \stackrel{\dot{0}}{0}$ & $\vdots \stackrel{\substack{0 \\
ٍ}}{0}$ & $\vdots \begin{array}{l}\dot{\infty} \\
\vdots \\
\dot{0} \\
\dot{0}\end{array}$ & 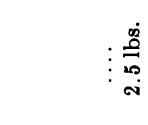 & $\vdots \stackrel{\dot{m}}{\stackrel{\infty}{0}}$ & 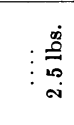 & 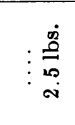 & 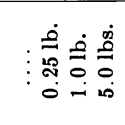 \\
\hline & & 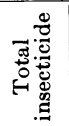 & 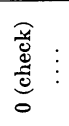 & 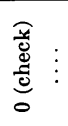 & 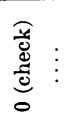 & 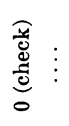 & 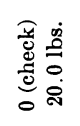 & 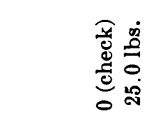 & 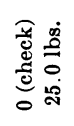 & 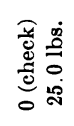 & 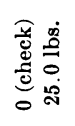 & 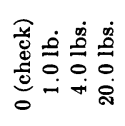 \\
\hline & \multicolumn{2}{|c|}{ 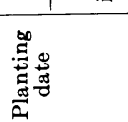 } & 总落 & 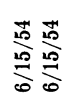 & 莫落 & 薄落 & $: \sum_{i=0}^{\frac{10}{20}}$ & $\sum_{\text {is }}^{\text {in }}$ & 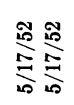 & 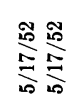 & 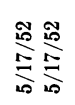 & 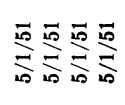 \\
\hline & \multicolumn{2}{|c|}{ 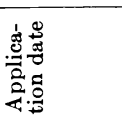 } & : 莟 & 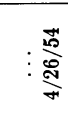 & 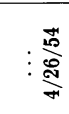 & 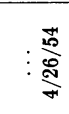 & 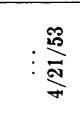 & $\stackrel{\sqrt{5}}{\stackrel{5}{i s}}$ & 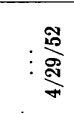 & 令 & 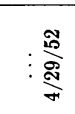 & 点点点点点 \\
\hline & \multicolumn{2}{|c|}{ 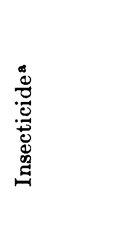 } & 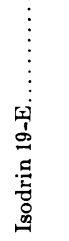 & & 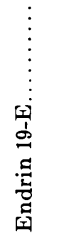 & & 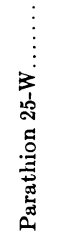 & 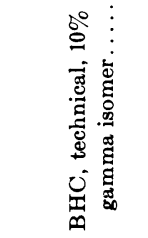 & & & & 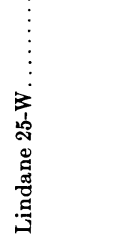 \\
\hline \multicolumn{3}{|c|}{ نे } & 氯 & & 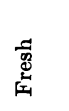 & & 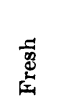 & 焉 & & & Ŭّ & 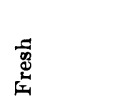 \\
\hline
\end{tabular}




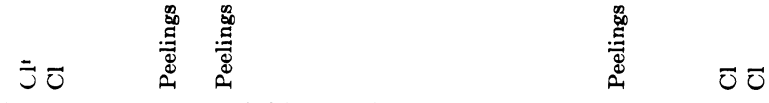

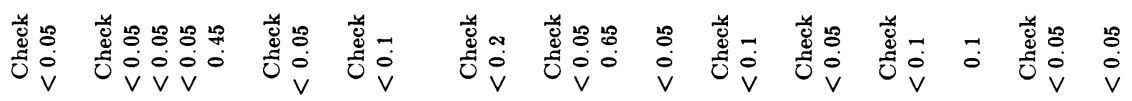

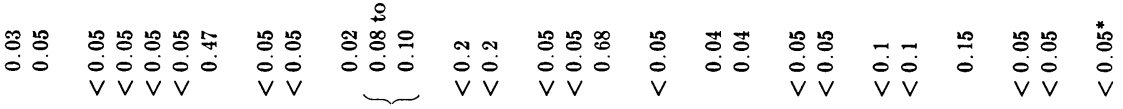

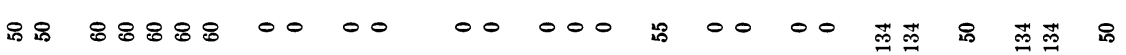

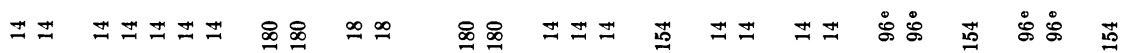

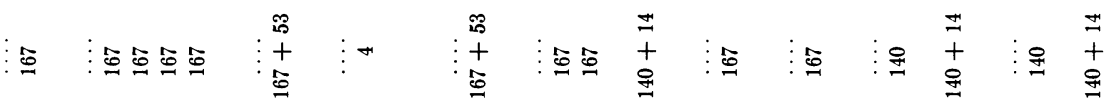

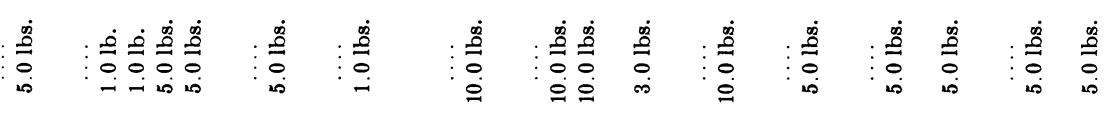

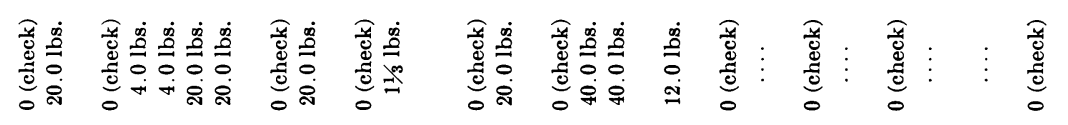

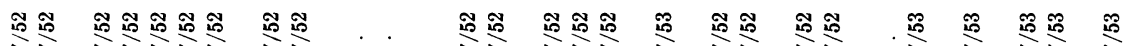

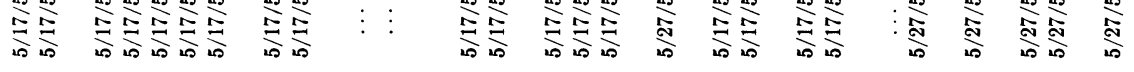

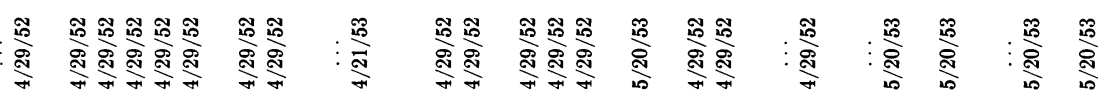

\begin{tabular}{|c|c|c|c|c|c|c|c|c|c|}
\hline 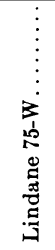 & 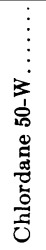 & 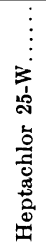 & & 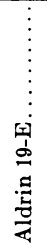 & 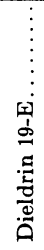 & 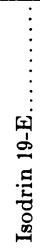 & & 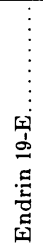 & \\
\hline io & 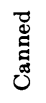 & 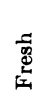 & 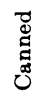 & $\begin{array}{l}\text { 芯 } \\
\text { 胥 }\end{array}$ & 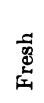 & 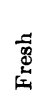 & 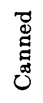 & 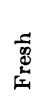 & $\begin{array}{l}\widetilde{J} \\
\text { ש్ } \\
\text { Uే }\end{array}$ \\
\hline
\end{tabular}




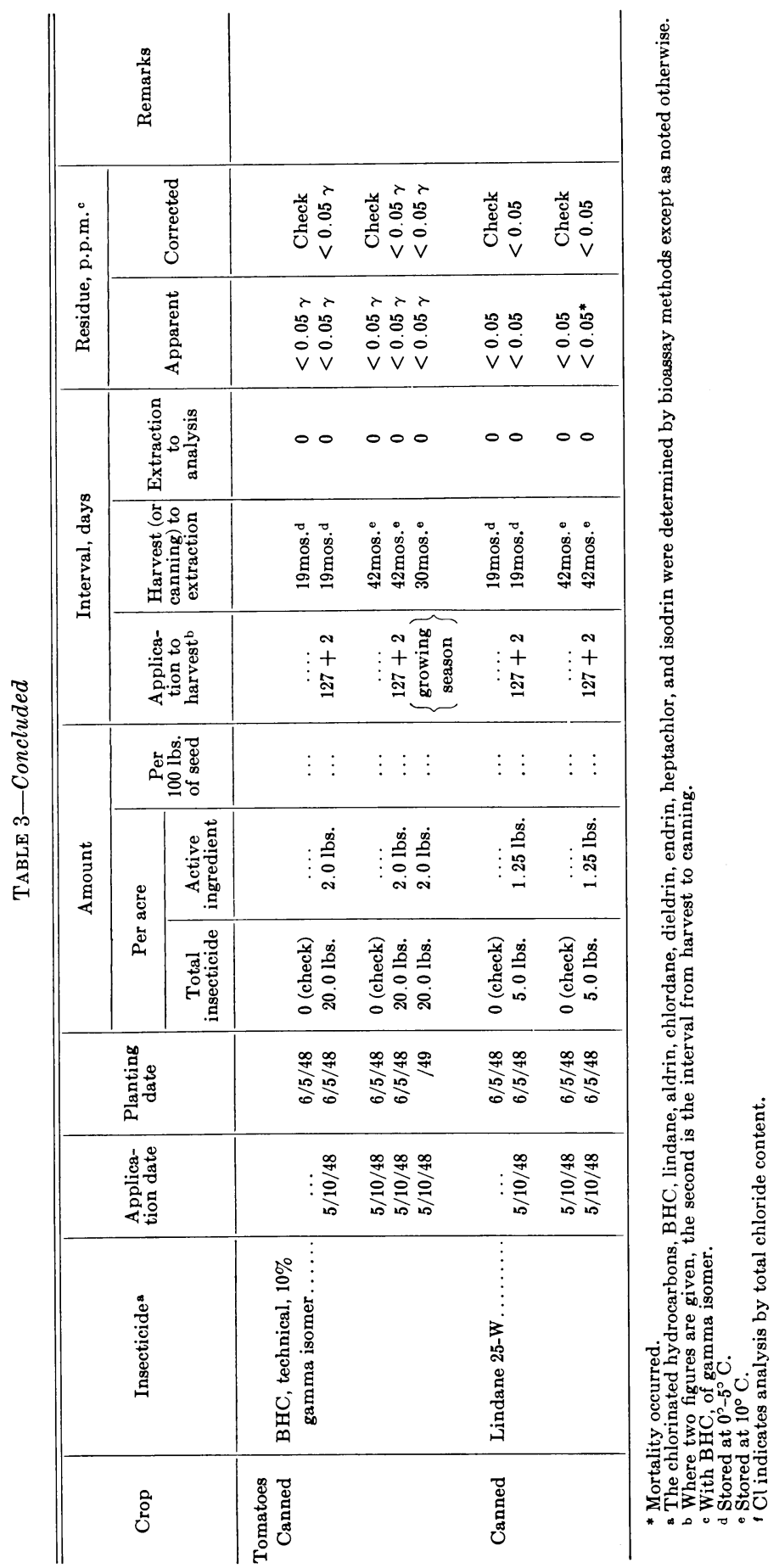


fresh or canned carrots or sweet potatoes. Aldrin at 10 pounds per acre gave detectable residue in fresh carrots $(0.05$ p.p.m. by bioassay in 1951 and 0.15 p.p.m. by chloride analysis in 1952). Unfortunately these carrots were not tested after canning. At 5 pounds per acre no aldrin was found in either fresh or canned carrots. With sweet and white potatoes only chloride determination was made, with negative results for each. Asparagus harvested 3 days after 7.6 pounds per acre of aldrin as an emulsion were worked into the soil had 0.4 p.p.m. as external contamination, and 21 days after application both the external and internal contaminations were 0.1 p.p.m. The closely related compound, isodrin, also gave positive results in canned carrots and in canned sweet potatoes, from treatments with 3 and 5 pounds per acre, respectively, in 1953, but not from 5-pound applications in 1954 .

On the other hand, neither dieldrin nor endrin gave contamination that could be detected in fresh or canned carrots, in fresh white potatoes, or in canned sweet potatoes - with the exception of one high result in carrots in 1951. Likewise, white potatoes were free from dieldrin.

A single result of no detectable parathion in fresh white potatoes harvested 180 days after a 5-pound per acre treatment is undoubtedly to be expected from the known short life of this compound. 


\section{LITERATURE CITED}

Agazzi, E. J., E. D. Peltors, and F. R. Brooks

1953. Combustion techniques for the determination of residues of highly chlorinated pesticides. By total chlorine analysis. Analyt. Chem. 25:237-40.

ALLEN, R. J. L.

1940. The estimation of phosphorus. Biochem. Jour. 34:858-65.

AmERican Cyanamid Company

1954a. Colorimetric method for the determination of malathion in the technical grade product and in insecticidal preparations (carbon tetrachloride method). Analytical Research Laboratory. 4 pp. Mimeo.

1954b. Malathion residues-apples. Analytical Research Laboratory. 4 pp. Mimeo.

AVERELL, P. R., and W. V. NORRIS

1948. Estimation of small amounts of O,O-diethyl-O-p-nitro thiophosphate. Analyt. Chem. $20: 753-56$.

HinREINER, E., and M. SIMONE

1956. Effects of soil insecticides on flavor of vegetable crops. Hilgardia 26:76-85.

Hornstein, I., H. ReYnolds, and G. L. Gilpin

1954. Pesticides and flavor. Benzene hexachloride content and flavor of peanuts grown in rotation with cotton dusted with this insecticide. Jour. Agr. Food Chem. 2: $776-78$.

Hoskins, W. M., J. M. WiTT, and W. R. ERwin

1952. Bioassay of 1.2.3.4.5.6-hexachlorocyclohexane (lindane). Analyt. Chem. 24:55560 .

Lange, W. H., and E. C. Carlson

1956. Residual soil insecticides for the control of wireworms affecting vegetable crops. Hilgardia 26:60-75.

Miskus, R. P., W. R. ERwin, and W. M. Hoskins

1956. Harvest residues of acaricides used on deciduous fruits. Hilgardia 26:46-59.

Ripper, W. E., R. M. Greenslade, and G. S. Hartuey

1950. A new systemic insecticide bis (bis dimethylamino phosphonus) anhydride. Bul. Ent. Res. $40: 481-501$.

Schechter, M. S., S. B. Solomon, R. A. Hayes, and H. L. Haller

1945. Colorimetric determination of DDT. Color test for related compounds. Indust. and Engin. Chem., Analyt. Ed. 17:704-9. 
The journal Hilgardia is published at irregular intervals, in volumes of about 600 pages. The number of issues per volume varies.

Subscriptions are not sold. The periodical is sent as published only to libraries, or to institutions in foreign countries having publications to offer in exchange.

You may obtain a single copy of any issue free, as long as the supply lasts; please request by volume and issue number from:

Agricultural Publications

22 Giannini Hall

Berkeley 4, California

The limit to nonresidents of California is 10 separate issues on a single order. A list of the issues still available will be sent on request.

In our publications it is sometimes convenient to use trade names of products or equipment rather than scientific identifications. In so doing it is unavoidable in some cases that similar products which are on the market under other trade names may not be cited. No endorsement of named products is intended nor is criticism implied of similar products which are not mentioned. 